This dissertation has been 64-9599

microfilmed exactly as received

WHERRY, Jr ;, Robert James, 1933-

TOWARD AN OPTIMAL METHOD OF EQUATLNG SUBGROUPS COMPOSED OF DIFFERENT SUBJECTS.

The Ohio State University, Ph.D., 1964

Psychology, experimental

Unversity Microfilms, Inc. A... f:.: 


\section{TOWARD AN OPTIMAL METHOD OF EQUATING SUBGROUPS COMPOSED OF DIFFERENT SUB JECTS}

\section{DISSERTATION}

Presented in Partial Fulfillment of the Requirements for the Degree Doctor of Philosophy in the Graduate School of the Ohio State University

By

Robert James Wherry, Jr., B.A., M.A.

\section{$\star * * * *$}

The Ohio State University

1964

Approved by

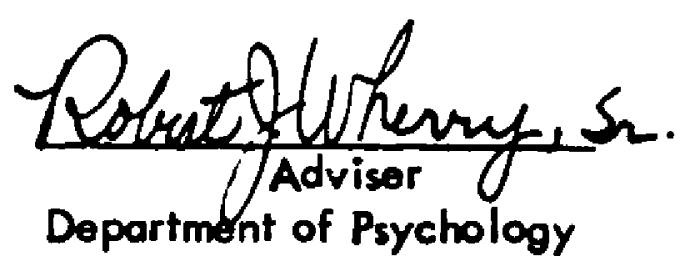




\section{ACKNOWLEDGMENTS}

My gratitude and appreciation are extended to my father Dr. Robert $\mathrm{J}$. Wherry, Sr., chairman of the committee under whose direction this study hos been made.

I am indebted to Mr. James R. Berkshire, Head, Aviotion Psychology Branch, Psychological Sciences Division, U.S. Naval School of Aviation Medicine, whose suggestions and support throughout this study were extremely helpful, and to the Commanding Officer of the U.S. Naval School of Aviation Medicine, Captain Clifford P. Phoebus, for providing the research facilities used during this study.

I am also grateful for many thought-provoking and stimulating classes in statistical methodology with Dr. Wherry, Dr. Herbert A. Toops, and Dr. James C. Naylor. Without these the entire dissertation would hove been impossible.

Thanks and appreciation are conveyed to Mrs. Alice Garman for deciphering the monuscript and typing of the numerous drafts and final copy of the dissertation.

To my wife, Barbara, I give special thanks for her patient understanding, constant encourogement, and love. 


\title{
VITA
}

\author{
November 28, 1933 Born - Lebanon, Tennessee \\ 1955 ..... B.A., The Ohio Stote University, Columbus, Ohio \\ 1956-1958 ... Line Officer, U.S. Navy, U.S. S. Strong (DD-758) \\ 1958- .... Medical Service Corps Officer, U.S. Navy- \\ Research Psychologist, Naval School of Aviation \\ Medicine, Pensacola, Florida. \\ 1960 ... . M.A., The Ohio State University, Columbus, Ohio

\section{PUBLICATIONS}

Waters, L.K. and Wherry, R.J., Jr., Factor Analysis of Selection Tests and Performance Measures in U.S. Naval School, Pre-Fiight. BuMed Project MR005.13-3003 Subtask 10, Report No. 2. Pensacola, Fla.: Naval School of Aviation Medicine, 1959.

Waters, L.K. and Wherry, R.J., Jr., A Factor Analysis of Aptitude and Achievement Tests and Performance in the Naval Air Training Program. BuMed Project MR005.13-3003 Subtask 10, Report No. 3. Pensocolo, Fla.: Naval School of Aviation Medicine, 1959.

Webb, W.B. and Wherry, R.J., Jr., Vigilance in Prolonged and Repeated Sessions. Perceptual and Motor Skills, 10: $111-114,1960$.

Wherry, R.J., Jr., A Test of New Rationale and Methodology for the ForcedChoice Technique. BuMed Project MR005.13-5001 Subtask 1, Report No. 21. Pensacola, Fla.: Naval School of Aviation Medicine, 1960 (M.A. Thesis).

Wherry, R.J., Jr., The Hypersphere Concept: A New Model for Correlation Theory. In Tri-Service Conference on Selection Research, ONR Report ACR60. Washington, D.C.: Office of Naval Research, 1960, Pp 143-186.

Wherry, R.J., Jr. and Waters, L.K., Factor Analysis of Primary and Basic Stages of Flight Training: Advanced Jet Pipeline Students. BuMed Project MR005.13-3003 Subtask 10, Report No. 4. Pensacola, Fla.: Naval School of Aviation Medicine, 1960.

Ambler, R.K., Bair, J.T., and Wherry, R.J., Jr., Factorial Structure and Validity of Noval Aviation Selector Variables. Aerospace Medicine, 31: 456-461, 1960. 
Waters, L.K. and Wherry, R.J., Jr., Predicting Voluntary Withdrawal from Flight Training by Means of a Forced-Choice Scale: Construction and Preliminary Validation. Special Report No. 61-2. Pensacola, Fla.: Naval School of Aviation Medicine, 1961.

Waters, L.K. and Wherry, R.J., Jr., Evaluation of Two Forced-Choice Formats. BuMed Project MR005.13-5001 Subtask 2, Report No. 10. Pensacola, Fla.: Naval School of Aviation Medicine, 1961 .

Waters, L.K. and Wherry, R.J., Jr., The Preference Index and Responses to Forced-Choice Pairs. Personnel Psychol., 15: 99-102, 1962.

Woters, L.K. and Wherry, R.J., Jr., The Effect of Intent to Bias on ForcedChoice Indices. Personnel Psychol., 15: 207-214, 1962.

Waters, L.K. and Wherry, R.J., Jr., A Note on Alternative Methods of Scoring a Forced-Choice Form. Personnel Psychol., 15: 315-317, 1962.

Doll, R.E. and Wherry, R.J., Jr., Separation of Aviation Officer Candidates from Cadets for Purposes of Predicting Voluntary Withdrawals. BuMed Project MR005.13-5001, Subtask 1, Report No. 23. Pensacola, Fla.: Naval School of Aviation Medicine, 1963.

Shoenberger, R.W., Wherry, R.J., Jr., and Berkshire, J.R., Predicting Success in Aviation Troining. BuMed Project MR005.13-3003 Subtask 10, Report No. 7. Pensacola, Fla.: Naval School of Aviation Medicine, 1963.

FIELDS OF STUDY

Major Field: Psychology

Major Area: Industrial. Professors Robert J. Wherry, Sr., Carrol L. Shartle, and James C. Naylor

Minor Area: Statistics. Professors Robert J. Wherry, Sr., Herbert A. Toops, and James C. Naylor 


\section{TABLE OF CONTENTS}

Chapter

1.

II.

INTRODUCTION .

RATIONALE .

III . EMPIRICAL DEMONSTRATION and CROSS VALIDATION .

IV. DISCUSSION ................

V.

SUMMARY

APPENDIXES . .

REFERENCES
Page

I

11

44

65

71

73

96 


\section{LIST OF TABLES}

Table

1. Theoretical Weights Used on $m$ Independent Factors and Error Factors for Determining an Individual's X score....

II. Various Ways of Defining the "Average" Weight $\left(\bar{w}_{f}\right)$ for

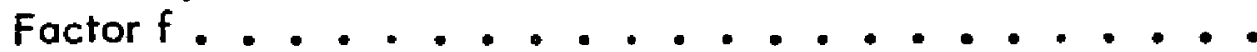

III. Procedure for Creating Dichotomous, Linear, Quodratic, and Cubic Pseudo Variables ............

IV. The Composition of the Experimental and Cross Volidation Sample with Regard to Subgroup Membership .......

V. Results of Wherry Test-Selection Technique Using Variable 19 as the Criterion and the "Common" Variables as Potential Selector Variables...............

VI. Summary Raw Score Dato for "Standardization" Variable (Y) and "Variable-to-be-Equated" on the Seven Subgroups Comprising the Experimental Sample .........

VII. The Means and Standard Deviations of the "Standardization" Variable, of the "Variable-to-be-Equated," and the Correlation Coefficients and the Transmutation Constants for the Subgroups .............

VIII. Computed Sums of X, $\mathrm{X}^{2}$, and Final Transmutation Constants $\left(\dot{a}_{g}^{\prime}\right.$ and $\left.\dot{b}_{g}^{\prime}\right)$ for Each Subgroup ..........

IX. Toble for Testing the Significance of Transmutation Equations Derived by the Slope and Intercept Method . . . . .

$X$. Table of Transmutation Constants and $r \ddot{X} Y^{\prime \prime}$ F Found in the First Iteration ...............

XI. Comparison of "Transmutation" Constants Derived from the vlope and Intercept" Method and the "Pseudo Voriable" Method (Using Only Dichotomous and Linear Pseudo Voriables)................. 


\section{LIST OF TABLES (contd.)}

Table

XI1. Transmutation Constants Derived from the "Pseudo Variable" Approach Using Dichotomous, Linear, Quadratic and Cubic Pseudo Variables .............

XIII. F-Table Showing the Level of Significance of the Increase in the Proportion of Variance Explainable Using All Pseudo Variables over Using Only Dichotomous and Linear Pseudo Variables..............

XIV. Comparison of Non-Transmuted, Linearly Transmuted, and Nonlinearly Transmuted Advanced Flight Grodes in the Cross Validation Sample using the Transmutation Constants Derived from the Experimental Sample.. . . . 


\section{LIST OF ILLUSTRATIONS}

Figure

1. The Resulf of an Evaluator Letting $\ddot{x}=\alpha+\alpha^{\prime} \bar{x}^{\prime}+\gamma^{2}$... '

2. The Result of an Evaluator Letting $\mathrm{X}={ }_{\alpha}{ }^{+}{ }_{\beta} \mathrm{X}-{ }_{\gamma} \mathrm{X}^{2}$...

3. The Result of 'an Evaluator Letting $X={ }_{\alpha}+{ }_{\beta} X+{ }_{\delta} X^{3} \ldots .$.

4. The Result of an Evaluator Letting $\dot{X}={ }_{\alpha}+{ }_{\beta} X-{ }_{\delta} X^{3} \ldots$

5.

A Plot of the Nonlinear Equations Shown in Table XII Over the Range of Data in Each Subgroup........ 


\section{INTRODUCTION}

Whenever we wish to compare the merit of two or more individuals for assignment to a given task, we are faced first with the problem of determining what traits, obilities, skills, characteristics, etc. are relevant to success on the task. Secondly, we must either collect data on the individuals to be evaluated or use data already collected on them. If the number of individuals to be evaluated is relatively small, then a single evaluator might possibly collect all the data deemed necessary for each trait being studied. I shall define "evaluator" as any instrument which purports to possess the ability to give the relative standings of two or more individuals on o given "observable" (i.e., trait, ability, skill, etc.). An evaluator may, by this definition, be a rater, a paper-and-pencil test, a performance test, an electrode imbedided in the skin, etc.

If we have a large number of individuals to be evaluated we may have to employ several evaluators to accomplish the evaluation of each observable. This would be especially true in areas where ratings are to be used. It is quite possible that we might be able to find one person who we felt knew one group of the individuals well enough in a given area to rate them, a second rater for a second group, etc. For another observable we might use one form of a paper-andpencil test on part of the group and a different form or forms on the remainder of the group. For yet another observable we might use English grades from high school A for some individuals, English grades from high school B for others, etc. 
The moment we begin using more than one evaluator for the same observable we introduce a host of problems which may be subsumed under the general title of "equivalence of scale" problems. This title includes such problems as "leniency," the tendency of one rater to consistently rate everyone higher than would the average roter, and "exaggeration," the tendency of one a) $\rightarrow$ rater to spread the scores of the ratees over a wider range than would an average rater. These are very common problems in the field of rating $(22,25,34,44)$. "Floor" and "Eeiling" effects, the failure of an evaluator to adequately Hiscriminate individuals at one end or the other of the continuum, are also "equivalence of scale" problems, but are most frequently discussed by those in the field of test construction $(8,23)$. "Composition" effects, concerned with the relative emphasis of different factors on the total evaluation score, have been discussed by both those who construct al ternate forms of tests $(3,12)$ and those in the field of rating $(13,21,27)$. The "halo" effect $(5,9,10,15,32,33,44$, $46,47)$ perhaps the most widely known type of rating bias, is a "composition" effect. "Reliability" which broadly considered is concerned with the contribution of an error factor to the total evaluation score, and "validity" which is concerned with the overlap of factors in the evaluation score with those in a criterion score are also considered here to be "composition" effects. These and other "equivalence of scale" problems and their solutions constitute the general topic of this dissertation.

Because of differences in the magnitude of the abovermentioned effects from one "evaluator" to the next, we cannot validly compare the scores of two or 
more individuals on a given observable when these have been obtained from different evaluators. For example, a rating of " $85^{\prime \prime}$ is not necessarily indicative that a ratee is better than another ratee who received a rating of only "78" from a different evaluator. A cumulative point-hour ratio of 3.00 from one university may not indicate the same calibre of student as a 3.00 from onother university. Even within the same university the "meaning" of marks may differ from department to department. In fact, the "meaning" of grades frequently differs among instructors within the same department. It is thus not surprising that even the best college entrance test can explain only about 50 per cent of the variance of actual college grades.

\section{METHODS FOR PREVENTING THE OCCURRENCE OF "EQUIVALENCE OF} SCALE" ERRORS

There are ways to avoid certain types of "equivalence of scale" errors. Among the "preventives" in the field of test construction are recommendations to include items from all levels of difficulty $(18,43)$. This is clearly an attempt to prevent a floor or ceiling effect from occurring. The entire history of the development of rating scales is really one attempt after another to develop scales which would be equivalent from one rater to another (anchor points, graphic rating scales, forced distributions, scaling techniques, etc.). In modern rating forms we usually find very coreful instructions (sometimes even short troining courses are given (14)) on how to avoid various types of bias in rating. This is done in the hope that "a word to the wise will be sufficient." The extent to which such instructions really prevent rating bias is rarely reported, and, if 
reported, is based on letting the different raters rate the same group of individuals. What would happen if two or more raters are asked to rate separate groups which really drastically differ in both average ability and spread of ability on the trait to be roted has to my knowledge, either not been done or, if done, the degree of presence of the various types of bias has not been established.

While I believe such preventives should be applied, there is no guarantee that they will always work as designed, and methods of removing the effects of non-equivalence are badly needed. METHODS FOR THE REMOVAL OF "EQUIVALENCE OF SCALE" ERRORS

Two major approaches to the problem of removing "equivalence of scale" errors are found in the literature. The first approach is based on the assumption that the group of individuals who were evaluated by evaluator $A$ (rater $A$, furm $A$, etc.) is similar (in all important aspects concerning possession of the trait or ability being measured) to the group of individuals who were evaluated by evaluator B. The second approach does not make this "equivalence of possession of trait rated" assumption. In the case where both evaluators have evaluated the same group of individuals, the assumption is usually made without question (olthough it is entirely possible that the two roters or two forms weren't measuring the same traits, and the assumption is not warranted). Until recently, the methods of equating al ternate forms of a test have uniformly made this assumption. Some people have suggested that if the assumption is true, all that would be necessary to adequately equate the scales of the two evaluators would be a linear transformation to one or both groups of test scores which would make the means 
and standard deviations of the two scales equal. Others (22), who have been bothered by the fact that the simple linear transformations would not remove differences between the two scales with regard to skewness and kurtosis, have recommended normalizing both sets of scores. Still others have felt that normalizing the scores might conceivably damage the interval nature of scale values in their more trusted form. For example, if form $A$ of the test has been developed by carefully observing all the rules for obtaining an interval scale for that form, and the distribution of scores obtained is not normal, the developers moy decide that the assumption of a normal distribution of the trait being measured is not warranted. These people have suggested that the percentile scores of the two forms be obtained and the raw score of form $A$ be assigned to the equivalent percentile score of form B. These and other methods of equating scales, when the "equivalence of possession of trait rated" in the two groups is assumed, are discussed by Flanagan (19) and Gulliksen (24). While the assumption of equivalence of possession of trait rated" is always questionable, methods using the assumption have been successfully employed by many investigators. For example, Berkshire (4) demonstrated that using standard scores (within classes) rather than raw scores of successive classes of students in the U.S. Naval School of Pre-Flight significantly raised the average intercorrelation among the courses being taught. While this is not conclusive evidence that the assumption was warranted, it does indicate that grading procedures from class to class were varying more drastically than were the ranges and averages of ability. More recently, Lord (28) has 
reported success at equating alternate forms of tests administered to different groups which had been constituted by random assignment of the entire group to the two forms.

Several methods using partial overlap among groups to be equated have been used. Thurstone's absolute scaling method (35) uses this procedure. In industrial psychology a majority of the methods for determining wage rates (39) may be considered to be variations of the partial overlap method. Usually a group of experts (from management and/or labor) select a number of "key" jobs which they rate and discuss until general agreement is reached on these "key" jobs concerning overall wage and/or amounts of various abilities required for each job. Independent raters may then evaluate different departments within the company and the ir ratings can be "equated" to the "key" job wage scale. Some of the key jobs should come from each department.

Several methods have been devised for equating the scales of two or more evaluators when there is no overlap among the groups evaluated by the difforent evaluators, and when one is unwilling to assume that the distribution of the trait being rated is the same from one subgroup to the next. The earliest statistical method for equating subgroups composed of different subjects was o method described by Toops (37) in 1933. It involved using one variable which was a "standardized" test (an intelligence test) as the variable against which the subgroup scores (grades from various high schools) could be "equated." Basically the method required finding the slope and intercept of each subgroup's scores with the scores of that subgroup on the standardization variable. Each score was 
"transmuted" (or "equated") by subtracting that subgroup's intercept and dividing the remainder by that subgroup's slope. Because of the nature of Toops' method I shall refer to it as the "slope and intercept" method of equating subgroups. Toops in his article does not give the rationale behind his method other than to say that the "transmuted" scores would take into account the intellectual differences of different schools. Unfortunately, Toops' paper was published only in an Ohio College Association Bulletin and is not a well known article. No real data were "transmuted" in his paper and, to my knowledge, the efficiency of the method was never demonstroted empirically.

Gulliksen (24) describes a procedure similar to Toops' "slope and intercept" method for equating alternate forms of a test which hove been administered to different groups of individuals. Gulliksen credits Tucker with developing the theory on which the procedure is based. Tucker's procedure was to estimate what the mean and standard deviation of each form would have been if both groups had taken both forms. This was accomplished by finding what the slope and intercept of the regression line of each form was to an "equating" variable (a variable on which the entire group has been tested), and then assuming that the slopes and intercepts would have been the same if the entire group had taken both forms. Using the statistics for correction for curtailment of range. Tucker could find the theoretical mean and standard deviation of each form if the entire group had taken both forms. A simple linear transformation to either form was then accomplished in order to make the theoretical means and standard deviations of the two forms 
equal. The results of Tucker's procedure, if one has a single "equating" variable, would be identical to Toops' method.

Tucker also included a modified procedure to use when one has more than a single "equating" variable. This procedure was identical to the single "equating" variable method except that the slope and intercept of one form to the best composite of the "equating" variables for the group which took that form are used instead of the regression line of that form to a single "equating" variable. (This procedure seems some what questionable, however, since one equates each group, i.e., each alternate form, to a different composite variable. This point will be discussed more fully in the rationale section.) Tucker's method, like Toops', was not published in a standard journal. It was published (38) in 1953 as one of the papers delivered at an invitational conference on testing problems. Gulliksen's mention of Tucker's method appeared in 1950. Its use was reported by Englehart (16) in 1959.

While techniques for equating subgroups composed of different people are in existence, they are rarely discussed and generally unknown. There is, nevertheless, an obvious need for understanding the causes of "equivalence of scale" errors, and for techniques designed to accomplish the removal of such errors. Two areas of need already mentioned are better prediction of college success (this was the point of Toops' method) and al ternate forms construction. I feel certain that the availability of a proven technique for handling these problems would be welcomed by the "selection" and "placement" fields of psychology. Ore example of an evaluation situation requiring a method of equating scores from subgroups 
composed of different individuals is found in naval aviation training and will serve in this dissertation as the vehicle for an empirical demonstration of a possible solution to such problems.

\section{BACKGROUND OF THE PROBLEM TO BE USED FOR EMPIRICAL DEMONSTRATION}

The U.S. Navy trains several types of aviators. While part of the training of all naval aviators is virtually identical ( $i . e .$, standardized for all students), the advanced phases of training are quite different, depending on what type of aircraft the student will be expected to fly when he graduates from training and joins the fleet. The cost of training all types of aviators is tremendously high; so high, in fact, that the assignment of individuals to the various advanced training pipelines in an optimal fashion could effect substantial training economies Such assignment can be accomplished by computers using linear programming (20), if a "figure of merit" can be established for every individual for each of the advanced training types. The "figure of merit" is a composite of such elements as "cost to train" (training for different types of aircraft is differentially costly), "worth to the Novy of this type of aviator," and "predicted differential success as each type of aviator" (fighter, patrol, helicopter, etc.). It is the need for this latter element which requires an ability to equate training success scores. Every student completing training does have an "Advanced Flight Grode" which indicates fairly accurately the relative success of a given aviator from that subgroup of oviators to other aviators from that same subgroup. The validity of these "Advanced Flight Grades" has been established by soveral investigations (30, 31$)$. 
Within a given type of advanced training these grades can be predicted foirly accurately by using data collected on the oviators prior to their assignment to the advanced training. However, a predicted grade, or an actual grade, of 302 in one subgroup does not necessarily indicate the same degree of absolute "success as a pilot" as a score (predicted or actual) of 302 from a different subgroup. The problem is complicated by the fact that there are seven different types of advanced training with different numbers of students in each type.

The proctical problem then is to find a method for equating the "Advanced Flight Grades" among the different subgroups of students in advanced training. Those individuals in the past who have had the administrative responsibility for assigning students to the different types of advanced training have ignored the lack of "equivalence of scale" among the se seven subgroups. This was due in part, 1 believe, to a lack of a comprehensive rationale which would embrace all of the "equivalence of scale" problems, and in part to the lack of proven method for equating subgroups composed of different individuals.

It is hoped that the rationale and the techniques to be set forth in this dissertation will, in some measure, heip fill this need. It is perhaps fitting that we quote from Toops' original article on the "slope and intercept" method. He said, "This method is developed below, in the hope that others may use it, discover and report it, faults, and, perchance, devise a better system, or one allowing adequately for more factors." 


\section{RATIONALE}

\section{REAL DIFFERENCES AMONG INDIVIDUALS}

In the hypersphere concept (45) of correlation it is assumed that there are a finite number $(m)$ of independent dimensions which account for all the real differences among all individuals. Each individual is represented (i.e., completely described) by a single point in this m-dimensional space, and all individuals could be enclosed by a m-dimensional envelope called the "hypersphere." A given individual's location may be specified by the perpendicular projections of the point representing that individual on the $m$ independent dimensions. Further, we may express these projections in terms of standard scores for each dimension. Thus, following accepted factor analytic theory (36),

$$
\text { Location of individual } i \rightarrow z_{1}, z_{2_{1}}, z_{3_{1}}, \ldots, z_{f_{1}}, \ldots, z_{m_{1}} \text {. }
$$

There are an infinite number of vectors running through this $m$ dimension hypersphere and these vectors may be described in one of several ways. We may use either some trigonometric function (such as the cosine) of the angle between the specified vector and each independent dimension, or we could use the relationship (determined by the Pearson product-moment correlation coefficient based on all the cases available) between the specified vector and each independent dimension. Thus,

$$
\begin{aligned}
& \text { Vector } X \rightarrow \cos \angle X O 1, \cos \angle X 02, \ldots, \cos \angle X O f, \ldots, \cos \angle X O m . \\
& \text { Vector } X \rightarrow r_{x_{1}}, r_{x_{2}}, r_{x_{3}}, \ldots, r_{X f}, \ldots, r_{x_{m}} .
\end{aligned}
$$


Wherry, Jr. (45) has shown that under certain conditions (when $\sigma_{1}=\sigma_{2}=$ $\left.\sigma_{3}=\ldots=\sigma_{f}=\ldots \sigma_{i k}\right)$ that the two expressions above are identical. In the following discussion we shall assume that these conditions are true.

When a given ubserver (a rater, a test, or some other type of measuring instrument) observes the locations of a group of individuals we assume that what he is really doing is observing the locations of the individuals along some vector through the hypersphere. Usually when a set of observations is being mode some random error, unrelated to any of the $m$ dimensions, creeps in. We may think of the error as being another independent dimension. Thus, a given individual is imperfectly observed to be ot

$$
z_{x_{1}}=r_{x_{1}} z_{2_{1}}+r_{x_{2}} z_{z_{1}}+r_{x_{3}} z_{s_{1}}+\ldots+r_{x_{f}} z_{f_{1}}+\ldots+r_{x_{m}} z_{m_{1}}+r_{x_{e}} z_{e_{1}}
$$

For simplification purposes, we shall simply call these $r_{x}$.'s weights and symbolize them by "w's". Thus,

$$
z_{x_{1}}=w_{1} z_{1_{1}}+w_{2} z_{z_{1}}+\ldots+w_{f} z_{f_{1}}+\ldots+w_{m} z_{m_{1}}+w_{e} z_{e_{1}}
$$

Where $z_{x_{1}}=$ the standard score expression of individual i's supposed location on vector $X$,

$z_{f_{1}}=$ the standard score expression of the location of
individual $i$ on factor $f$,

$z_{e_{1}}=$ the standard score expression of error for individual $i$,

$m$ = the total number of independent real factors,

f $=$ an unspecified factor, and

$w_{f}=$ the weight given factor $f\left(=r_{x f}\right)$. 


\section{DIFFERENCES AMONG EVALUATORS}

When a given rater is asked to rate a group of individuals on some given trait, or variable, the w's are usually unspecified for the most part. A second rater will undoubtedly have a different set of weights for the $m$ factors than did the first rater. Further, the relative contribution of error $\left(w_{e}\right)$ and the error score itself $\left(z_{e_{1}}\right)$ will probably be different among different raters.

The entire population of people might be broken down into $k$ subgroups and a different rater might be assigned to rate each subgroup. If we were able to discover what weights were used for each subgroup for each factor, we might table the values as seen in Table 1. Notice that each subgroup has a different error factor. This is to say that the error in one subgroup is unrelated to the error in a second subgroup.

\section{Table 1}

Theoretical Weights Used on $m$ Independent Factors and Error Factors for Determining on Indivicual's $X$ score

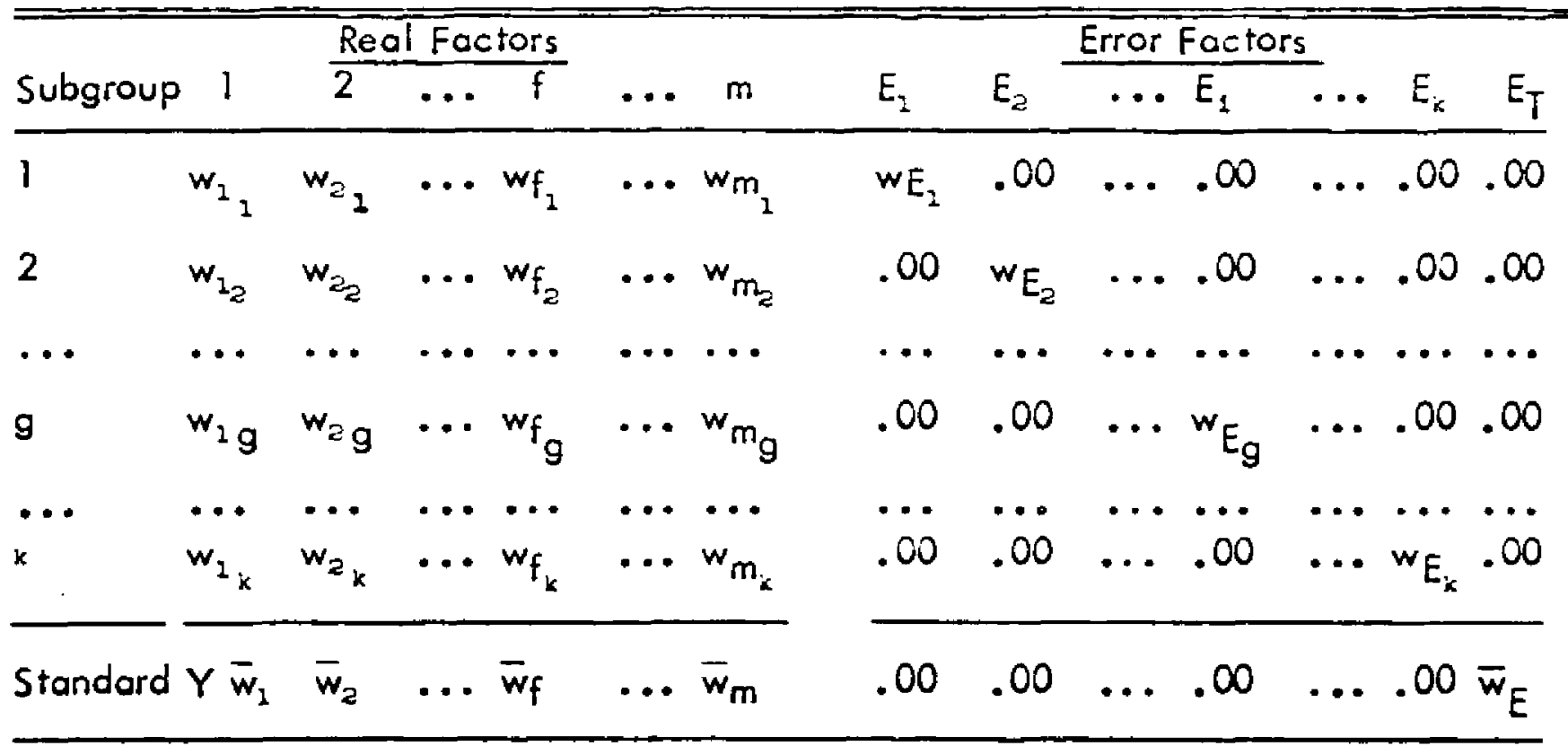


The "Reliability" Effect

Since each $w$ is a correlation coefficient, it represents the square root of the proportion of variance explainable by its factor, and because the factors are independent, the sum of the $\mathrm{w}_{\mathrm{g}}^{21} \mathrm{~s}$ for any subgroup will equal 1.00. In this way we may specify that the "reliability" $\left(\lambda_{\mathrm{g}}\right)$ effect in subgroup $g$ is equal to the square root of one minus the $w_{E_{g}}^{2}, i . e .$,

$$
\begin{aligned}
& \text { Index of } \\
& \text { reliability } \\
& \text { for subgroup }
\end{aligned}=\lambda_{g}=\sqrt{1-w_{E_{g}}^{2}}=\sqrt{\Sigma w_{g}^{2}} .
$$

$\mathrm{g}$

We do not assume that trie index of reliability would be the same omong subgroups. (This would depend on the various $w_{E}{ }^{s .}$ )

$$
\lambda_{1} \neq \lambda_{2} \neq \ldots \neq \lambda_{g} \neq \lambda_{k} \text {. }
$$

Further, we do not assume that the weight in one subgroup for any given factor will be the same as the weight for that factor in any other subgroup.

$$
w_{f_{1}} \neq w_{f_{2}} \neq \ldots \neq w_{f_{g}} \neq \ldots \neq w_{f_{i}} \text {. }
$$

There must be an average weight $(\bar{w})$ assigned to each of the $m$ independent factors which would represent a "standard" $(Y)$ on which our subgroups might be equated. However, it is not particularly easy to say how these average weights should be defined. For example, one way might be

$$
\bar{w}_{f}^{\prime}=\frac{n_{1} w_{f_{1}}+n_{2} w_{f_{2}}+\ldots+n_{1} w_{f_{g}}+\ldots+n_{k} w_{f_{k}}}{N} .
$$


In one sense this would give the "average" $w_{f}$, but this is differentially determined by the size of each subgroup. A second method would be to give equal weight to each subgroup's opinion about what magnitude $w_{f}$ should be. Thus,

$$
\bar{w}_{f}^{\prime \prime}=\frac{w_{f_{1}}+w_{f_{2}}+\ldots+w_{f_{g}}+\ldots+w_{f_{k}}}{k} .
$$

Still another method might be to consider the proportion of variance being explained, thus

$$
\bar{w}_{f}^{\prime \prime \prime}=\frac{n_{1} w_{f_{1}}^{2}+n_{2} w_{f_{2}}^{2}+\ldots+n_{g} w_{f}^{2}+\ldots+n_{k} w_{f_{k}}^{2}}{N} .
$$

Actually there are many otiner justifiable ways to define the "average" $w_{f}$. We show eight of these in Table 11.

\section{Table II}

Various Ways of Defining the "Average" Weight $\left(\bar{w}_{f}\right)$ for Factor $f$

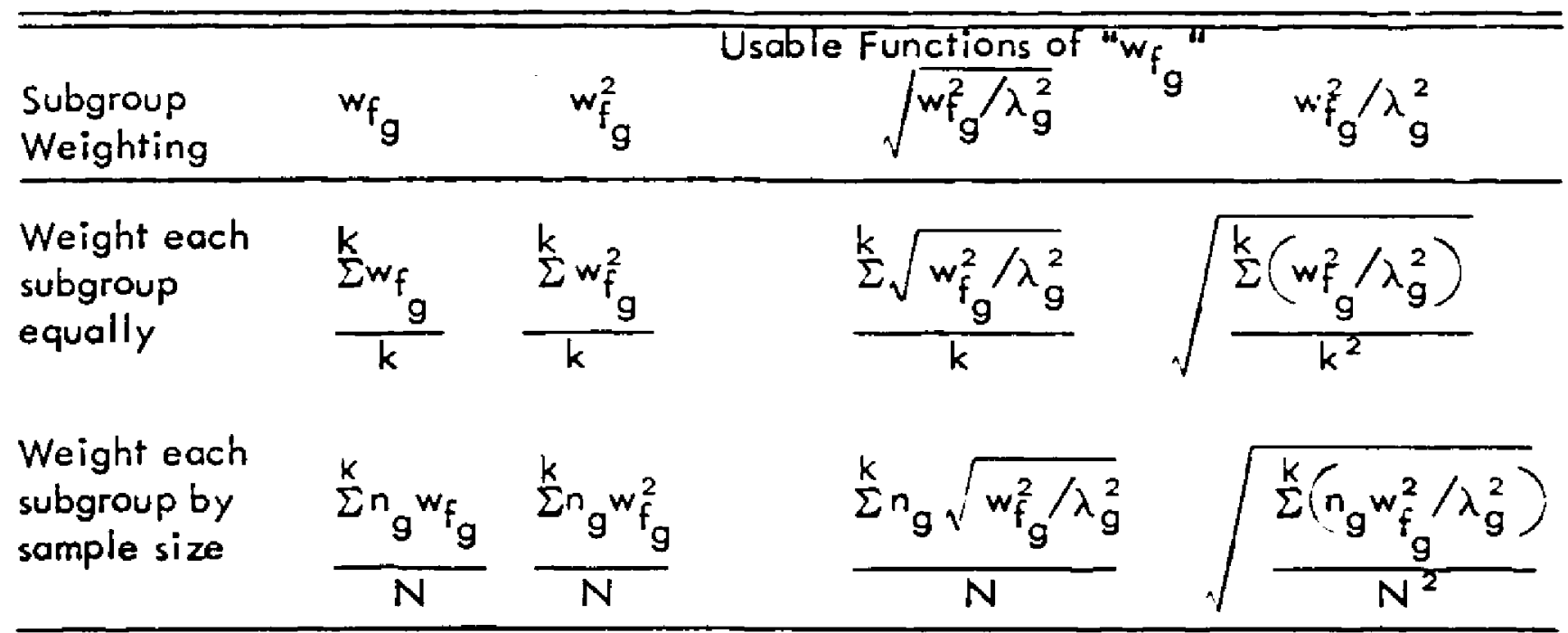

There would seem to be plausible reasons for using any one of these ways to define $\bar{w}_{f}$. Each would yield a slightly different vector (the $Y$ vector) against 
which subgroups could be equated. The relotive merits of the different methods are academic considerations since we would rarely hope to be able to define the independent factors (usually we only have one score per individual) much less accurately determine the weights that were actually being used on each factor in each of the k subgroups. Dingman and Guilford (13) and Jones (27) have discussed the problem of finding the optimal vector to maximize composition effects among different evaluators.

Let us merely say that we shall attempt to find a set of scores ( $Y$ scores) which contain an "average" composite of the factor weights being used in the subgroups. These scores will be the "standard" against which we will attempt to equate the subgroups. An individual's score (expressed in standard score form) on the $Y$ vector would be

$$
z_{Y_{1}}=\bar{w}_{1} z_{F_{2_{1}}}+\bar{w}_{2} z_{F_{a_{1}}}+\ldots+\bar{w}_{f} z_{F_{f_{1}}}+\ldots+\bar{w}_{m} z_{F_{m_{1}}}+\bar{w}_{E_{1}}{ }^{z} E_{1} \cdot
$$

In turn we may combine the true portion of the $z_{Y}$ score as follows

$$
Y_{1}=\bar{w}_{1} z_{F_{1}}+\bar{w}_{z_{F_{2}}}+\ldots+\bar{w}_{f_{1}} z_{F_{1}}+\ldots+\bar{w}_{m} z_{F_{m_{1}}} \cdot
$$

Equation (12) really becomes a definition of the $Y$ vector. We may say that his entire score is

$$
\begin{aligned}
& { }^{z} Y_{1}=\lambda_{y} \cdot Y_{1}+\sqrt{1-\lambda_{y}^{2}} \cdot e_{Y_{1}}, \\
& \text { where } \lambda_{y}=\sqrt{\frac{m}{\Sigma} \bar{w}_{f}^{2}} .
\end{aligned}
$$


The "Composition" Effect

The correlation between the scores the entire sample would have received if they had all been assigned to subgroup $g$ and the standard would be

$$
r_{X_{N_{g}}} Y_{N}=\dot{\theta}_{g}=\lambda_{g} \lambda_{y} \sum w_{f_{g}} \bar{w}_{f} \text {, and }
$$

The correlation between the "reliable" portion of $X$ and the reliable portion of $Y$ would be

$$
\theta_{g}=\frac{\dot{\theta}_{g}}{\lambda_{g} \lambda_{Y}} .
$$

This "unattenuated" correlation $\left(\theta_{g}\right)$ will be called the "composition" effect.

Now we may conisider a person's subgroup score to be composed in part of the "true" part of the standard and that part of the subgroup score which is independent of the "true" part of the standard. We may call this second part the "uniqueness" $\left(U_{g_{1}}\right)$ of subgroup g's score for individual $i$. Thus,

$$
X_{g_{1}}=\theta_{g} Y_{1}+\sqrt{1-\theta_{g}^{2}} \cdot U_{g_{1}}
$$

The uniqueness in turn can be subdivided into a non-error part (the "true" variance in subgroup i's scores unrelated to the $Y$ vector), and an error part. The former we shall denote by the letter "Sg" (the "specific" portion of a subgroup $\mathrm{g}$ scores) while the latter is the previously discussed $\mathbf{e}_{\mathbf{g}_{1}}$. Since we already know that the weight that $e_{g_{1}}$ gets is $w_{E_{g}}\left(=\sqrt{1-\lambda_{g}^{2}}\right)$ then we can show

$$
\sqrt{1-\theta_{g}^{2}} \cdot U_{g_{1}}=\sqrt{\lambda_{g}^{2}-\theta_{g}^{2}} \cdot s_{g_{1}}+\sqrt{1-\lambda_{g}^{2}} \cdot{ }^{\theta_{g_{1}}} \cdot
$$


The "Exaggeration" Effect

Any given subgroup evaluator may tend to spread the observed scores $\left(X_{g_{1}}\right)$ out or to compress them too much. This tendency is known as the "exaggeration" effect. We shall assume that this works in a simple multiplicative fashion on the $\mathrm{X}_{\mathrm{g}}$ scores. Thus,

$$
\dot{\mathrm{X}}_{\mathrm{g}_{1}}=\dot{\beta}_{\mathrm{gt}_{\mathrm{t}}} \mathrm{X}_{\mathrm{g}_{1}}
$$

Where $\dot{\beta}_{g t}=$ the "exaggeration" effect in subgroup $g$ at time $t$.

The "Leniency" Effect

The "leniency" effect, the tendency to give each person in a given subgroup a higher or lower score than he deserves, is assumed to work in an additive fashion. We may now write the equation for the $i^{\text {th }}$ individual in subgroup $g$ when both an "exaggeration" and "leniency" effect are operating.

$$
\ddot{x}_{g_{1}}=\dot{\alpha}_{g_{t}}+\dot{x}_{g_{1}}=\dot{\alpha}_{g_{t}}+\dot{\beta}_{g_{t}} x_{g_{1}},
$$

where $\dot{\alpha}_{g t}=$ the "leniency" effect at time $t$ in subgroup $g$.

\section{FLUCTUATIONS WITHIN EVALUATORS}

It will be helpiul in understanding "leniency" and "exaggeration" to think of each evaluator as if he had been given a "rubber yardstick" to measure the individuals in his group. "Exaggeration" effects result because different evaluators stretch their yardsticks differentially taut. To assume that $\dot{\beta}_{g t}$ is constant for all subjects rated by evaluator $g$ is to assume that evaluator $g$ can maintain the same degree of tautness in his yardstick of all times. Such on assumption is probably not warranted if the "evaluator" is a rater. It is entirely possible that the degree of tautness in one rater's yardstick may undergo gradual 
changes as a function of time. Similar comments may be true of "leniency" effects as well. A rater or instructor may conceivably become progressively more lenient as a function of time, or raters may be more lepient on Mondays than they are on Fridays. Coombs' (11) rationale recognizes such fluctuations.

The "composition" effect will probably also show fluctuation from day to day as well as gradual shiftsover time. It is certainly not difficult to imagine a rater's definition of what constitutes "leadership" changing in the course of time. We can also hypothesize fluctuations in the reliability of a rater's ratings over time. As a rater learns more and more about the individuals he is rating, his ratings should be more free of error.

While within-evaluator changes in non-equivalence effects is a fascinoting problem, especially those of a gradual shift nature, it is beyond the scope of this dissertation. We shall assume that over the period of time that the ratings we hove were obtained, the various fluctuations mentioned above have occurred in a random fashion. Our concern will be with the overage "leniency," the average "exaggeration," etc. We shall let

$$
\begin{aligned}
& \dot{\alpha}_{g_{t}}=\alpha_{g}+\Delta_{\alpha_{g t}}, \text { and } \\
& \dot{\beta}_{g_{t}}=\beta_{g}+\Delta_{\beta_{g t}},
\end{aligned}
$$

where $\alpha_{g}$ = the average "leniency" effect, in subgroup $g$,

$\beta_{\mathrm{g}}=$ the average "exaggeration" effect in subgroup $\mathrm{g}$,

$\Delta \alpha_{g_{t}}=$ the difference between the actual and the average
"leniency" effects, and

$$
\begin{aligned}
& \Delta_{\beta_{\text {gt }}}=\text { the difference between the octual and the overage } \\
& \text { "exaggeration" effects. }
\end{aligned}
$$


Then, substituting Eqs. (20.1) and (20.2) into Eq. (20)

$$
\ddot{x}_{g_{1}}=\alpha_{g}+\beta_{g} x_{g_{t}}+\left(\Delta_{\alpha_{g t}}+\Delta_{\beta g t} \cdot x_{g_{1}}\right) \text {. }
$$

Since the fiuctuations ( $\Delta$ 's) are random, they will not correlate with any other terms in our equations. Since the fluctuations are also deviation scores, they will sum to zero for the entire group. We shall make similar assumptions regarding fluctuations in "composition" and "reliability" effects. With these assumptions made we can consider all fluctuation terms ( $\Delta$ 's) to have already been accounted for in our error term for individual $i\left(e_{g_{q}}\right)$. Dropping the $\Delta$ terms from Eq. (20.3) and substituting Eqs. (17) and (18) we obtain

$$
\ddot{x}_{g_{1}}=\alpha_{g}+\beta_{g} \theta g Y_{1}+\beta_{g} \sqrt{\lambda_{g}^{2}-\theta_{g}^{2}} \cdot s_{g_{1}}+\beta_{g} \sqrt{1-\lambda_{g}^{2}} \cdot e_{g_{1}},
$$

$$
\text { where } \begin{aligned}
\ddot{x}_{g_{1}} & =\text { the } i^{\text {th }} \text { individual 's raw score in subgroup g, } \\
\alpha_{g} & =\text { the "leniency" effect in subgroup g, } \\
\beta_{g} & =\text { the "exaggerotion" effect in subgroup g, } \\
\theta_{g} & =\text { the "composition" effect in subgroup g, } \\
\lambda_{g} & =\text { the "reliability" effect in subgroup g, } \\
Y_{1} & =\text { individual i's location on the } Y \text { vector, the vector } \\
S_{g_{1}} & =\text { individual i's location on the "specific" dimension } \\
\text { in subgroup g. } & \text { individual } i \text { 's location on the error dimension in } \\
e_{g_{1}} & \text { subgroup } g .
\end{aligned}
$$


The "standardizing" variable is assumed to also hove undergone an "exaggeration" and "leniency"effect. Thus from Eq. (14) we may write the final ${ }^{1}$ equation for a "standardizing" variable (the variable to be used to cquate the subgroups) score as

$$
\dot{Y}_{1}=\alpha_{y}+\beta_{y} \lambda_{y} Y_{1}+\beta_{y} \sqrt{1-\lambda_{y}^{2}} \cdot e_{y_{1}}
$$

Where $\alpha_{y}=$ the "leniency" effect on the standardizing variable, $\beta_{y}=$ the "exaggeration" effect on the standardizing variable, $\lambda_{y}=$ the "reliability" effect on the standardizing variable, $Y_{1}=i$ 's location of the vector being used to equate the subgroups,

$\dot{Y}_{1}=i$ 's raw score on the standardizing variable, and $e_{y_{1}}=i$ 's location on on error dimension in standard score form.

Now the sum of the row scores in subgroup $g$ would be

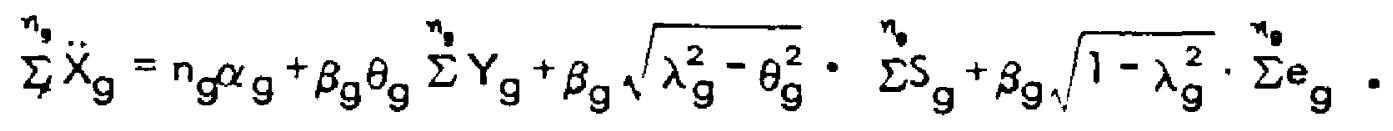

Dividing the above equation by $\mathrm{n}_{\mathrm{g}}$, we could find the mean of the row scores in subgroup $\mathrm{g}$.

$$
\overline{\ddot{X}}_{g}=\frac{\sum_{g} \ddot{X}}{n_{g}}=\alpha_{g}+\beta_{g} \theta_{g} \bar{Y}_{g}+\beta_{g} \sqrt{\lambda_{g}^{2}-\theta_{g}^{2}} \cdot \bar{s}_{g}+\beta_{g} \sqrt{1-\lambda_{g}^{2}} \bar{e}_{g} .
$$

A deviation score in subgroup 9 would be found by subtracting Eq. (23) from (21).

$$
\ddot{x}_{g_{1}}=\ddot{x}_{g_{1}}-\overline{\ddot{x}}_{g}=\beta_{g} \theta_{g} y_{g}+\beta_{g} \sqrt{\lambda_{g}^{2}-\theta_{g}^{2}} \cdot s_{g_{1}}+\beta_{g} \sqrt{1-\lambda_{g}^{2}} \cdot e_{g_{1}}
$$

"Inclusion of "floor" or "ceiling" and "differential treatment of extremes" effects will be considered later. 
The mean score of the standardizing variable scores in subgroup $g$ would be from equation (22), following the same logic.

$$
\overline{\dot{Y}}_{g}=\frac{\sum_{g}^{n_{g}}}{n_{g}}=\alpha_{y}+\beta_{y} \lambda_{y} \bar{Y}_{g}+\beta_{y} \sqrt{1-\lambda_{y}^{2}} \cdot \bar{e}_{y_{g}} \cdot
$$

A deviation score on the standardizing variable would be found by subtracting Eq. (25) from Eq. (22). Thus,

$$
\dot{y}_{g_{1}}=\beta_{y} \lambda_{y} y_{g_{1}}+\beta_{y} \sqrt{1-\lambda_{y}^{2}} \cdot e_{y_{1}} \text {. }
$$

Squaring these deviation scores and summing through the $n_{g}$ cases in subgroup 9

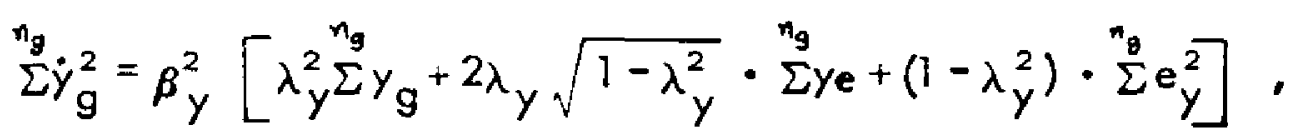

but ${ }^{n_{g}}$ ye should equal 0.0 and $\sum_{g}^{n_{g}^{2}}{ }_{y}$ will equal $n_{g}$, therefore,

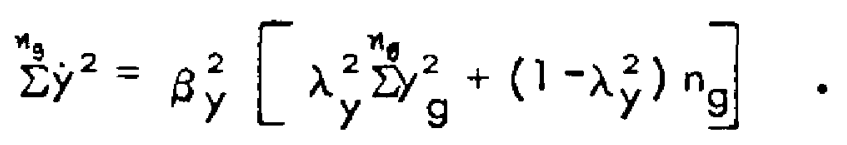

The sum of the cross products of a $\dot{y}$ score and a $\ddot{x}$ score will be

$$
\begin{aligned}
& \stackrel{n_{2}}{\Sigma \ddot{x}_{y}}=\beta_{y} \lambda_{y} \beta_{g} \theta_{g}{ }^{n_{g}} \Sigma y_{g}^{2}+\beta_{y} \lambda_{y} \beta_{g} \sqrt{\lambda_{g}^{2}-\theta_{g}^{2}}{ }^{n_{g}} g
\end{aligned}
$$

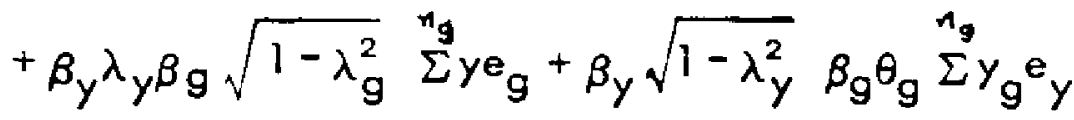

$$
\begin{aligned}
& +\beta_{y} \sqrt{1-\lambda_{y}^{2}} \beta_{g} \sqrt{\lambda_{g}^{2}-\theta_{g}^{2}} \quad{ }^{n_{g}} s_{g} e_{y}
\end{aligned}
$$

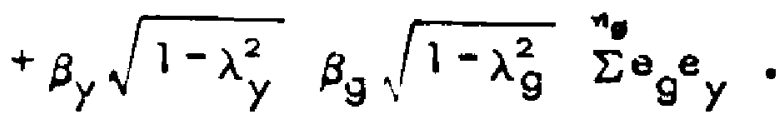


However, there should be no correlation among $S, Y, e_{g}$, or e $y^{\prime}$ therefore,

$$
\begin{aligned}
& \sum_{g} y=\ddot{n}_{g} n_{g}=\sum y_{g} e_{g}^{n_{g}}=\sum s_{g} e_{y}=\sum e_{g} e_{y}=0.0, \text { and } \\
& n_{g} \ddot{x}_{y_{1}}=\beta_{y} \lambda_{y} \beta_{g} \theta_{g} \ddot{n}^{n_{g}} y_{g}^{2} .
\end{aligned}
$$

Dividing $\sum_{g}^{n_{g}}$ by $\sum_{g}^{n_{g}} y^{2}$, we may find the slope $\left(b_{g}\right)$ of $\ddot{X}_{g}$ on $\dot{Y}_{g}$.

$$
\begin{aligned}
& b_{g}=\frac{\sum_{g}^{n_{x}} \dot{n}_{g}}{\sum \dot{y}^{2}}=\frac{\beta_{y} \lambda_{y} \beta_{g} \theta g{ }^{n_{g}} y_{g}^{2}}{\beta_{y}^{2}\left[\lambda_{y}^{2} \sum^{n_{g}} y_{g}^{2}+\left(1-\lambda_{y}^{2}\right) n_{g}\right]}, \\
& =\frac{\beta_{g} \theta_{g}}{\beta_{y}\left[\lambda_{y}+\frac{\left(1-\lambda_{y}^{2}\right)}{\lambda_{y}} \cdot \frac{{ }^{n g}}{n_{n} y_{g}^{2}}\right]} .
\end{aligned}
$$

The intercept $\left(a_{g}\right)$ of the $\ddot{X}$ scores on the $\dot{Y}$ scores for suiggroup $g$ is found by

$$
a_{g}=\overline{\ddot{X}}_{g}-b_{g} \overline{\dot{Y}}_{g}
$$

Substituting Eqs. (23), (25), and (30) into the above and assuming $\bar{e}_{g}=\bar{e}_{y_{g}}=0.0$, we obtain 


$$
\begin{gathered}
a_{g}=\alpha_{g}+\beta_{g} \theta_{g} \bar{Y}_{g}+\beta_{g} \sqrt{\lambda_{g}^{2}-\theta_{g}^{2}} \cdot \bar{s}_{g}-\frac{\alpha_{y} \beta_{g} \theta_{g}}{\beta_{y}\left[\lambda_{y}+\frac{\left(1-\lambda_{y}^{2}\right)}{\lambda_{y}} \cdot \frac{n_{g}}{\Sigma y_{g}^{2}}\right]} \\
-\frac{\beta_{g} \theta g \beta_{y} \lambda_{y} \bar{Y}_{g}}{\beta_{y} \lambda_{y}\left[1+\frac{1-\lambda_{y}^{2}}{\lambda_{y}^{2}} \cdot \frac{\left.n_{g}\right]}{\Sigma y_{g}^{2}}\right]}, \\
=\alpha_{g}+\beta_{g} \theta_{g} \bar{Y}_{g}+\beta_{g} \sqrt{\lambda_{g}^{2}-\theta_{g}^{2}} \bar{S}_{g} \\
-\frac{\alpha_{y} \beta_{g} \theta_{g}}{\beta_{y} \lambda_{y}\left[1+\frac{\left(1+\lambda_{y}^{2}\right)}{\lambda_{y}^{2}} \cdot \frac{n_{g}}{\Sigma y_{g}^{2}}\right]}-\frac{\beta_{g} \theta_{g} \bar{Y}_{g}}{1+\frac{\left(1+\lambda_{y}^{2}\right)}{\lambda_{y}^{2}} \cdot \frac{n_{g}}{\Sigma y_{g}^{2}}}
\end{gathered}
$$

TRANSFORMING A SET OF SCORES TO HAVE A SLOPE OF 1.00 AND AN INTERCEPT OF 0.0 WITH A SECOND SET OF SCORES

In order to transform a set of scores so they will hove a slope of 1.00 and an intercept of 0.0 with a second set of scores all we must do is subtract the present intercept and divide the remainder by the present slope. This is, of course, Toop's "slope and intercept" method. Let us now transform our $\ddot{X}$ scores in subgroup $g$ so that they have a slope of 1.00 and an intercept of 0.0 with the $\dot{Y}$ scores. These new transformed scores will be symbolized as $\ddot{X}$, thus

$$
\ddot{x}_{g_{1}}=\frac{\ddot{x}_{g_{1}}-a_{g}}{b_{g}}
$$


Substituting Eq. (21) for $\ddot{X}_{g_{1}}$ and Eqs. (30) and (31) for the values of $a_{g}$ and $b_{g}$, we obtain

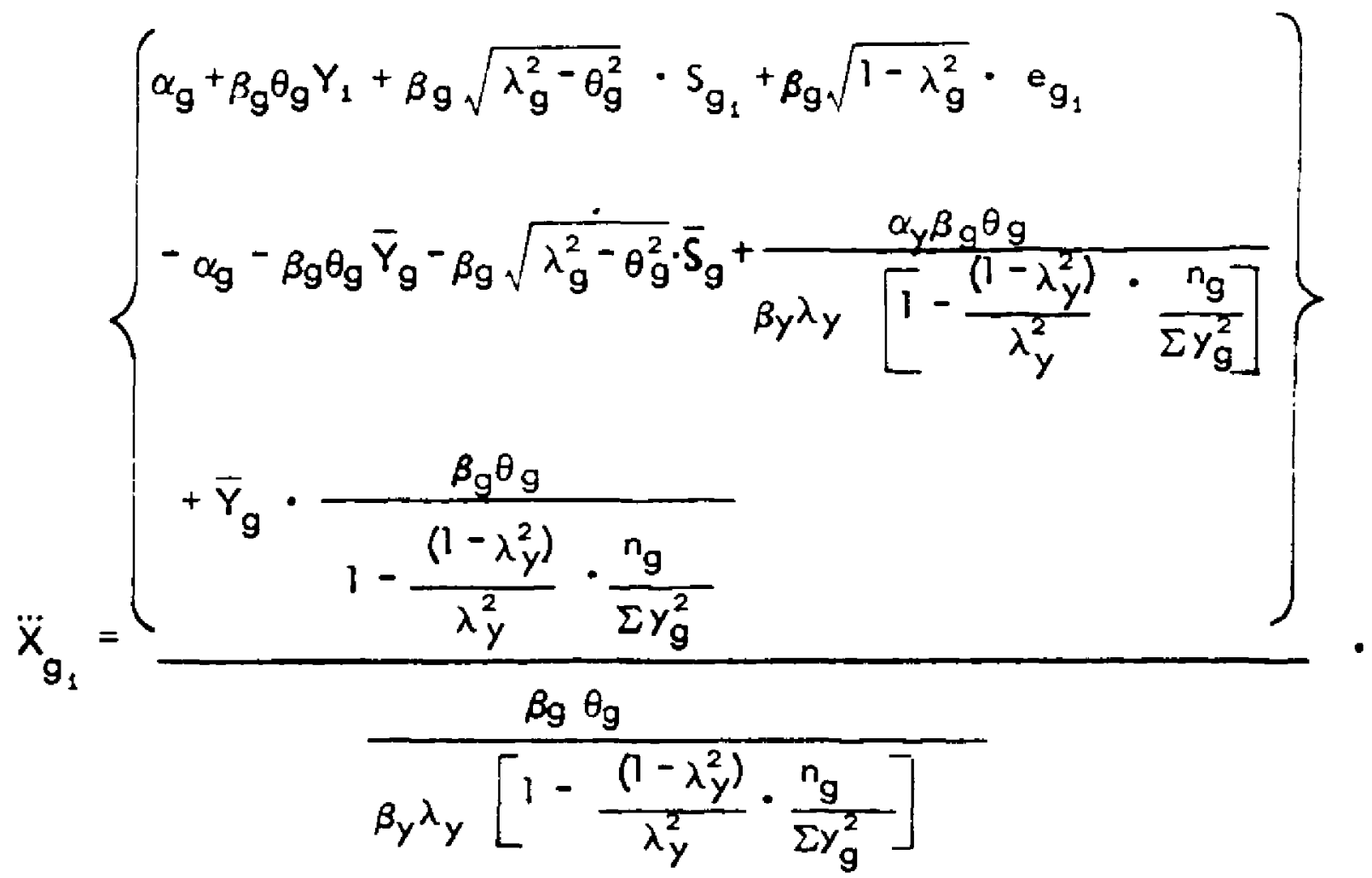

Collecting like tarms and dividing the last two terms in the numerator by the denominator

$$
\ddot{X}_{g_{1}}=\frac{\beta_{g} \theta_{g} y_{1}-\beta_{g} \sqrt{\lambda_{g}^{2}-\theta_{g}^{2}} \cdot s_{g_{1}}+\beta_{g} \sqrt{1-\lambda_{g}^{2}} \cdot e_{g_{1}}}{\beta_{y} \lambda_{y}\left[1-\frac{\left(1-\lambda_{y}^{2}\right)}{\lambda_{y}^{2}} \cdot \frac{n_{g}}{\Sigma y_{g}^{2}}\right]}+\alpha_{y}+\beta_{y} \lambda_{y} \bar{Y}_{g} \cdot
$$


Rearranging the terms and reducing

$$
\begin{aligned}
& \ddot{x}_{g_{1}}=\alpha_{y}+\beta_{y} \lambda_{y} Y_{1}+\beta_{y} \lambda_{y}\left[1-\frac{\left(1-\lambda_{y}^{2}\right)}{\lambda_{y}^{2}} \cdot \frac{n_{g}}{\Sigma y_{g}^{2}}\right] \cdot y_{g_{1}} \\
& +\beta_{y} \lambda y \cdot \frac{\sqrt{\lambda_{g}^{2}-\theta_{g}^{2}}}{\theta_{g}} \cdot s_{g_{1}} \cdot\left[1-\frac{\left(1-\lambda_{y}^{2}\right)}{\lambda_{y}^{2}} \cdot \frac{n_{g}}{\Sigma y_{g}^{2}}\right] \\
& +\beta_{y} \lambda_{y} \cdot \frac{\sqrt{1-\lambda_{g}^{2}}}{\theta_{g}} \cdot\left[1-\frac{\left(1-\lambda_{y}^{2}\right)}{\lambda_{y}^{2}} \cdot \frac{n_{g}}{\Sigma y_{g}^{2}}\right] \cdot e_{g_{1}}
\end{aligned}
$$

\section{DIFFERENCES AMONG GROUPS EVALUATED}

The "Curtailment" Effect

In several parts of the above equation we see the term $n_{g} / \Sigma y_{g}^{2}$ which is equal to $1 / \sigma_{Y_{g}}^{2}$. The reader will recall that the $Y$ 's referred to here are standard scores (see Eq. (13)), and that the total variance of $Y^{\prime}$ s would be 1.00 if we include all persons in the entire group rather than only those in subgroup g. Thus, $1 / \sigma_{g}^{2} g$ is the ratio of the original variance of the $Y$ 's to the curtailed variance of the $Y^{\prime}$ ' in the $g^{\text {th }}$ subgroup. We may symbolize this "curtailment" effect as $\Phi_{g}$ ' thus

$$
\Phi_{g}=\frac{\sigma Y^{2} \text { total }}{\sigma{ }^{\sigma} n_{g}}=\frac{\begin{array}{l}
\text { original variance of the } y \text { vector } \\
\text { scores for entire group }
\end{array}}{\begin{array}{l}
\text { curtailed variance of the } y \text { vector } \\
\text { scores for subgroup } g
\end{array}} \text {. }
$$


Substituting Eq. (34) into Eq. (33) and regrouping our terms, we obtain

$$
\begin{aligned}
\ddot{x}_{g_{1}} & =\alpha_{Y}+\beta_{y} \lambda_{y}\left(\bar{Y}_{g}+y_{g_{1}}\right)-\left[\beta y \lambda y \cdot \frac{\left(1-\lambda_{y}^{2}\right)}{\lambda_{y}^{2}} \cdot \Phi_{g}\right] \cdot y_{g_{1}} \\
& +\beta_{y} \lambda_{y} \frac{\sqrt{\lambda_{g}^{2}-\theta_{g}^{2}}}{\theta_{g}} \cdot\left[1-\frac{\left(1-\lambda_{y}^{2}\right)}{\lambda_{y}^{2}} \Phi_{g}\right] \cdot{ }^{s} g_{1} \\
& +\beta_{y} \lambda_{y} \frac{\sqrt{1-\lambda_{g}^{2}}}{\theta_{g}} \cdot\left[1-\frac{\left(1-\lambda_{y}^{2}\right) \Phi_{g}}{\lambda_{y}^{2}}\right] \cdot e_{g_{1}} .
\end{aligned}
$$

However, $\bar{Y}_{g}+y_{g_{1}}=Y_{g_{1}}$ and substituting this and collecting all terms with By $\lambda_{y}$ and all terms with $\left(1-\lambda_{y}^{2}\right) \theta_{g} / \lambda_{y}^{2}$ together we obtain

$$
\begin{aligned}
\ddot{x}_{g_{1}} & =\alpha_{y}+\beta_{y} \lambda y\left[Y_{g_{1}}+\frac{\sqrt{\lambda_{g}^{2}-\theta_{g}^{2}}}{\theta_{g}} \cdot s_{g_{1}}+\frac{\sqrt{1-\lambda_{g}^{2}}}{\theta g} \cdot e_{g_{1}}\right. \\
& -\frac{\left(1-\lambda_{y}^{2}\right) \Phi_{g}}{\lambda_{y}^{2}} \cdot\left(\gamma_{g_{g}}+\frac{\sqrt{\lambda_{g}^{2}-\theta_{g}^{2}}}{\theta_{g}} \cdot s_{g_{1}}\right. \\
& \left.\left.+\frac{\sqrt{\left(1-\lambda_{g}^{2}\right)}}{\theta_{g}} \cdot e_{g_{1}}\right)\right]
\end{aligned}
$$

where $\alpha_{y}=$ the "leniency" effect in the "standardization" variable, $\beta_{y}=$ the "exaggeration" effect in the "standardization"
variable, $\lambda_{y}=$ the "reliability" effect in the "standardization" variable, $\lambda_{g}=$ the "reliability" effect in the "subgroup" scores, $\theta_{g}=$ the "composition" effect in the "subgroup" scores, 


$$
\begin{aligned}
& \Phi_{\mathrm{g}}=\text { the "curtailment" effect in the subgroup, }
\end{aligned}
$$

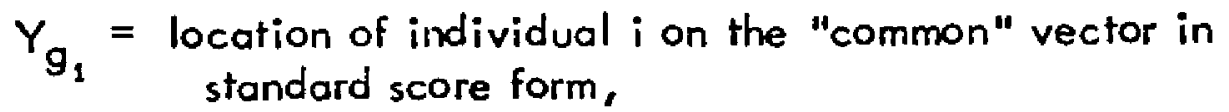

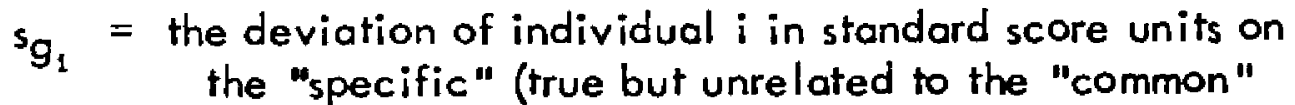

$$
\begin{aligned}
& Y \text { factor) dimension in subgroup } g \text {, } \\
& \begin{array}{l}
e^{e} g_{1}=\text { the deviation of individual } \boldsymbol{i} \text { in standard score units on } \\
\text { an "error" dimension, and }
\end{array} \\
& y_{g_{1}}=\text { the deviation of individual } i \text { from the average score mean } \\
& \left(\bar{z}_{\gamma_{g}}\right) Y \text { score in subgroup } g \text {, and } \\
& \dddot{x}_{g_{1}}=\text { individual } i \text { 's "transmuted" subgroup score. }
\end{aligned}
$$

These $\dddot{X}$ scores are called "transmuted" scores following Toop's notation (28).

$$
\text { Since } \alpha_{y} \text { and } \beta_{y} \text { will be the same for a transmuted score from any subgroup, }
$$
and amount only to a linear transformation of all the transmuted scores we need not concern ourselves with these terms.

If we sum the transmuted scores for subgroup $g$ and divide by $n_{g}$ we may obtain the mean transmuted score for subgroup $\mathrm{g}$, thus

$$
\overline{\ddot{X}}_{g}=\frac{n_{g} \dddot{X}_{g}}{n_{g}}=\alpha_{y}+\beta_{y} \lambda_{y} \bar{Y}_{g} .
$$

This is mue because the deviation scores in a given subgroup will sum to zero. From Eq. (35) we see that the transmuted scores of the subgroups will definitely equate the means of the $k$ subgroups regardless of the value of $\lambda_{y}$ as long as $\lambda_{y}$ does not equal zero. That is, if we wish to find the relative standings of various subgroups with respect to the "true "portion of a "standardizing" variable Eq. (36) will accomplish this goal. 
However, we usually wish to not only equate the subgroups but also to equate individuals from different subgroups as well. Let us now examine how well the "transmutation" equation accomplishes this goal. . The "Transmutation Regression" Effect

From Eq. (35) we may examine the relative contribution of the various "effects." One of the more interesting terms in Eq. (35) is the $y_{g_{1}}$ term. The reader may see that this term is always working against fully equating individuals from different subgroups as it is a function of where an individual was on the $Y$ vector with reference to his own subgroup. Further, the sign of this effect is always negative. Thus a person who was high on the $Y$ vector within his own group gets penalized while one who is low on the $Y$ vector in his own group gets a bonus. There is thus a regressing toward their own mean, $\bar{Y}_{g}$, in the transmutation equation. In fact, we shall call this the "transmutation regression" effect.

The extent of the "transmutation regression" effect is in turn a function of "reliability" effect of the standardization variable and the "curtailment" effect in that subgroup. That is, the narrower the range of the $\mathrm{Y}$ vector ability in a given subgroup, the larger the "transmutation regression" effect.

The reliability of the standardizing variable has an in teresting influence on the "transmutation regression" effect in that the higher the reliability of the "standardization" variable the smaller the "transmutation regression" effect, regardless of the magnitude of the "curtailment" effect. 
In fact, as the "reliability" effect of the standardization variable approaches 1.00 then

$$
\ddot{x}_{g_{1}} \rightarrow \alpha_{y}+\beta_{y}\left[\mathrm{Y}_{g_{1}}+\frac{\sqrt{\lambda_{g}^{2}-\theta_{g}^{2}}}{\theta_{g}} \cdot s_{g_{1}}+\frac{\sqrt{1-\lambda_{g}^{2}}}{\theta_{g}} \cdot e_{g_{1}}\right] \text {. }
$$

One might say that he is not concerned over what the various subgroups are measuring in "common" but he has a set of scores on some variable that he would like to equate the subgroups on. He may even maintain that he has a perfect set of scores to which he would like to equate various subgroups. In such a case he may assume $\lambda_{y}=1.00$ and Eq. (37) becomes applicable. The extent to which he has equated the subgroups then becomes merely a function of the "reliability" and "composition" effects within the various subgroups. The proportion of the $\dddot{X}$ variance that is attributable to the "standardization" variable, in such a case, tums out to be $\theta_{g}^{2}$.

\section{TOWARD AN OPTIMAL SOLUTION}

The point may be roised that while the preceding rationale is satisfactory from the standpoint that one may see the relative contributions of such influences as "leniency," "exaggeration," "reliability," "composition," etc., we do not know if the "transmutation" equations we obtain for the subgroups are, in fact, the optimal ones.

The "transmutation" equation for subgroup $\mathrm{g}$, as shown in Eq. (32), will be of the form

$$
\ddot{x}_{g_{1}}=\frac{\ddot{x}_{g_{1}}-a_{g}}{b_{g}}
$$


where $a_{g}=$ the intercept of the $\ddot{X}$ scores on the $\dot{Y}$, scores for subgroup $\mathrm{g}$,
and $b_{g}=$ the slope of the $\ddot{X}$ scores on the $\dot{Y}$ scores for subgroup $g$. We may rewrite the above equation as

$$
\dddot{x}_{g_{1}}=\frac{\ddot{x}_{g_{1}}}{b_{g}}-\frac{a_{g}}{b_{g}} .
$$

letting

$$
\begin{aligned}
& \dot{b}_{g}=\frac{1}{b_{g}} \text { and } \\
& \dot{a}_{g}=\frac{a_{g}}{b_{g}},
\end{aligned}
$$

we can put the "transmutation" equation in the more familiar form of a linear transformation equation where

$$
\ddot{x}_{g_{1}}=\dot{a}_{g}+\dot{b}_{g} \ddot{x}_{g_{1}} \text {. }
$$

The question of whether there possibly may be better sets of $\dot{a}$ 's and $\dot{b}$ 's for transmuting the various subgroups' row scores demands that we define what the criterion for "better" would be. It seems reasonable to assume that the higher the correlation between the $\ddot{X}$ (transmuted) scores and the $\dot{Y}$ (standardizing) scores, for the entire group, the better the solution. The "Floor or Ceiling" and "Differential Treatment of Extremes" Effects

Beyond the problem of whether $\dot{a}_{g}$ and $\dot{b}_{g}$ are the optimal constants for a linear transformation is the additional problem of whether a simple linear transformation is adequate. After all, we really have no way of knowing if a more realistic equation might not be 


$$
\ddot{x}_{g_{1}}=\alpha_{g}+\beta g \ddot{x}_{g_{1}}+\gamma_{g} \ddot{x}_{g_{1}}^{2}+\delta_{g} \ddot{x}_{g_{1}}^{3}+\ldots .
$$

Certainly Eq. (40) would give us a far more general modal in which to work, and there are some reasons to believe that the higher order terms would be psychologically as meaningful as the "leniency" $(\alpha)$ and "exaggeration" $(\beta)$ terms. For example, the quadratic effect $(\gamma)$ may be indicative of a "floor or ceiling" effect in a given subgroup as seen in Figures 1 and 2 . The cubic effect $(\delta)$ may be indicative of a "differential treatment of extremes" effect as seen in Figures 3 and 4.

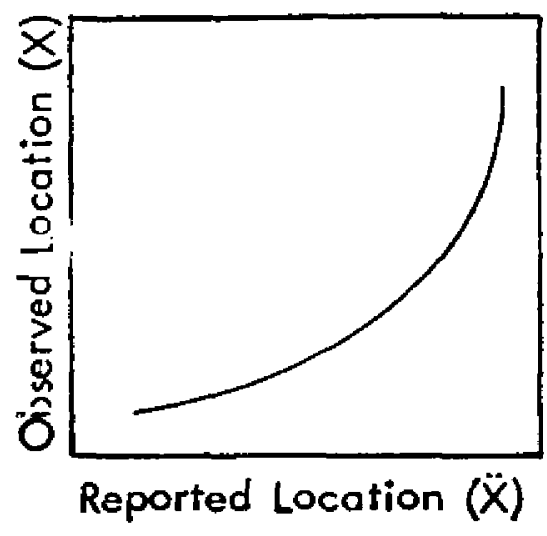

Fig. 1. - The Result of an Evaluator Letting $\ddot{X}=\alpha+\beta X+\gamma x^{2}$.

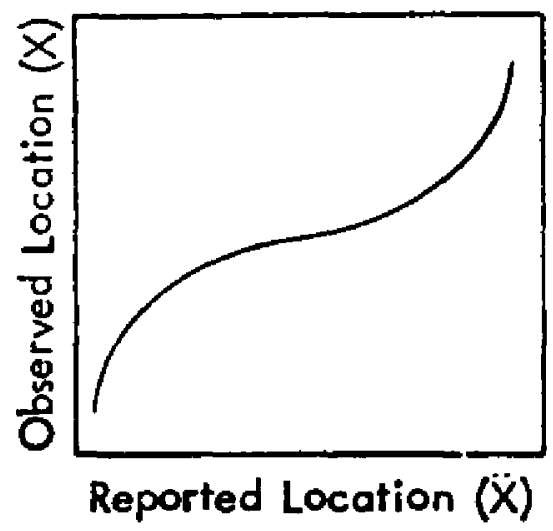

Fig. 3. - The Result of an Evaluator Lotting $\ddot{X}=\alpha+\beta X+\delta X^{3}$.

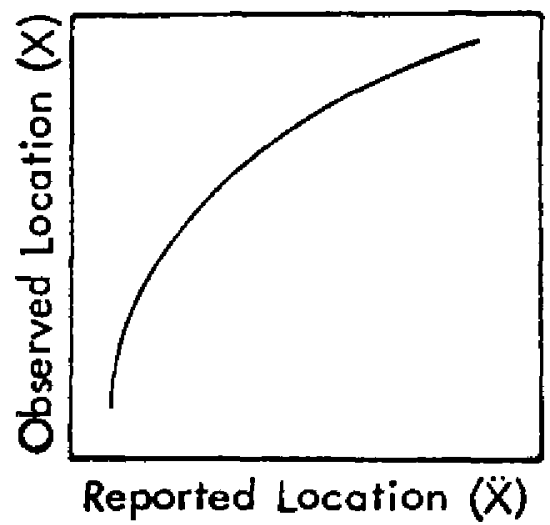

Fig. 2. - The Result of an Evaluato Letting $\ddot{X}=\alpha+\beta X-\gamma X^{2}$.

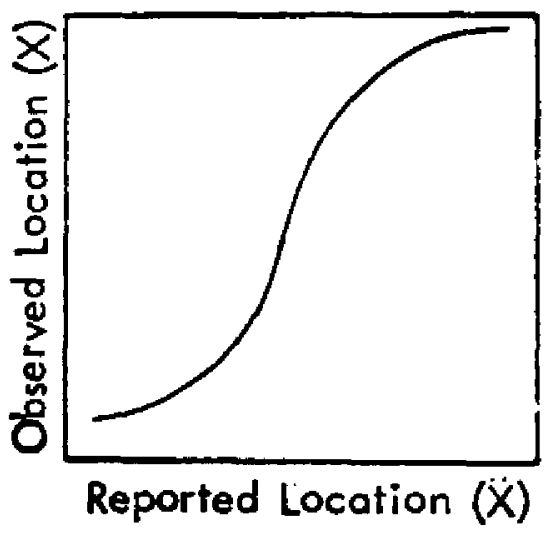

Fig. 4. - The Result of an Evaluator Letting $\ddot{X}=\alpha+\beta X-\delta X^{3}$. 
The "slope and intercept" method is obviously not capable of handling these higher order terms. The desire to find a method capable of handling the higher order terms and one which would simultaneously solve the equations for all groups resulted in a different approach to the problem of equating subgroups. A Technique for Handling Non lineor "Nbn-Equivalence of Scale" Errors

The technique which will be described below was developed as an outgrouth of a proof that the correlation ratio $(\eta)$ is actually a multiple correlation coefficient $(R)$ and should be considered as part of the Pearson family of correlation coefficients. In 1944 Wherry, Sr. (42) had proven that the optimal score values, from a least squares standpoint, to assign to categorical data for use in multiple correlational studies would be the mean of the criterion scores, each subgroup for class) of the categorical variable had obtained. It seemed rather obvious that the traditional method of coding categorical data, by the use of nominal scaling, was not the only way of recording cotegorical information; each class could be treated as a separate dichotomous variable. Thus we could have one dichotomous variable on which members of the second class received a code of "I " and members of all other classes received a code of " 0 , "etc. If there were $k$ classes in the categorical variable, one could create $k$ dichotomous variables. If the $k$ dichotomous variables are then used as predictor variables in a multiple correlation analysis to predict a non-categorical variable, the multiple correlation coefficient $(R)$ will be equal to the correlation ratio $(\eta)$. Several other interesting findings are worth noting. First, any $k-1$ of the $k$ dichotomous 
variables will yield identical multiple correlations, because after selecting any set of $k-1$ dichotomous variables, no variance will remain for the unselected dichotomous variable. This gives the proof that the appropriate degrees of freedom for the correlation ratio is $k-1$. Secondly, the raw score beta weights and the constant term of the prediction equation derived do, in fact, yield Wherry, Sr's "Multi-serial" weights. The third finding is that the shrunken multiple correlation coefficient $(\bar{R})$ is equal to Kelly's eqsilon $(\epsilon)$, the unbiased estimate of the correlation ratio. The prediction equation obtained is of the form (assuming the $k^{\text {th }}$ dichotomous variable was the one not selected)

$$
\hat{Y}_{1}=b_{1} X_{1_{1}}+b_{2} X_{2_{1}}+b_{3} X_{3_{1}}+\ldots+b_{k-1} X_{k-1}+C
$$

For an individual who "belonged" to class $1, X_{1}(=1.00)$ is the only score in the prediction equation that will be non-zero, and the above equation will reduce to

$$
\hat{Y}_{1}=b_{1}(1)+C=b_{1}+C \text {. }
$$

For an individual who belonged to the $k^{\text {th }}$ class, the equation would reduce to $\hat{\mathrm{Y}}_{k_{1}}=C$.

Another interesting finding concerned the matrix of intercorrelations among these created dichotomous variables. It can be shown that a single factor can account for all the off-diagonal entries if the loadings on this factor have the values $\sqrt{\left(p_{g} / q_{g}\right) i}$, where $p_{g}=$ the proportion of people in class $g, q_{g}=$ the. proportion of people not in class $g$, and " $i$ " is the imoginary mathematical number $(=A)$. Because of the "imaginary" nature of these dichotomous variables, 
I have referred to them as "pseudo" variables to indicate their "unreal" or "imaginary" qualities. The $k$ dichotomous pseudo variables may be symbolized $P_{D_{1}} \rightarrow P_{D_{k}}$

Other interesting findings included showing that if the variable being predicted was a set of ranks rather than an "interval" type variable, the squared multiple correlation coefficient $\left(R^{2}\right)$ was equal to the Kruskal-Wallis "H" divided by $(N-1)$. If the variable to be predicted was itself a dichotomous varible, the squared multiple correlation was equal to the Chi Square test for unmatched samples divided by N. It was also established that Kendall's coefficient of concordance (W), rather than being a measure of relationship, is a measure of the proportion of variance of the ranked data that is explainable by knowing which individuals the various judges were ranking, i.e., $R^{2}=W$.

Prior to my own work in this area, and unknown to me ot the time, Bottenberg and Christal (6) had developed an "iterative technique for clustering criteria which would retain optimum predictive efficiency." In their work, they had made use of what I referred to above as "dichotomous pseudo variables." In addition, they had used what I will refer to as linear pseudo variables. Linear pseudo variables are used in their technique for non-categorical data. Given a variable "X," we can create $k$ linear pseudo variables $\left(P_{L_{k}} \rightarrow P_{L_{k}}\right)$. A person who was in the first subgroup will receive a score of "X" on $P_{L_{2}}$ and a score of "O" on all the other $P_{L}$ variables. A person from the second subgroup will receive a score of "X" on $P_{L_{3}}$ and a score of "O" on the other $P_{L}$ variables, etc. 
Bottenberg and Christal showed that by using dichotomous and linear pseudo variables as predictor variables, it was possible to simultaneously solve different multiple linear regression equations for different subgroups of individuals. Further, they stated that the weights derived for each subgroup by their method would be identical to the weights for that subgroup if that subgroup's data were considered separately.

I should point out that Bottenberg and Christal did not call their predictor variables by any special name as I hove. I think, however, referring to these "created" variables as "pseudo" variables is a good method for keeping them from being confused with regular interval or dichotomous variables. It is perhaps fitting to point out that the pseudo linear variables are products of the pseudo dichotomous variables and the " $X$ " variable. Therefore, referring to the Bottenberg and Christal technique as a method of "Producing Simultaneous Equations Using Dichotomous Observation," or simply, the "pseudo" technique, seems, to me, to be a good way of copturing the essence of the technique.

In order to extend the Bottenberg and Christal technique to handle simultaneous optimal solutions of non linear regression equations for different subgroups, all that was necessary was to create higher order polynomial pseudo variables; $k$ quadratic pseudo variables $\left(P_{Q_{1}} \rightarrow P_{Q_{k}}\right)$ and $k$ cubic pseudo variables $\left(P_{C_{1}} \rightarrow P_{C_{k}}\right)$

During the accomplishment of this dissertation, Bottenberg and Ward (7) published an excellent and comprehensive poper on multiple regression techniques which includes a section on the kind of model extension which I am proposing as 
a method for no $n$ linear equating of non-overlapping subgroups. The decision to choose a polynomial approach rather than some other type of nonlinear system (40) was governed by considerations mentioned in the rationale section. Creating the "Pseudo" Variables for Equating Subgroups

There will be one dichotomous pseudo variable $\left(P_{D_{1}}\right.$ through $\left.P_{D_{k}}\right)$ for each subgroup. If a person is a member of subgroup l, he will receive a score of "I" on $P_{D_{1}}$ and a score of " 0 " on the other $P_{D}$ variables. If the is a member of subgroup 9 he would receive a score of "l" on $\mathrm{PD}_{9}$ and a score of "O" on all the other $\mathrm{P}_{D}$ variables. In the same fashion there will be one linear pseudo variable $\left(P_{L}\right.$ through $P_{L_{k}}$ ) for each subgroup. A person will receive a score of $X_{g_{1}}$ (his nontransmuted or original score) on the linear pseudo variable $\left(P_{L_{g}}\right)$ representing his subgroup and a score of "O" on all the other $P_{L}$ variables. There will also be one quadratic pseudo variable $\left(P_{Q_{1}}\right.$ through $\left.P_{Q_{k}}\right)$ and one cubic pseudo variable $\left(P_{C_{1}}\right.$ through $\left.P_{C_{k}}\right)$ for each subgroup. A person from subgroup $g$ will receive a score of $X_{g_{1}}^{2}$ on $P_{Q_{g}}$, a score of $X_{g_{1}^{3}}$ on $P_{C_{g^{\prime}}}$ and scores of "O" on all other $P_{Q}$ and $P_{C}$ variables. Table III shows how the scores for the various pseudo variables are derived. 


\section{Table III}

Procedure for Creating Dichotomous, Linear, Quadratic, and Cubic Pseudo Variables

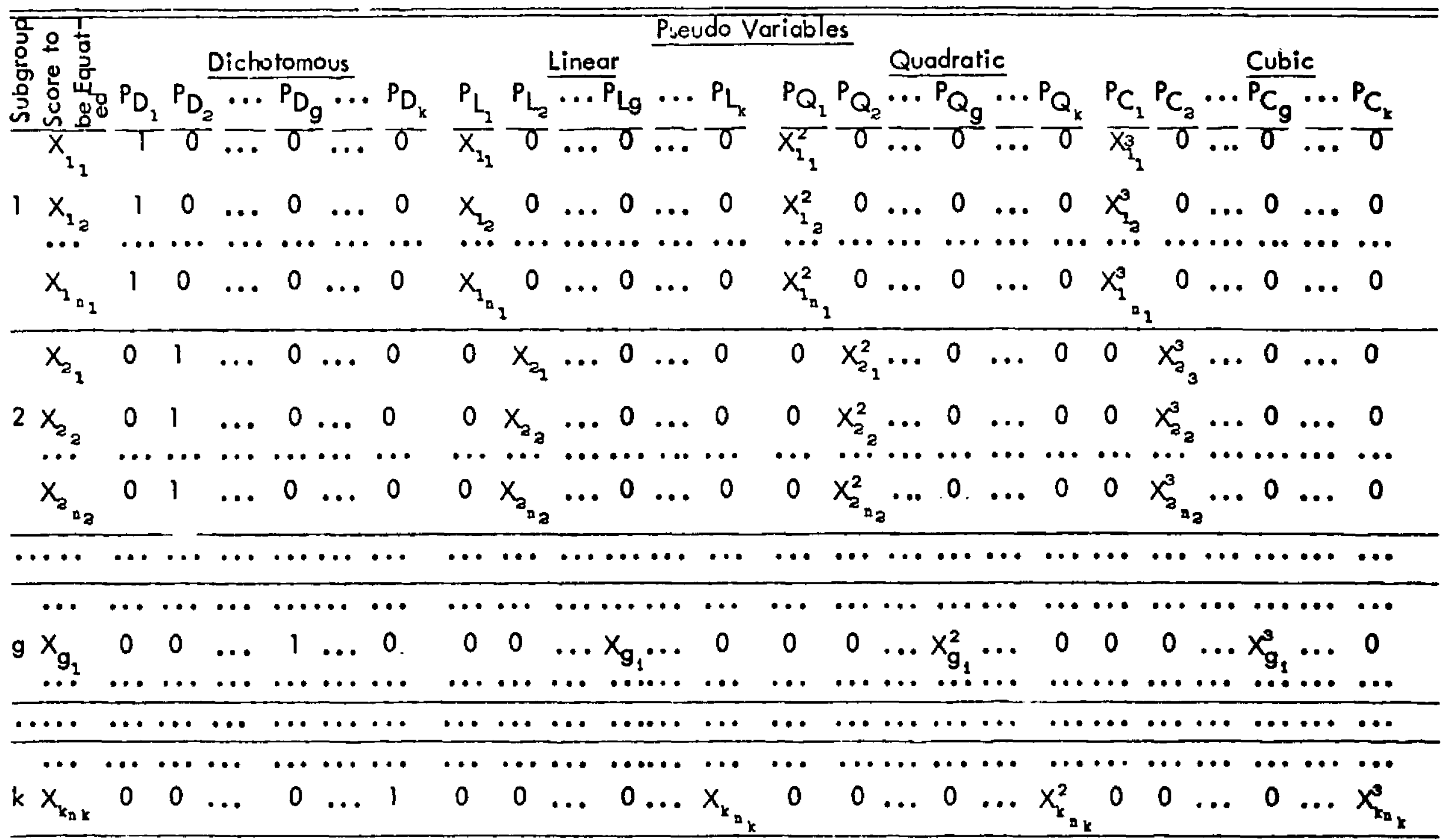


If all of the pseudo variables are used in a multiple correlational method to predict the standardization variable $(Y)$ we may obtain a prediction equation of the form

$$
\begin{aligned}
& \hat{Y}_{1}=\alpha_{P_{D_{1}}} \cdot X_{P_{D_{1}}}+\alpha_{P_{D_{2}}} \cdot X_{P_{D_{a_{1}}}}+\ldots+\alpha_{P_{D_{g}}} \cdot X_{P_{D_{g}}}+\ldots+\alpha_{P_{D_{k}}} \cdot X_{P_{D_{x_{1}}}} \\
& +\beta P_{L_{1}} \cdot X_{P_{L_{1}}}+\beta_{P_{L_{2}}} \cdot X_{P_{L_{1}}}+\ldots+\beta_{P_{L_{g}}} \cdot X_{P_{L_{g_{1}}}}+\ldots+\beta_{P_{L_{k}}} \cdot X_{P_{L_{1}}} \\
& +\gamma_{P_{Q_{1}}} \cdot X_{P_{Q_{1}}}+\gamma_{P_{Q_{2}}} \cdot X_{P_{Q_{2_{1}}}}+\ldots+y_{P_{Q_{g}}} \cdot X_{P_{Q_{g_{1}}}}+\ldots+\gamma_{P_{Q_{k}}} \cdot X_{P_{Q_{k_{1}}}} \\
& +\delta P_{C_{1}} \cdot X_{P_{C_{1}}}+{ } \delta P_{C_{2}} \cdot X_{P_{C_{2}}}+\ldots+\delta P_{C_{g}} \cdot X_{P_{C_{g_{1}}}}+\ldots+\delta P_{C_{k}} \cdot X_{P_{C_{1}}}+C
\end{aligned}
$$

Where $\alpha$ PD. $=0$ raw score prediction weight for a dichotomous
psoudo variable,

$$
\begin{aligned}
& X_{P_{D_{1}}}=\text { the score individual } i \text { received on a dichotomous } \\
& \text { pseudo variable, }
\end{aligned}
$$$$
B \mathrm{P}_{\mathrm{L} .}=\begin{aligned}
& \text { a raw score prediction weight for a linear pseudo } \\
& \text { variable, }
\end{aligned}
$$$$
\begin{gathered}
X_{P_{L_{1}}}=\text { the score individual } \mathrm{i} \text { received on a linear pseudo } \\
\text { variable, }
\end{gathered}
$$$$
y_{P_{Q} .}=\begin{aligned}
& \text { a raw score prediction weight for a quadratic pseudo } \\
& \text { variable, }
\end{aligned}
$$$$
\begin{aligned}
& \mathrm{X}_{\mathrm{P}_{Q_{1}}}=\text { the score individual } \mathrm{i} \text { received on a quadratic pseudo } \\
& \text { variable, }
\end{aligned}
$$$$
\begin{gathered}
{ }^{6 \mathrm{P} C} \text {. the raw score prediction weight for a cubic pseudo } \\
\text { variable, }
\end{gathered}
$$$$
X_{P_{C_{1}}}=\text { the scogre individual } i \text { received on a cubic pseudo }
$$ 


$$
C=a \text { constont to be odded. }
$$

For an individual in the $g^{\text {th }}$ subgroup the only scores in the entire prediction equation which will not necessarily equal zero will be $X_{P_{D_{g}}}(=1)$, $X_{P_{L_{g}}}\left(=\ddot{x}_{g_{2}}\right), X_{P_{Q_{g}}}\left(=\ddot{x}_{g_{2}^{2}}^{2}\right)$, and $X_{P_{C_{g}}}\left(=\ddot{x}_{g_{1}}^{3}\right)$.

Thus for all the persons in the $\mathrm{g}^{\text {th }}$ subgroup Eq. (41) will simplify to

$$
\begin{aligned}
& \hat{Y}_{1(g)}=\left(\alpha P_{D_{g}}+C\right)+{ }_{R P_{L_{g}}} \cdot \ddot{X}_{g_{g}}+\gamma P_{Q_{g}} \cdot \ddot{X}_{g_{q}}^{2}+\delta P_{C_{g}} \cdot \ddot{X}_{g_{1}}^{3} \cdot \\
& \text { Now letting } \stackrel{\circ}{\mathrm{a}}_{\mathrm{g}}=\left(\alpha \mathrm{P}_{\mathrm{D}_{\mathrm{g}}}+\mathrm{C}\right) \text {, } \\
& \grave{\mathrm{b}}_{\mathrm{g}}=\beta_{\mathrm{P}_{\mathrm{L}_{\mathrm{g}}}} \text {, } \\
& \dot{c}_{\mathrm{g}}=\gamma_{\mathrm{P}_{\mathrm{g}}} \text {, and } \\
& \stackrel{\circ}{d}_{g}=S P_{C_{g}} \text {, we obtain } \\
& \hat{Y}_{1(g)}=c_{g}+\ddot{b}_{g} \ddot{X}_{1}+\dot{c}_{g} \ddot{X}_{1}^{2}+\dot{d}_{g} \ddot{X}_{1} \text {. }
\end{aligned}
$$

Similarly for each subgroup we may obtain an equation such as Eq. (43) above. We know that $\dot{a}, \dot{b}, \dot{c}$, and $\dot{d}$ are the optimal weights to use for transmuting the $\ddot{X}$ scores for each subgroup. If only the dichotomous and linear pseudo variables were used in arriving at the prediction equation, we could find out if $\dot{a}_{g}$ and $\dot{b}_{g}$ (derived by the "slope and intercept" method) are equivalent to ${ }^{\circ} g$ and $\dot{b}_{g}$ (derived from the "pseudo variable" method). This will be done in the results section. According to Bottenberg and Christal (6) they should be.

Since the solution has optimized the correlation between the "standardization" variable $\dot{Y}$ and the pseudo variables we know that the "transformation" equations are the mest" that can be arrived at using only the 
first three powers of the scores to be equated. Of course, it is possible that we may have fit too much error by using all the terms but this shortcoming could be resolved by using a test-selection technique instead of selecting all but one of the pseudo dichotomous variables. Thus, if for a given subgroup, the cubic effect does not add significantly to the amount of variance explained, there would then be no " $d$ " term in that subgroup's final "transformation" equation. Finding the "Best Possible" Standardization Variable $(\dot{Y})$

Toops (37), in his original article on "The Transmutation of Marks, " which set forth the "slope and intercept" method, had used an intelligence test as the "standardization" variable against which he equated grades from various high schools. He had the following comments regarding the "standardization" variable used to equate subgroups.

.... it will be clear that the transmuting equation is affected by the validity of the measuring rod used to equate the marks. It follows, then, that one should employ the best possible measuring rod. This means ideally--we take it-the best cross-section of the 'content' of the curricula of the several schools of the geographical area over which the marks are being rendered comparable. The average of four annual intelligence tests of high school pupils would be better than one... (37)

Since the "slope and intercept" method of transmuting scores requires a single "standardization" variable it is obvious that if one has but a single variable to use as the "standardization" variable that it is the "best available" one, even if it might not be the "best possible" one. While 1 am in agreement with Toops that an average of four annual intelligence tests would undoubtedly be better than a single intelligence test, I do not necessarily believe it to be the "best available" one. If, for example, differentially weighting the four annual intelligence tests (in his case) 
would ultimately yield a correlation between the entire group's transmuted marks and the weighted composite of the four annual intelligence tests which was higher than the correlation between the transmuted marks and a simple average of the intelligence tests, then the weighted composite would be a better "standardization" variable than the simple average. This is true because it would have raised the overall "composition" effects ( $\theta$ 's) for the various subgroups.

In Joops' case, where the four possible equating variables are highly homogeneous with regard to content, the difference between a weighted average and a simple average would probably be minimal. If, however, the possible equating variables were markedlydifferent in content then the weighted composite should be markedly superior to a simple average. This presents a second problem of deciding how to weight possible equating variables to obtain the optimum "standardization" variable.

One method which suggested itself was to use the equating variables to optimally predict the "variable-to-be-equated" for the entire sample. This would yield a set of weights for the equating variables which could be used to obtain a predicted "variable-to-be-equated" score $(\hat{\ddot{x}})$ for each person which would then serve as a "standardization" variable score (i.e., $\dot{Y}=\widehat{\ddot{X}})$. Since these predicted scores are the result of a single equation which is the same for each subgroup there should be little, if any, differential "leniency, " "exaggeration, " "floor," "ceiling," or "differential treatment of the extremes" effects from one subgroup to another in this standardization variable. Further, because we have found the optimal set of weights for the equating variables we should have also maximized the total contribution of the "composition" effects for all subgroups. In order to keep the "reliability" effect of the "standardization" variable maximal a test- 
selection method, such as Wherry, Sr.'s (41), could be used. This will guard against overfitting of error in the prediction equation. 


\section{EMPIRICAL DEMONSTRATION AND CROSS VALIDATION}

\section{SAMPLE}

The data analyzed in this study were gathered on all graduates of the naval aviation training program who had entered training between 1 January 1960 and 31 December 1960. As students enter training they are assigned a class number and an alphabetical sequence number. Experimental Sample

Alternately numbered students were assigned to the experimental sample. The composition of the experimental sample with regard to subgroup classification is given in Table IV.

Table IV

The Composition of the Experimental and Cross Volidation Sample With Regard to Subgroup Membership

\begin{tabular}{ccc}
\hline $\begin{array}{l}\text { Subgroup } \\
\text { (Advanced Flight } \\
\text { Training Pipeline) }\end{array}$ & $\begin{array}{c}\text { Nof } \\
\text { Experimental } \\
\text { Somple }\end{array}$ & $\begin{array}{c}\text { N of } \\
\text { Cross Validation } \\
\text { Sample }\end{array}$ \\
\hline 1 & 65 & 70 \\
2 & 109 & 103 \\
3 & 128 & 121 \\
4 & 41 & 47 \\
5 & 71 & 66 \\
6 & 38 & 34 \\
7 & 160 & 159 \\
TOTAL & 612 & 605 \\
\hline
\end{tabular}


Cross Validation Sample

The remainder of the graduating students $(n=605)$ were assigned to the cross validation sample. The composition of the cross validation sample with regard to subgroup classification is given in Table IV.

\section{VARIABLES}

Equating Variobles

A. Selection Test Variobles. Prior to being designated as a flight student, all applicants for naval flight training must successfully pass the following tests.

1. Aviation Qualification Test. This is a sixty-minute omnibus intelligence test designed to reject applicants incapable of performing adequately in the ground school portion of their training. High correlations with commercial tests of intelligence have been demonstrated (2). Administrations of the test. at receiving stations (field) and during the first week at the U.S. Naval School, Pre-Flight (laboratory) correlated .71. This coefficient is attenuated somewhat since only those applicants possing the field administration were accepted into the program. While only the totol AQT raw score was used in this study the AQT is composed of five sub-scales.

la) Mathematics: This sub-scale is composed of 45 items emphasizing basic mathematical reasoning and is concerned primarily with solving verbally stoted problems algebraically and with the handling of geometric relationships.

ib) Vocabulary: This scole is composed of 24 five oltemate multiple choice items covering word moaning. 
lc) Practical Judgment: This scale is composed of 10 items in which conflict situations are presented; one of five alternative courses of action must be chosen.

1d) Dial Reading: In this 21-item scale the cadet is instructed to perform a specified series of operations if dial A has such-and-such a reading, to perform a different series of operations if dial B has a reading of such-and-such, et cetera. In each item, the codet is presented with 3 to 5 dials which he must first read and then indicate the proper operations to be performed.

le) Matching: The 15 items in this scale present two sets of letternumber combinations to which the subject is required to indicate whether the sets are identical or different.

2. Mechanical Comprehension Test. This is a forty-five minute test dealing with ability to perceive physical relotionships and handle familiar concepts of everyday mechonics. Each of the 76 items is pictorial in nature. The subject responds to a question about the pictured relation with one of three al ternatives. A reliability of .87 has been reported for the test (17).

3. Biographical Inventory. This is an untimed questionnaire containing elements of personal history, expressions of interest and attitudes, and selected informational items.

4. Spatial Apperception Test. This is a ten-minute spatial orientation test. Specifically, it requires the subject to visualize the relationship between the presented attitude of a plane and the territory over which it is flying. Altemateform reliability of .70 wos found (1) on a rather restricted sample. 
B. Pre-Flight School Variaoles. Prior to recoiving in-flight training, all students must complete the acodemic courses listed below.

5. Mathematics. This is a twenty-four hour course on basic mathematical principles. The content ranges from elementary algebra to a brief introduction to calculus. The course grade is derived from phose quizzes and a final examination.

6. Physiology. This is a nine-hour course covering selected topics from elementary physiology and the effect of flight on physiological systems. The course grade is determined by a final examination.

7. Principles of Flight. This is a thirty-hour course on basic aerodynamics. The course grade is derived in the same manner as the mathematical grade.

8. Engineering. The content of this course is centered around a thirty-one hour study of reciprocating engines and aircraft systems. Three hours at the end of the course are devoted to jet engines. The course grade is derived in the same manner as the mathematical grade.

9. Novigation. This thirty-three hour course is designed to give the student an understanding of the basic concepts of novigation and proficiency in the use of the E-10 computer. Course content is limited to dead reckoning novigation, except for a brief introduction to celestial navigation at the end of the course. The course grade is derived in the same manner as the mathematical grode. While the above courses do not exhaust the curriculum of the U.S. Noval 
School, Pre-Flight, they do represent courses which all students going through noval aviation training are required to take.

C. Ptimary Flight Training Variables. Upon successful completion of PreFlight Training, all students received their primary flight training which is composed of two in-flight stages of training.

10. Pre-Solo. This stage, flown in the T-34, is devoted to dual instruction for the purpose of qualifying students to fly solo. It consists of ten dual instructional hops, a check hop by a member of the unit's check board, and a solo flight by the student. Major instructional areas in the pre-solo stage of training include achieving correct plane attitude in flight, effective use of trim tabs, coordinating of controls, and pre-flight plane checks, emergency procedures, take-offs and landings.

11. Precision $(\mathbf{T}-34)$. This stage is devoted to instruction and practice in precision maneuvers in the T-34 aircraft. Emergency procedures, full-flap, crosswind, and touch-and-go landings, chandelles, wing-overs, spins, stalls, steep turns, and small field procedures were covered. The student has the same instructor that he had in pre-solo. This stage includes seven dual hops, ten solo hops, and a final dual check hop.

D. Basic Flight Training Variables. All students in this study followed the same basic flight training curriculum which is composed in part, of the following stages of training.

12. Transition $(T-28)$. This stage provides dual instruction in the $T-28$ aircraft for the purpose of qualifying students to fly solo in the T-28. Material 
covered in this stage corresponds closely to that covered in the pre-solo $(T-34)$ stago. It includes seven dual instruction hops, a dual check hop, and a solo flight by the student.

13. Precision-Acrobatics $(T-28)$. This variable is the student's average grade from the following two stages.

130) Precision. This stage is devoted to instruction and practice in precision maneuvers in the T-28. Material covered is identical to that found in the precision $(T-34)$ stage. The student has the same instructor as in the transition stage. This stage includes two dual instructional hops, four solo hops, and a dual check hop.

136) Acrobatics. This stoge is flown in the T-28 and is devoted to teaching the student acrobatics and further developing his precision flying techniques. A portion of each dual flight is devoted to practice of precision stage maneuvers, with major emphasis on small field procedures and wing-overs. Barrel rolls, slow rolls, lops, Immelmann turns, 1/2 Cubon 8's, and other instructor approved acrobatics are introduced. The stage includes three dual hops, six solo hops, and a check hop. The student has the same instructor for acrobatics as he had in the two preceding stages of transition and precision.

14. Basic Instruments $(T-28)$. This stage, flown in the $T-28$, consists of eleven instructional hops and a final check hop. Almost all of the maneuvers flown in this stoge are performed by the student under the instrument flying hood. Major emphasis, from the standpoint of grades, is on such fundamentals as climb to 
altitude, nose and wing position, cockpit procedures, and standard and half standard rate turns. More intricate maneuvers and patterns occur later in this stoge. 15. Night Familiarization $(T-28)$. This stage, flown in the T-28, introduces the student to flying at night. Emphas is is primarily on take-offs, landings, and flying to vorious checkpoints.

16. Radio Instruments (T-28). This stage, flown in the $T-28$, consists of various radio instruments for bearing and radial interception, tracking, station passage, orientation, penetration, and GCA. Two two-hour hops or a single fourhour hop is devoted to flying to various check points by radio novigation. A final check hop covers all material given in this stage.

17. Formation $(T-28)$. This stage consists of eight dual and seven solo hops. Major emphasis is on rendezvous procedures, formation turns, and altering positions in formation. This stage is also flown in the T-28.

18. Gunnery $(T-28)$. This stage, flown in the $T-28$, introduces the student to weapon systems in naval aircraft. The student receives practice at firing at targets from the aircraft.

E. Voriable to be Equated

19. Advanced Flight Grade. This grade is a composite of students' advanced in-flight training grades. The number and nature of the grades in the composite vary according to which advanced pipeline the student was in. It is this grade which is to be equated. 


\section{RESULTS}

Experimental Study Group Analysis (Slope and Intercept Method)

The analysis will be broken into eight procedural steps for discussion

purposes.

1. Matrix of Correlation Coefficients Among "Equating" Voriables and "Variableto-be-Equated "Obtained

Pearson product-moment correlation coefficients were computed among the 18 "equating" variables and the "variable-to-be-equated" (Advanced Flight

Grade) for the entire experimental somple $(N=612)$. These correlation coefficients are shown in Appendix 1.

2. Wherry Test-Selection Technique Used to Find "Optimal Standardization" Variable

Using the variable-to-be-equated (variable 19) as the criterion voriable and the 18 "equating" variables os potential selector variables, the Wherry TestSelection technique (41) was accomplished. Only eight variables were selected for the prediction equation. The results of step 2 are shown in Table $V$.

3. Prediction of Scores of the Variable-to-be-Equated; "Standardization" Variable Scores Obtained

Using the prediction equation weights shown in Table $V$ a prediction of what score each of 612 subjects in the experimental sample should hove received in Advanced Flight Grade was computed. These predicted grades were then used as the "standardization" variable scores against which the subgroups were equated. The standardization variable appears as variable 20 in Appendix 1. 
Table V

Results of Wherry Test-Selection Technique Using Variable 19 as The Criterion and the "Common" Variables as Potential Selector Variables

\begin{tabular}{cclcc}
\hline $\begin{array}{l}\text { Order of } \\
\text { Variables } \\
\text { Selected }\end{array}$ & $\begin{array}{c}\text { Number of } \\
\text { Selected } \\
\text { Variable }\end{array}$ & $\begin{array}{c}\text { Name } \\
\text { of } \\
\text { Variable }\end{array}$ & $\begin{array}{c}\text { Shrunken } \\
\text { Multiple R } \\
\bar{R}\end{array}$ & $\begin{array}{c}\text { Prediction } \\
\text { Equation Raw } \\
\text { Score Betas }\end{array}$ \\
\hline 01 & 17 & Formation & .505 & .191532 \\
02 & 09 & Navigation & .583 & .169281 \\
03 & 12 & Transition & .618 & .100652 \\
04 & 16 & Radio Instruments & .634 & .051899 \\
05 & 14 & Basic Instruments & .640 & .047576 \\
06 & 11 & Precision & .641 & .038367 \\
07 & 07 & Aerodynamics & .642 & -.036411 \\
08 & 04 & S.A.T. & .642 & .033569
\end{tabular}

Constant to be added to sum of products of raw score betas times raw scores $=165.15$

4. Subgroup Data Sums on the "Standardization" Variable $(\dot{Y})$ and the "Variable-to-be-Equated"

The 612 cases were separated into their seven subgroups and the n's, sums, sums of squares, and sums of cross products were computed. These data are shown in Toble VI.

\section{Table VI}

Summary Raw Score Data for "Standardization" Variable $(\dot{Y})$ and "Variableto-be-Equated" on the Seven Subgroups Comprising the Experimental Sample

\begin{tabular}{|c|c|c|c|c|c|c|}
\hline \multirow[b]{2}{*}{ Subgroup } & \multicolumn{4}{|c|}{ Variable-to-be-Equated } & \multicolumn{2}{|c|}{ Standardization Variable } \\
\hline & $n_{g}$ & $\Sigma \ddot{X}$ & $\Sigma \ddot{X}^{2}$ & $\Sigma \dot{Y}$ & $\Sigma \dot{Y}^{2}$ & $\Sigma \ddot{X} \dot{Y}$ \\
\hline 1 & 65 & 19599 & 5887257 & 19505 & 5854071 & 5870212 \\
\hline 2 & 109 & 32772 & 9854896 & 33023 & 10005633 & 9929320 \\
\hline 3 & 128 & 38468 & 11564928 & 38355 & 11494819 & 11528856 \\
\hline 4 & 41 & 12495 & 3808967 & 12391 & 3745333 & 3776636 \\
\hline 5 & 71 & 21471 & 6494971 & 21356 & 6424742 & 6459189 \\
\hline 6 & 38 & 11471 & 3463931 & 11399 & 3419885 & 3441537 \\
\hline 7 & 160 & 47656 & 14201688 & 47851 & 14312561 & 14254914 \\
\hline Total & $\overline{612}$ & 183892 & $\overline{55276638}$ & 183880 & 55257044 & 55260664 \\
\hline
\end{tabular}


5. Computation of Means, Standard Deviations, Correlations, and

Transmutation Constants for the Subgroups

The subgroup statistical data shown in Table VIl were computed. The transmutation constants are functions of the slopes $\left(b_{g}\right.$ 's) and intercepts $\left({ }_{g} g\right.$ 's) of the various subgroups $X$ scores on the $Y$ scores.

$$
\begin{aligned}
& \dot{a}_{g}=-a_{g} / b_{g} \text {, and } \\
& \dot{b}_{g}=1 / b_{g} .
\end{aligned}
$$

This allows the computation of a "transmuted" score to be in the form $\dddot{x}_{g_{1}}=$ $\dot{a}_{g}+\dot{b}_{g} \ddot{x}_{g_{q}}$, rather than $\ddot{x}_{g_{q}}=\left(\ddot{x}_{g_{1}}-a_{g}\right) / \hat{b}_{g} \cdot$

\section{Table VII}

The Means and Standard Deviations of the "Standardization" Variable and of the "Variable-to-be-Equated" and the Correlation Coefficients and

\begin{tabular}{|c|c|c|c|c|c|c|c|}
\hline \multirow[b]{2}{*}{ Subgroup } & \multicolumn{2}{|c|}{ Variables to be Equated } & \multicolumn{3}{|c|}{ Standardization Variable } & \multicolumn{2}{|c|}{ Transmutation Constant } \\
\hline & $\vec{x}_{9}$ & $\sigma_{\chi_{g}}$ & $\bar{Y}_{g}$ & $\overline{\sigma Y}$ & $r \ddot{X Y Y}$ & $\overline{a_{g}}$ & $\dot{b}_{g}$ \\
\hline $\begin{array}{l}1 \\
2 \\
3 \\
4 \\
5 \\
6 \\
7\end{array}$ & $\begin{array}{l}300.907 \\
300.660 \\
300.531 \\
304.756 \\
302.408 \\
301.868 \\
297.850\end{array}$ & $\begin{array}{l}5.267 \\
3.889 \\
5.653 \\
5.035 \\
5.252 \\
5.615 \\
6.776\end{array}$ & $\begin{array}{l}300.076 \\
302.963 \\
299.648 \\
302.219 \\
300.788 \\
299.973 \\
299.068\end{array}$ & $\begin{array}{l}4.058 \\
2.833 \\
3.753 \\
3.598 \\
3.932 \\
3.572 \\
3.374\end{array}$ & $\begin{array}{l}.7251 \\
.5048 \\
.7288 \\
.5426 \\
.6505 \\
.7069 \\
.6815\end{array}$ & $\begin{array}{l}131.961 \\
192.369 \\
154.231 \\
184.021 \\
153.519 \\
164.189 \\
197.986\end{array}$ & $\begin{array}{l}.558 \\
.367 \\
.483 \\
.387 \\
.486 \\
.449 \\
.339\end{array}$ \\
\hline Totol & 300.477 & 5.899 & 300.457 & & .6481 & & \\
\hline
\end{tabular}
the Transmutation Constants for the Subgroups

6. Transformation of $\ddot{X}$ scores so they will have a slope of 1.00 and an intercept of zero with the $\hat{Y}$ varicible by-passed

One could at this point multiply each $\ddot{x}_{1}$ score by $\dot{b}_{g}$ and add $\dot{a}_{g}$ to the product. These would give tronsmuted scores for each subgroup that would have a 
slope of 1.00 and an intercept of zero with the standardized variable. The total group mean and standard deviation of the "standardization" variable were themselves derived from the total group mean and standard deviation of the "variable-tobe-equated." This was inherent during the accompiishment of the Wherry TestSelection technique. The standard deviation of the transmuted scores will, in turn, be much smaller than the standard deviation of the "standardization" variable. The net result of this would be that the total group standard deviation of the transmuted scores would probably be much smaller than the original total group standard deviation of the "variable-to-be-equated." It was decided, therefore, to do one total group linear transformation to these "first" transmuted scores to make their mean and standard deviation equal to the mean and standard deviation of the original total group mean and standard deviation of the "variable-to-be-equated." In order to find the linear transformation capable of doing this we needed to know what the mean and standard deviation of these "first" transmuted scores would be.

The over-all linear transformation to the transmuted scores is of the form

$$
\dddot{x}_{g_{1}}^{\prime}=c+d \dddot{x}_{g_{1}}
$$

where $d=\sigma \ddot{x}_{t} / \sigma \ddot{x}_{t}$,

$$
\begin{aligned}
& c=\overline{\ddot{x}}_{t}-d \overline{\ddot{x}}_{t} \text {, } \\
& \ddot{x}_{g_{1}}=\dot{a}_{g}+\dot{b}_{g} \ddot{x}_{g_{1}} \text {, and } \\
& \dddot{X}_{g_{1}}^{\prime}=\text { a "new" transmuted score, which will have a total group mean }
\end{aligned}
$$

The intermediate summary data necessary to compute the values of $c$ and $d$ ore shown in Table VIII. 
Because, however, $\dddot{x}_{g_{1}}=\dot{a}_{g}+\dot{b}_{g} \ddot{x}_{g_{1}}$ and $\dddot{x}_{g_{1}}^{\prime}=c+d \ddot{x}_{g_{1}}$, then

$$
\begin{aligned}
\dddot{x}_{g_{1}}^{\prime} & =c+d\left(\dot{a}_{g}+\dot{b}_{g} \ddot{x}_{g_{1}}\right), \\
& =c+d \dot{a}_{g}+d \dot{b}_{g} \ddot{x}_{g_{1}} .
\end{aligned}
$$

Letting $\ddot{a}_{g}^{\prime}=c+d \dot{a}_{g}$, and $\dot{b}_{g}=d \dot{b}_{g}$, we may compute "new" transmutation constants for each subgroup. These values are also shown in Table VIII.

\section{Table VIII}

Computed Sums of $\ddot{X}, \ddot{X}^{2}$, and Final Transmutation Constants $\left(\ddot{a}_{g}^{\prime}\right.$ and $\left.\ddot{b}_{g}^{\prime}\right)$ for Each Subgroup

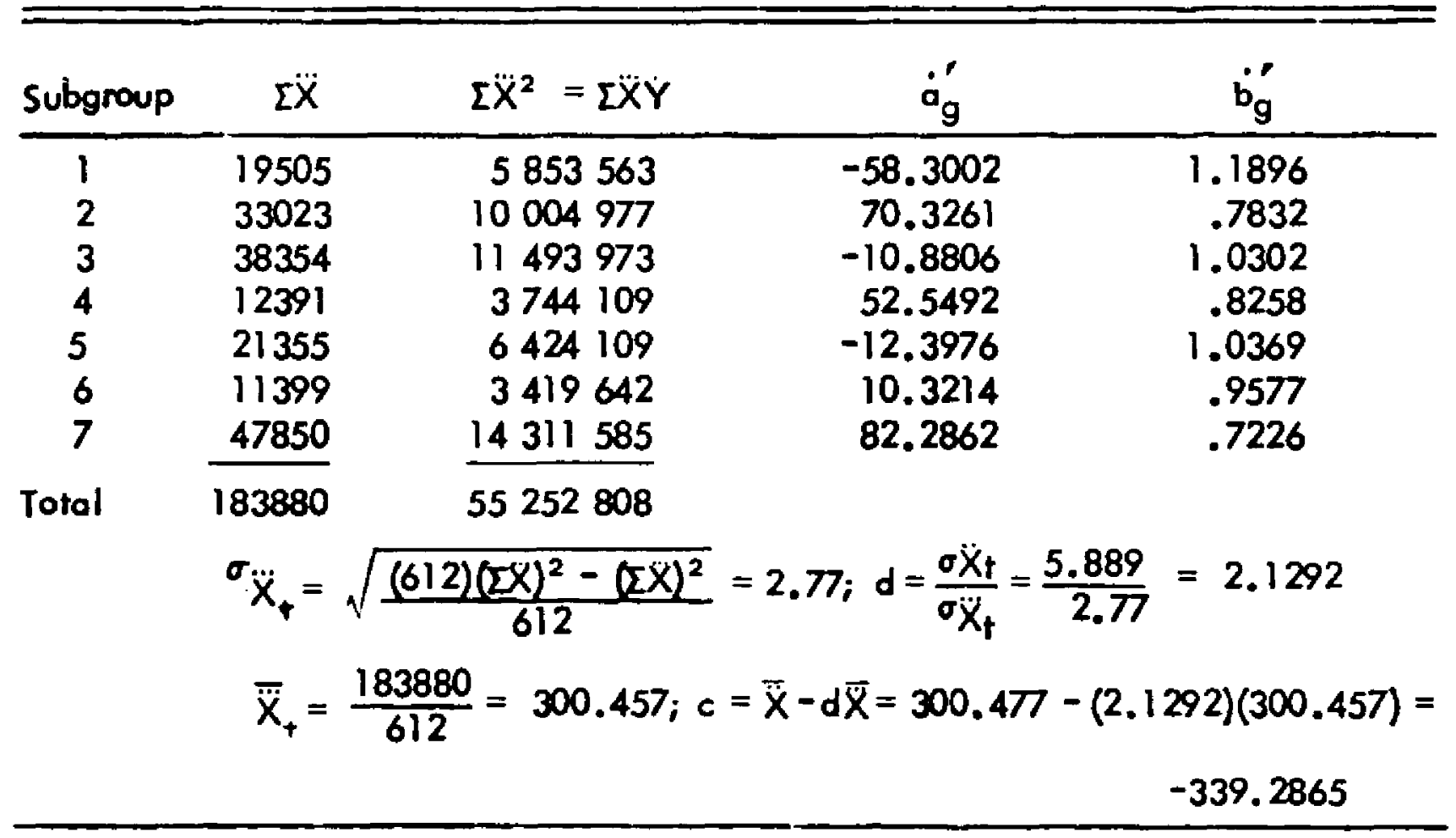

7. Computation of Total Group's Correlation Between the "Transmuted" Scores and the "Standardization" Variable Scores

Supposedly we have now equated the seven subgroups according to the equations in the "rotionale" section of this paper. We now ask the question of whether these $\dot{o}_{g}$ 's and $\dot{b}_{g}$ 's have significantly changed the relotive locations of the individuals for intro-subgroup comparisons. 
Since the transmutation scores within a subgroup ore merely linear transformations of the original scores then the transmuted scores will not be able to increase in the proportion of the standardization variable's variance within a subgroup that is explainable. However, since different subgroups have received different linear transformations the total proportion of the variance of the standardization variable explainable should have increased for the group as a whole. The correlation between the transmuted scores and the standardization variable for the entire group was found to have increased from .6481 to .7246 . Table IX shows that the F-ratio for the transmutation equations was found to be 10.886 with 12 and 591 degrees of freedom. An F-ratio of this magnitude is significant beyond the .001 level and tells us that the subgroups did have significantly different "leniency" and "exaggeration" effects. (Only 12 degrees of freedom are lost because we may consider one subgroup as the "standard" and equate the other subgroups to it.)

Table IX

Table for Testing the Significance of Transmutation Equations Derived by the Slope and Intercept Method

\begin{tabular}{|c|c|c|c|c|c|c|}
\hline Source & D.F. & $\mathbf{R}$ & $\mathbf{R}^{2}$ & $\begin{array}{l}\text { Proportion of } \\
\text { Variance } \\
\text { Attributable to }\end{array}$ & MS & F-ratio \\
\hline $\begin{array}{l}\text { Multiple Correlation } \\
\text { Equation }\end{array}$ & 8 & .6481 & .4200 & .4200 & .0525 & 65.321 \\
\hline $\begin{array}{l}\text { Transmutation } \\
\text { Equation }\end{array}$ & 12 & .7246 & .5250 & .1050 & .00875 & 10.886 \\
\hline Residual & 591 & & & .4750 & .0008037 & \\
\hline Total & 611 & & & 1.0000 & & \\
\hline
\end{tabular}

Significant beyond the .001 lovel. 
8. Need for Iterating the Solution Established and Transmuted Scores Obtained

We know from the preceding step that the subgroups did originally have significantly different "leniency" and "exaggeration" effects. Transmuted "Advanced Flight Grodes " were computed for each subject using the transmutation constants $\left(\dot{a}_{g}\right.$ and $\left.\dot{b}_{g}\right)$ found in Step 6 for the subgroup of which he was a member. Since these grades have less bias in them the total group's Advanced Flight Grade may now correlate somewhat differently with the "predictor" variables. This, in tum, might allow a better determination of a "standardization" variable on which to equate the groups, i.e., the subgroups may have better "composition" with a new composite variable. For these reasons it was decided that the procedure should be iterated.

\section{FIRST ITERATION ACCOMPLISHED}

The correlation matrix was obtained and the Wherry Test-Selection technique accomplished in the same monner as before. The multiple correlation coefficient $(R \ddot{X} \dot{Y} d$ was found to be .7339 which indicated the presence of an obtainoble vector $\left(\dot{Y}^{\prime}\right)$ that would be slightly more related to the transmuted scores than the original vector (original $R \ddot{X}{ }^{\prime} \dot{Y}=.7246$ ). (It is difficult to say whether this increase is significant or not. $\dot{Y}$ ' was a composite of fewer varidbles than was $\dot{Y}$. In one sense, then, it has fewer degrees of freedom than $\dot{Y}$. ) Using the new prediction equation, new "standardization" scores were computed for all subjects. Steps 3 through 7 were occomplished and yielded the transmutation constants seen in Table $X$. It can readily be seen that the $\ddot{b}_{g}^{\prime}$ 's are approaching 1.00 and $\ddot{a}_{g}^{\prime}$ 's are approaching 0.0 , and we should expect very little change in the total group 
correlation between Advanced Flight Grade and the "standardization" variable.

This was found to be true; the correlation coefficient increased only from . 7339 to .7343. The F-ratio was actually less than $1.00(F=.8)$ which indicated "overfitting" of random error was probably present in the "transmutation constants" in Table $X$. We should, in the face of a non-significant F-ratio, not use this second set of constants.

\section{Table $X$}

Table of Transmutation Constants and $r_{\ddot{X} Y} Y^{\prime}$ ' Found in the First Iteration

\begin{tabular}{cccc}
\hline Subgroup & & \multicolumn{3}{c}{ Transmutation Constants } \\
\hline 1 & $r \ddot{X} \dot{Y}^{\prime}$ & -16.1094 & $b_{g}^{\prime}$ \\
2 & .7606 & -6.6847 & 1.0533 \\
3 & .5249 & 8.7624 & 1.0229 \\
4 & .7200 & 20.1103 & .9706 \\
5 & .5031 & 7.9457 & .9340 \\
6 & .6525 & 7.7030 & .9723 \\
7 & .7011 & 9.3158 & .9732 \\
\hline
\end{tabular}

\section{SECOND ITERATION ACCOMPLISHED}

To find if this was true a second iteration was accomplished. As anticipated the multiple correlation dropped from .7343 to .7329 , and the final overall correlation after transmuting the scores a third time showed no increase at all.

COMPARISON OF THE "SLOPE AND INTERCEPT" METHOD WITH THE "PSEUDO" VARIABLE METHOD

In oddition to the variables previously mentioned dichotomous, linear, quadratic, and cubic pseudo variables were manufactured for each subgroup. The intercorrelotions among these and the other voriables are also shown in Appendix 1. In order to compare the results of the "slope and intercept" method with the "pseudo 
variable" method only the dichotomous and linear pseudo variables were used to predict the same standardization varicble (variable 20) used during the "slope and intercept" method.

Using all 14 of these pseudo variables (variables $21-34$ ), the multiple correlation was found to be equal to .7247 . The raw score regression weights are shown in Table XI. Comparison of these weights ( 8 's and $\left.b^{\prime} ' s\right)$ and those shown in Table VII (the $\dot{a}$ 's and $\dot{b}$ 's) shows that the two techniques are in fact identical (within rounding error) as far as results obtained are concerned. This is what was expected from the Bottenberg and Christal paper(6). Thus, if one is concerned only with removing "leniency" and "exaggeration" bias, the "slope and intercept" method will yield a solution identical with that given by the "pseudo variable" method using only dichotomous and linear variables.

\section{Table XI}

Comparison of "Transmutation" Constants Derived. from the "Slope and Intercept" Method and the "Pseudo Variable" Method (Using Only Dichotomous and Linear Pseudo Variables)

\begin{tabular}{|c|c|c|c|c|}
\hline Subgroup & \multicolumn{2}{|c|}{ Slope and Intercept Constants } & \multicolumn{2}{|c|}{ Pseudo Variable Constants } \\
\hline $\begin{array}{l}1 \\
2 \\
3 \\
4 \\
5 \\
6 \\
7\end{array}$ & $\begin{array}{l}131.961 \\
192.369 \\
154.231 \\
184.021 \\
153.519 \\
164.189 \\
197.986\end{array}$ & $\begin{array}{l}.558 \\
.367 \\
.483 \\
.387 \\
.486 \\
.449 \\
.339\end{array}$ & $\begin{array}{l}131.968 \\
192.346 \\
154.236 \\
184.004 \\
153.486 \\
164.225 \\
198.007\end{array}$ & $\begin{array}{l}.558 \\
.367 \\
.483 \\
.387 \\
.487 \\
.449 \\
.339\end{array}$ \\
\hline Multiple R & & & & \\
\hline
\end{tabular}


The Pseudo Variable Approach using Quadratic and Cubic Terms

A multiple correlation using all of the 28 pseudo variables as predictors was computed. The raw score weights to be used in the equation

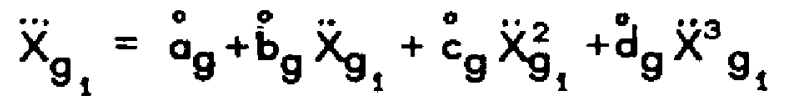

are shown in Table XII.

Tole XII

Transmutation Constants Derived from the "Pseudo Variable" Approach Using Dichotomous, Linear, Quadratic, and Cubic Pseudo Variables

\begin{tabular}{ccccc}
\hline \hline Subgroup & $\dot{a}$ & $\dot{b}$ & $\dot{c}$ & $\dot{d}$ \\
\hline 1 & 249.39576 & -.22001 & .001303 & -.00000004026 \\
2 & 244.57538 & .04108 & .000451 & .00000019183 \\
3 & 251.66059 & -.07556 & .000484 & .00000099245 \\
4 & -439.63646 & 4.11595 & -.004012 & -.00000495186 \\
5 & 332.74979 & -.51062 & .000730 & .00000201406 \\
6 & 503.45862 & -1.56635 & .002103 & .00000281772 \\
7 & 309.06867 & -.30635 & .000605 & .00000104215 \\
\hline
\end{tabular}

The multiple correlation using the 28 pseudo variables as predictors was found to be $\mathbf{. 7 3 8 5}$. The question of whether this solution, using the cubic and quadratic terms, is better than the solution obtained when only dichotomous and linear pseudo variables were used can be answered by finding if the increase in the multiple correlation is a significant one. Table XIII presents the F-table information which shows that this solution is better beyond the .05 level. 
Table XIII

F-Table Showing the Level of Significance of the Increase in the Proportion of Variance Explainable Using All Pseudo Variables Over Using Only Dichotomous and Linear Pseudo Variables

\begin{tabular}{|c|c|c|c|c|c|c|c|}
\hline Source & d.f. & $\mathbf{R}$ & $R^{2}$ & \% of Variance & MS & $\mathbf{F}$ & Leve! \\
\hline $\begin{array}{l}\text { Original } \\
\text { Multiple R }\end{array}$ & 8 & .6481 & .4200 & 42.00 & .052500 & 66.6209 & $\star \star \star *$ \\
\hline $\begin{array}{l}\text { Dichotomous } \\
\text { and Linear }\end{array}$ & 12 & .7247 & .5250 & 10.50 & .008750 & 11.1035 & $\star * *$ \\
\hline $\begin{array}{l}\text { Quadratic and } \\
\text { Cubic }\end{array}$ & 14 & .7385 & .5453 & 2.03 & .001450 & 1.84 & $\star$ \\
\hline $\begin{array}{l}\text { Unexplained } \\
\text { Variance }\end{array}$ & $\underline{577}$ & & & 45.47 & .000788 & & \\
\hline Total & 611 & & & 100.00 & & & \\
\hline
\end{tabular}

Significont beyond the .001 level.

* Significant beyond the .05 level.

While the proportion of variance explained by the addition of the quadratic and cubic term did increase a significant amount, the absolute increase was quite small and is of little proctical significance. A plot of the non linear equations over the range of data in their respective subgroups is shown in figure 5 . From inspection of figure 5, it appears that the cubic term was relatively unimportant in all but the fourth subgroup.

\section{THE CROSS VALIDATION STUDY}

In addition to the question of whether the linear and nonlinear transmutation equations allow us to explain significantly more of the "standardization" variable's variance than without transmutation, there is also the question of how 


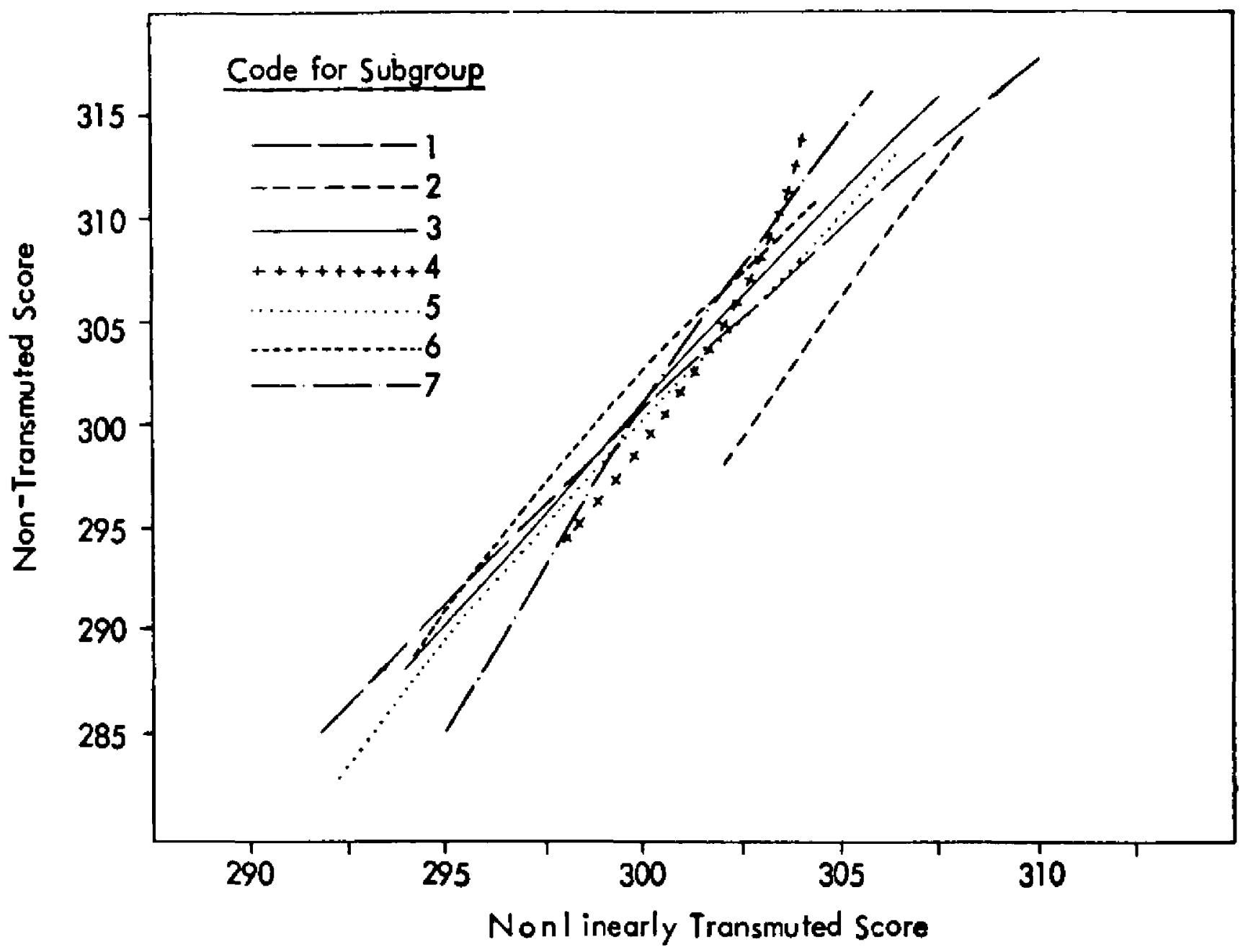

Figure 5. - A Plot of the Nonl inear Equations Shown in Table Xll Over the Range of Data in Each Subgroup 
well the tronsmutation equations derived from one sompling of a population will perform in a second sompling of the population.

To determine this the linear and non linear equations derived from the experimental somple mere used to transmute the Advanced Flight Grodes of the cross validation sample. This procedure yields three different sets of Advanced Flight Grades: (1) the "raw" or non-transmuted, (2) the linearly transmuted, and (3) the n on linearly transmuted. The question of which of these sets of scores is the most "error-free" can be, I believe, answered by determining which set has the most predictable variance. Since no degrees of freedom are lost in doing a priori transformations on the cross validation data, the set of scores having the most predictable variance would be the best set to use (i.e., it would be the most "errorfree" set).

Pearson product-moment correlation coefficients were obtained among all the equating variabless and these three sets of Advanced flight Grades. These correlation coefficients are given in Appendix II. Three multiple correlations were accomplished using the equating variables as predictors and each of the sets of Advanced Flight Grades as criterio. The results of this procedure are shown in Table XIV.

From inspection of Table XIV it is quite obvious that either of the transmuted sets of grades would be "better" (i.e., more "error-free") than the non-transmuted grades. The increase of 9.30 in the per cent of variance explainable between the non-transmuted and linearly transmuted scores is comparable to that found in the experimental sample (i.e., 10.50 per cent). The increase of only 0.13 per cent 
from the linearly transmuted to the n onlinearly transmuted scores was somewhat disappointing compared with the increase found in the experimental sample (i.e., 2.03). However, this does detract from the fact that the n on linearly transformed set of scores was, indeed, the most error-free set.

\section{Table XIV}

Comparison of Non-Transmuted, Linearly Transmuted, and Nonl inearly Transmuted Advanced Flight Grades in the Cross Validation Sample Using the Transmutation Constants Derived from the Experimental Sample

\begin{tabular}{lccc}
\hline $\begin{array}{l}\text { Type of Advanced } \\
\text { Flight Grade }\end{array}$ & $\begin{array}{c}\text { Multiple } \\
\text { Correlation }\end{array}$ & $\begin{array}{c}\text { \% of Voriance } \\
\text { Predictable }\end{array}$ & $\begin{array}{c}\text { Differences in } \\
\text { \% of Variance }\end{array}$ \\
\hline Non-Transmuted & .7029 & 49.41 & 09.30 \\
Linearly Transmuted & .7663 & 58.71 & 00.13 \\
Non l inearly Transmuted & .7671 & 58.84 & \\
\hline
\end{tabular}

The question of whether transmutation equations derived from one sample of data will work on a different sample of dato was not asked with a view toward recommending the use, for example, of transmutation equations derived from one year's data to equate the next year's data. This would involve the problem of the stability of transmutation equations over time, a problem which, while interesting, is not investigated here. The cross validation procedure followed here was concerned instead with how much confidence we could have in using the transformation equations on the data they were derived from. Clearly, if they work (and they did) on a separate random sample of individuals spanning the same time period, then we should not hesitate to use the equations on the sample from which they were derived. 


\section{DISCUSSION}

In the foregoing chapters I have attempted to present a rationale which would be applicable to most of the major suspected causes of non-equivalence of scales among evaluators. The techniques which have been rer ted in this dissertation are intended for the removal of four types of these non-equivalence errors: "leniency," "exaggeration," "floor" or "ceiling" effects, and "differential treatment of extremes." The rationale section, to some extent, shows how other nonequivalence errors, such as the magnitude of the "reliability," and "composition" effects, and some confounding problems, such as the magnitude of the "curtailment" and "transmutation regression" effects enter into the general problem of equating subgroups composed of different individuals.

The removal of non-equivalence errors attributable to differential "composition" effects within subgroups was not aftempted in this study. It seems, however, to be a combination of a factor analytic type of a problem and a criterion definition problem which would easily fit into the rationale presented.

\section{COMMENTS REgARDING THE "OPTIMAL" STANDARDIZATION VARIABLE}

The method used for obtaining the "standardization" variable, by using all available equating variables to predict the "variable-to-be-equated," and then using the predicted variable-to-be-equated scores as the "standardization "variable scores, seoms, to me, to be superior to using either the single best available variable or a simple average of available variables. (I must confess, however, some disoppointment that the solution showed no significant improvement after 
iterating it.) Upon further consideration of the optimal standardization problem I have thought of one method which would, without question, find the optimal "standardization" vector for any sample of data regardless of the number of subgroups. Since the "optimal" standardization vector is that vector which will hove the highest correlation with the "best" set of weights for all the pseudo variables, then the problem can be perfectly resolved by Hotelling's Canonical correlation technique (26), using the "equating" variables as the "criterio" and the pseudo variables os the "predictors." Whether this technique would yield a significantly better solution than the one used in this dissertation is a question that will remain unanswered here. There is the possibility, however, that the Hotelling procedure might do better in the experimental sample but worse in cross validation because it would have used all the equating variables and thus fit too much error.

\section{COMMENTS REGARDING THE UTILITY OF THE PSEUDO VARIABLE APPROACH}

The pseudo variable approach allowed us to prove that Toop's "slope and intercept" method does provide the optimal linear transformation equation for each subgroup. The pseudo variable opproach accomplished this because it was a method which solved for all subgroups simultaneously, maximizing the proportion of variance explainable in the entire group; only with such a solution could this have been ultimately proven. (Bottenberg and Christal's paper had, of course, indicated that the results would turn out this way.) However, use of the pseudo variable approach to equate subgroups requires one pseudo variable for each term in the transmutation equation for each subgroup. If one had many subgroups to equate (e.g., fifty high schools) and wanted to include up to the quadratic term 
in the transmutation equations, he might encounter some difficulty in finding a computer large enough to handle the problem (200 pseudo variables plus the predictor variables). Obviously, then, a solution which would solve one subgroup at a time is ultimately more desirable. Much as Toops found the best linear transformation equation for a given subgroup, one could find the best $n$ on linear transformation equation for a given subgroup. This could be done in several different ways One method would be to simply create, for example, an $\ddot{X}^{2}$ and $\ddot{X}^{3}$ score in addition to the standardization variable score $(\dot{\gamma})$ and the "variable-to-be-equated" score $(\ddot{X})$ which one would already have. Using only the data in a given subgroup compute the correlations for the four variables and then use $\ddot{x}, \ddot{X}^{2}$, and $\ddot{X}^{3}$ to predict $Y$. The raw score beta weights for $\ddot{X}, \ddot{X}^{2}$, and $\ddot{X}^{3}$ will correspond to $\dot{b}, \dot{c}$, and $\dot{d}$ respectively, and the constont to be added will be $\dot{a}$. The pseudo variable approach can be used to prove that "transmutation" equations derived in this manner are, in fact, optimal.

It is perhaps worth pointing out the dissimilarity of the application of the pseudo variable approach in the Bottenberg and Christal paper and in the problem which was studied here. Bottenberg and Christal were interested in obtaining simultoneous prediction equations of a criterion score for several subgroups (different schools), for which they linearly "pseudoized" the predictor variables and left the criterion variable as it was. The problem here was to equate the criterion scores from each subgroup for which the criterion score was $n$ on linearly "psoudoized" and the predictor variables were left as they were. Their concern soems to have been primorily with within-subgroup comporisons whereas mine has 
been with betweerrsubgroup comparisons. Now that the various subgroup scores have been equated we also would be concerned with getting different prediction equations for each subgroup. Our purpose in equating the subgroup scores was so that when we finally did obtain a predicted score of, for example, "302" in subgroup 1 for individual $i$ and a predicted score of "304" in subgroup 2, we would know that the higher score indicated a higher degree of success as an aviator if the man is assigned to subgroup 2 than if he is assigned to subgroup 1 .

Bottenberg and Christal used the pseudo variable approoch to find out if the prediction equation for one school was significantly different from the prediction equation for a second school. Their stated purpose was to reduce the number of prediction equations needed or, more simply, to reduce the number of criterion groups. Of course, it is possible that two schools' prediction equations differed significantly not because of what was important for success at each school, but because the meaning of grades at one school was not equivalent to the meaning of grades at the second school. Thus, both in their application and the one studied here, the subgroup criterion scores should be equated first.

\section{COMMENTS REGARDING THE RELATIVE EFFICACY OF LINEAR TO NON- LINEAR TRANSMUTATION EQUATIONS}

While it is true that the data studied in this dissertation seemed to be relatively free of "floor" or "ceiling," and "differential treatment of extremes" effects (with the possible exceptien of subgroup 4), this should not be considered as a license to be sotisfied with a simple linear transformation. The presence or absence of these kinds of effects will vary from study to study depending on the nature of the 
observable being studied and the type of evaluator being used. For example, these effects may turn out to be highly important when dealing with ratings.

If the needed transformation to a given subgroup is really merely linear, then the constants for the quadratic and cubic terms of the non linear equation will turn out to be zero. It is, of course, impossible to explain less of a subgroup's variance by using the best non linear equation than by using the best linear equation. The question, then, is whether the $n$ on linear equation is significantly better than the linear equation. (This can be answered by accomplishing the F-test shown in Table XIII.) This brings up another possible improvement in the technique. One could use a test-solection technique to determine which voriables $\left(\ddot{x}, \ddot{x}^{2}\right.$, and or $\ddot{X}^{3}$ ) should be used for a given subgroup. Thus, only when a term adds a significant amount to the predictable variance would it appear in the transmutation equation for that subgroup.

THE PRACTICAL IMPLICATIONS OF TRANSMUTING SCORES

We now have a proven technique for the removal of certain types of "nonequivalence" errors. The question of whether transmuting scores should be accomplished depends, first of all, on the expected use of the scores.

If the scores are to be used only to evaluate the relative merit of individuals from the same subgroup (i.e., within-subgroup comparisons) then there would be no gain from accomplishing linear transmutations and, perhaps, only a slight gain from use of $n$ onlinear transmutations. If the scores are to be used to evaluate the relative merit of individuals from different subgroups $(0.9 .$, between-subgroup comparisons), then the technique is advantogeous. 
The cost today, unlike thirty years ago, of transmuting scores, is quite reasonable if computers are used. How much benefit one will realize from transmuting scores will have to be determined empirically for each new study. The ultimate worth of transmuting sets of scores is not only the gain in the proportion of variance that will be explainable, but also the degree of confidence we will be able to hove in our data. That is, even if no gain derives from applying the transmutation technique, we would at least know that our scores were free of "leniency," "exaggeration," "floor or ceiling," and "differential treatment of extremes" effects. This alone moy justify the use of the technique.

The ultimate worth of using the technique will be determined by whether savings resulting from the gain in operational validity of the transmuted scores offsets the cost of using the technique. 


\section{SUMMARY}

Whenever two or more individuals are to be compared on the basis of scores obtained from different evaluators, certain differential non-equivalence errors should be removed from their scores. A rationale for understanding how these non-equivalence errors affect a set of scores is presented. Various nonequivalence errors such as "leniency," "exaggeration," "floor and ceiling," "differential treatment of extremes," and various "composition" effects such as differential emphasis of factors, reliability, and validity are included in the rotionale. The confounding effect of differential spread of ability and differential average ability among subgroups is discussed.

The problem of optimally removing non-equivalence errors involves, first, finding the best variable or composite of variables to use as a "standardization" variable against which the data from different evaluators may be equated. One method for accomplishing this goal is described and used in the dissertation, and a second method, involving the use of canonical correlation, is discussed. Once the "standardization" variable has been determined, the problem of equating dato from different evaluators may be accomplished in a variety of ways. Toops' "slope and intercept" method is here demonstrated to have the capability of removing linear non-equivalence (i.e., differential "leniency" and "exaggeration"). Another mathod, the "pseudo variable" approach, is proposed for the removal of linear and non linear ("floor or coiling" and "differential 
treatment of extremes") non-equivalence errors. Toops ' method is shown to be a special case of the "pseudo variable" opproach.

Data are analyzed and transmuted by bot'i methods and some superiority of the nonlinear solution is demonstrated. Tests of significance for determining whether transmutation equations will significantly improve (i.e., make more "errorfree") a set of scores are given. The transmutation equations derived from one sample $(N=612)$, seven subgrnups of data, were shown to be able to remove 21.6 per cent of the non-transmuted unexplained variance. In a second sample $(N=605)$ of data the same equations were able to remove 18.64 per cent of the unexplained variance.

It is recommended that whenever the relative merit of two or more individuals must be determined on the basis of scores derived from different evaluators use of the methods described here be considered. 


\section{APPENDIX 1}

Intercorrelations, Means, and Standard Deviations of Variobles Used In The Experimental Study 


\begin{tabular}{|c|c|c|c|c|c|c|}
\hline $\begin{array}{l}\because=\overline{7} \\
\therefore 1\end{array}$ & 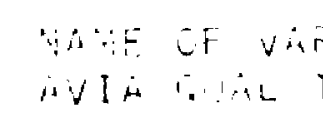 & 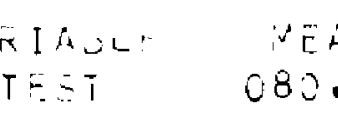 & $\begin{array}{l}S T .015 \\
013.4\end{array}$ & & & \\
\hline $1: 1$ & 1. ¿lu iuso & .347562520 & $-.03 i c: c 158$ & .106342190 & .534024400 & $.3 \geqq 5551880$ \\
\hline$\therefore 7$ & $.36571-320$ & .274301270 & .459739600 & .029606236 & .026750826 & .124171430 \\
\hline 13 & .098959772 & .243713770 & -.030097001 & .299656170 & .034525027 & .147886110 \\
\hline 15 & $.14775: 35:$ & - 265565650 & -.511719215 & $.09927504 a$ & -.306860578 & -.005280318 \\
\hline 25 & -.064107733 & .026317257 & -.034752249 & -.011317245 & .349702871 & -.005515832 \\
\hline 31 & -.004428722 & -.061253559 & .027279651 & -.0350 .72706 & -.010782533 & .100132790 \\
\hline 37 & $-.0 \therefore 2339924$ & -.003592650 & -.050571143 & .028207295 & -.035311690 & -.009985644 \\
\hline 43 & $.1 \div 3436345$ & .001957775 & $-.0631+5325$ & -.054896373 & .028831142 & -.035337071 \\
\hline
\end{tabular}

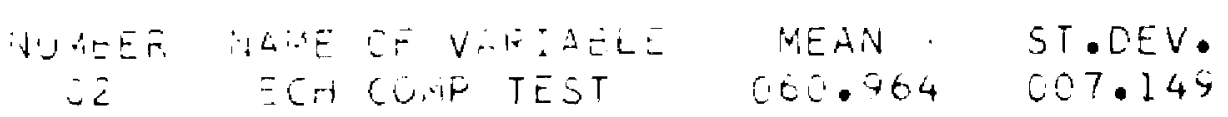

$\begin{array}{rrrrrrrr}12 & 02 & 1.01003000 & .066635884 & .150195880 & .248272470 & .343718720 & .357990090 \\ 02 & 08 & .432684300 & .197015560 & .127729810 & .151410270 & .111231680 & .163246330 \\ 02 & 14 & .160096370 & .019862510 & .124880030 & .156861940 & .190131550 & .119704720 \\ 02 & 20 & .203971930 & -.045745959 & .108681200 & .027314668 & .011404240 & -.000319555 \\ 02 & 26 & -.010072191 & -.088558321 & -.044028305 & .102826030 & .027780877 & .012490442 \\ 02 & 32 & .00856223 & -.009259638 & -.087173246 & -.043876330 & .108963910 & .028242807 \\ 32 & 38 & .013578395 & .002077860 & -.008295243 & -.085699331 & -.041436254 & .109594870 \\ 12 & 44 & .027945727 & .014211416 & .003055827 & -.007708996 & -.083984888 & \end{array}$




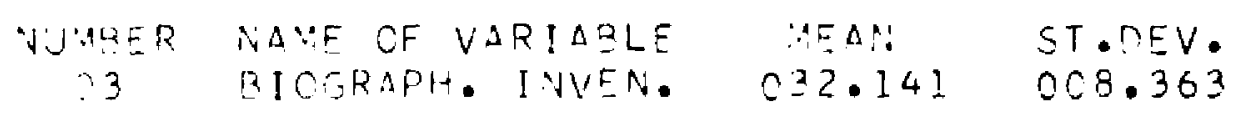

\begin{tabular}{|c|c|c|c|c|c|c|}
\hline 0303 & 1.0000000 & -.013537920 & -.165897960 & 134007 & .024417900 & .032320219 \\
\hline 39 & $=.058141344$ & .259343930 & .124553380 & .127800010 & .159674530 & 87272 \\
\hline 15 & .055418934 & $\{445542: 0$ & .11589 & .076287755 & .042722891 & 944614 \\
\hline 21 & .022742094 & .27 & $-.0461 ? 2474$ & .000564326 & -.032931835 & -.0 \\
\hline 27 & .005120581 & $C 87$ & $.070 x 0273]$ & -.045580 & .00 & -.1 \\
\hline 33 & -.039295498 & .006567955 & .025942851 & .078312644 & -.045073445 & \\
\hline 9 & $.03357748 ?$ & -.040243367 & .008048798 & $.02606,931$ & .370910258 & -.0 \\
\hline 45 & 911586 & 33177 & 041140540 & .01066303 & & \\
\hline
\end{tabular}

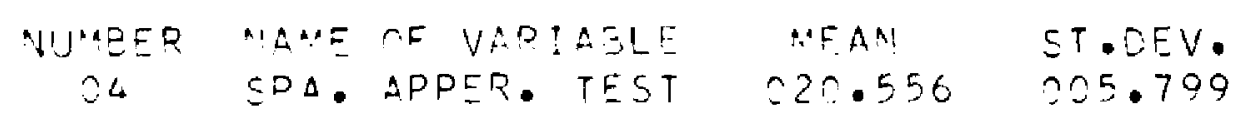

\begin{tabular}{|c|c|c|c|c|c|c|}
\hline $54 \quad 04$ & 1.00202000 & - 058955894 & .083443763 & .233194270 & .070215692 & .122998570 \\
\hline $04 \quad 10$ & .144099110 & .155529870 & .076882193 & .195025470 & 202505350 & 550 \\
\hline 0416 & $.16 C 249630$ & .163162130 & .122966460 & .164309190 & .252379370 & .003556794 \\
\hline $34 \quad 22$ & .015794325 & .049117248 & .027301564 & -.004790813 & .006876526 & 808 \\
\hline $34 \quad 28$ & .005138549 & .015532674 & .052051030 & .027602514 & -.00 & .0 \\
\hline $24 \quad 34$ & -.075728024 & .006863252 & .015355453 & .054950429 & 787847 & -.003242592 \\
\hline 46 & .007745409 & -.074028040 & .007975750 & .015356427 & .058096291 & .027548675 \\
\hline 46 & $=.002819446$ & .008635331 & -.0714425 & & & \\
\hline
\end{tabular}




\begin{tabular}{|c|c|c|}
\hline 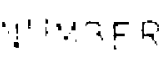 & AAUE OF VARIARLT & $\because r A M$ \\
\hline-5 & $\because \triangle T H E \because A T I C S$ & 050.051 \\
\hline
\end{tabular}

\begin{tabular}{|c|c|c|c|c|c|c|}
\hline 505 & $1.0: 00.00 \%$ & . $23 \leq 392420$ & .421481500 & .258205680 & .502307090 & .005767492 \\
\hline 11 & .029436060 & 31045550 & $.129666 t=0$ & .242380660 & .223915647 & .284810320 \\
\hline 17 & 58268872 & .065268743 & .168541030 & .277940580 & 998250 & 740 \\
\hline 23 & 031068931 & .075875649 & $.0671=$ & -.001448192 & 743140 & 312 \\
\hline 29 & $87578 \approx 0$ & .033599648 & .0771005 .6 & -.0650260 & 1 & 360 \\
\hline 35 & 7382581 & .100828500 & .03613 & 376504 & -.962 & 866 \\
\hline 41 & 619450 & .007918390 & .109003300 & .38838842 & & -.0 \\
\hline 47 & 41 & & & & & \\
\hline
\end{tabular}

\begin{tabular}{|c|c|c|c|c|c|c|}
\hline $\begin{array}{c}\text { NIMAER } \\
: 6\end{array}$ & $\begin{array}{l}\text { VAME OF VAF } \\
\text { P-YSIOLOGY }\end{array}$ & I $\triangle B L E$ & $\begin{array}{l}S T \cdot D E \\
1108.2\end{array}$ & & & \\
\hline 2506 & 1.00000000 & 413483570 & .410921670 & .290445140 & .082103844 & .099092958 \\
\hline 3612 & .036843437 & 61779830 & .162563850 & .022860716 & .155563930 & .069169788 \\
\hline $20 \quad 18$ & .102471530 & .126086960 & .165240680 & -.101391190 & .052451998 & -.029380297 \\
\hline $26 \quad 24$ & .078864318 & -.008844261 & .094896016 & -.037925391 & -.100594750 & .052014218 \\
\hline 3630 & -.028672471 & .079438879 & -.007339187 & .095418435 & -.035912190 & -.099697884 \\
\hline $26 \quad 36$ & .051685266 & -.027975907 & .079979766 & -.006009443 & .095961807 & -.033981231 \\
\hline $26 \quad 42$ & -.098712636 & $.05: 376904$ & -.027704138 & .080171695 & -.003566943 & .095888329 \\
\hline 3648 & -.031223344 & & & & & \\
\hline
\end{tabular}




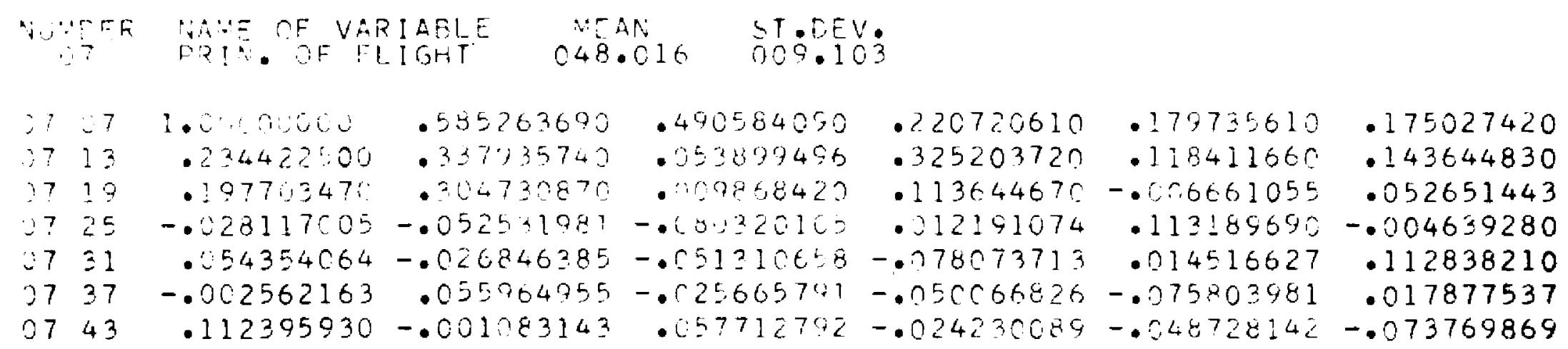

$\begin{array}{clll}\text { VUAEER NAME OF VARIAELE } & \text { MEAN } & \text { ST. JEV. } \\ 08 & \text { FNGINEERING } & 051.587 & 008.860\end{array}$

$\begin{array}{rrrrrrrr}28 & 18 & 1.00000000 & .391677190 & .234776400 & .192108150 & .142301290 & .163117120 \\ 08 & 14 & .053990210 & .098000233 & .202212460 & .164369310 & .181072940 & .190073440 \\ j 8 & 20 & .077783090 & .023268313 & .056911193 & -.052642775 & .026519875 & .052035182 \\ 08 & 26 & .029583962 & -.086402284 & .025347010 & .056238138 & -.050236738 & .027413033 \\ 08 & 32 & .052517729 & .031087232 & -.083909366 & .027515069 & .055762685 & -.0048045211 \\ 08 & 38 & .028294280 & .052915876 & .032502339 & -.081558700 & .030722970 & .055260352 \\ 08 & 44 & -.045991717 & .029165064 & .054059969 & .034162478 & -.0078105533 & \end{array}$




\begin{tabular}{|c|c|c|c|c|c|c|}
\hline $\begin{array}{c}N U .48 R \\
: 9\end{array}$ & $\begin{array}{l}\text { NAWE OF VAR } \\
\text { NAVIGATION }\end{array}$ & $\because A S L E$ & $\begin{array}{l}S T \cdot C E \\
O C S .4\end{array}$ & & & \\
\hline$\therefore 9 \quad 09$ & 1.01000000 & .188478450 & .218362570 & .243324450 & .203847290 & .358828040 \\
\hline$: 9: 5$ & .059111803 & .457900843 & .149034250 & .203209930 & .364854420 & .560186500 \\
\hline$: 321$ & .047987730 & .078951087 & -.020594603 & .063929801 & .010990083 & .031794213 \\
\hline 1927 & -.14586460 & .050004696 & .079491946 & -.016491712 & .066448911 & .014036261 \\
\hline 1932 & .034243265 & -.141544800 & .52267647 & .080103108 & $-.01231 \div 386$ & .068879565 \\
\hline 930 & .016946503 & .036696761 & -.137812110 & .054255180 & .080527911 & -.008330882 \\
\hline 9445 & $.07: 787801$ & .020250197 & .339043830 & -.133998460 & & \\
\hline
\end{tabular}

$\begin{array}{clll}\text { YJUER NAME OF VARIASLE } & \text { NEAN } & \text { ST.DEV. } \\ \text { IU PRE-SCLC T-34 } & 295.908 & 008.343\end{array}$

$\begin{array}{rrrrrrrr}10 & 10 & 1.00000003 & .543685380 & .404610310 & .387773420 & .337350840 & .230902270 \\ 10 & 16 & .299750480 & .403963070 & .104359520 & .331597550 & .507479520 & -.019103997 \\ 10 & 22 & .200658100 & -.006399047 & .043676182 & .019875083 & -.091325093 & -.144575410 \\ 10 & 28 & -.015250830 & .001934490 & -.003348418 & .044373221 & .021801537 & -.090720258 \\ 10 & 34 & -.140039670 & -.011191991 & .003267100 & -.000067484 & .044811225 & .023813401 \\ 10 & 40 & -.090124684 & -.135288450 & -.006339285 & .004421650 & .003030935 & .045015785 \\ 10 & 46 & .026029545 & -.089262565 & -.0130433370 & & & \end{array}$




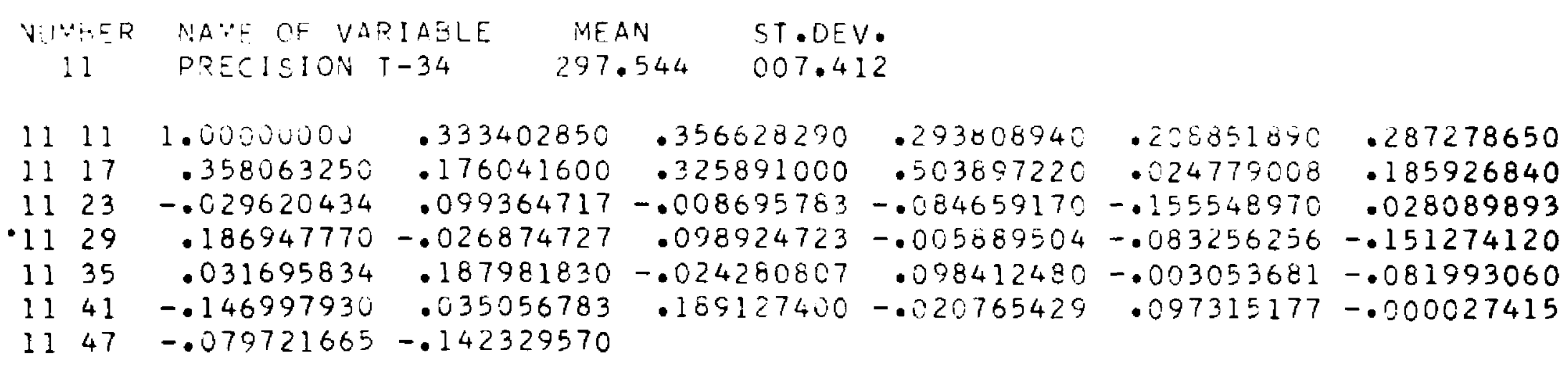

$\begin{array}{clll}\text { NUMBER NAYE GF VARIALLE } & \text { NEAN } & \text { ST.DEV. } \\ 12 & \text { TRANSITION } & 295.809 & 010.406\end{array}$

$\begin{array}{rrrrrrrr}12 & 12 & 1.00007000 & .484305370 & .374539510 & .179109590 & .351861060 & .415522920 \\ 12 & 18 & .267561050 & .448402950 & .088796870 & -.049219371 & .227718030 & -.064683227 \\ 12 & 24 & .067731558 & .004203974 & -.055787919 & -.0114857880 & -.044996061 & .228845840 \\ 12 & 30 & -.059904768 & .069331817 & .007732644 & -.053924689 & -.0109142040 & -.040571965 \\ 12 & 36 & .029032200 & -.055089384 & .070649742 & .011055671 & -.051914454 & -.0103228870 \\ 12 & 42 & -.035411884 & .0230998460 & -.049521861 & .072125817 & .015444693 & -.050412405 \\ 12 & 48 & -.096723588 & & & & & \end{array}$




\begin{tabular}{|c|c|c|c|c|c|c|}
\hline $\begin{array}{l}\text { UMER } \\
13\end{array}$ & $\begin{array}{l}\text { NAME CF VA } \\
\text { PRECISION }\end{array}$ & $\begin{array}{l}\text { ABLE } \\
\text { ROE. }\end{array}$ & $\begin{array}{l}S T \cdot D \\
012 .\end{array}$ & & & \\
\hline 1313 & $\mathrm{SAOC}$ & .367907360 & .183975780 & .320312870 & .413985020 & .218754140 \\
\hline 319 & .370679150 & .535064030 & 07442717 & .223979040 & -.114384410 & 547580 \\
\hline 325 & -.603140798 & -.037950507 & -.139218550 & .011205364 & .225393330 & -.110638580 \\
\hline 332 & .121627150 & $\pm 8 \div \subseteq 8 \%$ & $-.036 .1678 t 0$ & -.135323900 & .015064271 & .226680320 \\
\hline $13=?$ & -.196726290 & .122235 .220 & 000297312 & $-.0342327 E$ & -.121261270 & .019801858 \\
\hline 1343 & .228782472 & -.102732740 & .123454070 & .002372340 & -.031828541 & -.127006800 \\
\hline
\end{tabular}

$\begin{array}{cccc}\text { VIMER IAVE CF VARIASLE } & \text { MEAN } & \text { ST.DEV. } \\ 14 & \text { WASIC INSTR. } & 301.180 & 013.944\end{array}$

$\begin{array}{rrrrrrrr}14 & 14 & 1.01000000 & .222915290 & .569744900 & .327697580 & .157443850 & .418107770 \\ 14 & 26 & .641837260 & -.023459205 & .006243150 & -.085572457 & .124499180 & -.028453433 \\ 14 & 26 & -.062555811 & -.096608901 & -.020217132 & .007619470 & -.081496977 & .125424480 \\ 14 & 32 & -.026013857 & -.055774958 & -.093844952 & -.016858977 & .0209511740 & -.0077720300 \\ 14 & 38 & .126281640 & -.023666949 & -.056984170 & -.088038707 & -.012780460 & .0210460980 \\ 14 & 44 & -.072203034 & .126727040 & -.020120746 & -.053733205 & -.081452618 & \end{array}$

$1444-.072203034 \quad .126727040-.020120746-.053733265-.081452618$

$\begin{array}{clll}\text { WUMEER NAIE OF VARIAELE } & \text { MEAN } & \text { ST.DEV. } \\ 15 & \text { NIGHT FAMILIAR. } & 306.928 & 024.401\end{array}$

\begin{tabular}{|c|c|c|c|c|c|c|}
\hline 1515 & 1.00000000 & .176764050 & .227232660 & .105335050 & .185033530 & .2676370 \\
\hline 1521 & .027313715 & $09420854 ?$ & -.006552625 & .053822210 & -.071491419 & - \\
\hline 27 & -.084195510 & .028258789 & .100387460 & $=.004064405$ & .054050975 & \\
\hline 33 & .012239749 & -.082348094 & .023342744 & .101573570 & -.001739482 & - \\
\hline 39 & -.0068990606 & .013251975 & -.080278340 & .029906646 & .102545030 & .601 \\
\hline 45 & .254 .66 & $=.015$ & 44 & 5209 & & \\
\hline
\end{tabular}




\begin{tabular}{|c|c|c|c|c|c|c|}
\hline $\begin{array}{c}404 E E R \\
16\end{array}$ & $\begin{array}{l}\text { NA'VE OF VA } \\
\text { RADIO INST }\end{array}$ & ] $A: L E$ & $\begin{array}{l}\text { ST.OE } \\
\text { Cl } 5.3\end{array}$ & & & \\
\hline 616 & 2.00:000000 & .348668310 & .205960790 & .448285760 & .587610750 & -.002836090 \\
\hline 22 & .251040980 & -.121130180 & .065913704 & .003449314 & -.00130 & 142890 \\
\hline 28 & .000527648 & .252798060 & -.115941480 & .067496573 & .006954214 & .001510993 \\
\hline 34 & -.139316800 & .003851824 & .254779910 & -.110929260 & .068905351 & .009831529 \\
\hline 40 & $.004445 ; 535$ & -.134159680 & .008171711 & .256135090 & -.104960960 & .069829024 \\
\hline 46 & .013428991 & .006808869 & -.128666700 & & & \\
\hline
\end{tabular}

\begin{tabular}{|c|c|c|c|c|c|c|}
\hline $\begin{array}{c}U N 3 E R \\
17\end{array}$ & $\begin{array}{l}\text { NAYE OF VAF } \\
\text { FORMATION }\end{array}$ & I $A B L E$ & $\begin{array}{l}\text { ST.DE } \\
009.4\end{array}$ & & & - \\
\hline 1717 & 1.00000000 & 224587140 & .507379020 & .701156570 & -.073502941 & .273400030 \\
\hline 1723 & -.101103570 & .105602930 & .064870375 & -.030595173 & -.183493000 & -.070123316 \\
\hline 1729 & .275494540 & -.055814512 & $.10729: 030$ & .067464260 & -.020887049 & -.176364250 \\
\hline 1735 & -.066603999 & .277393540 & -.090550664 & .108702280 & .070195997 & -.027166489 \\
\hline 1741 & -.169114720 & -.062387627 & .280223910 & -.084847868 & .109882650 & .072931450 \\
\hline 1747 & -.025189945 & -.160393100 & & & & \\
\hline
\end{tabular}

$\begin{array}{cccc}\text { IUIAER NAME OF VARIABLE } & \text { MEAN } & \text { ST.DEV. } \\ 18 & \text { GUNNERY } & 307.013 & 013.584\end{array}$

$\begin{array}{rrrrrrrr}18 & 18 & 1.01601000 & .242487000 & .357204550 & -.036250083 & .169013300 & -.075915740 \\ 18 & 24 & .034384018 & -.014622257 & .035143132 & -.079685494 & -.034122220 & .170157720 \\ 18 & 30 & -.073020296 & .033813180 & -.013419448 & .035906556 & -.0075975528 & -.031610513 \\ 18 & 36 & .0171193840 & -.070062126 & .033150366 & -.012071139 & .036815818 & -.0072166749 \\ 18 & 42 & -.023301975 & .0172836720 & -.066803631 & .032917370 & -.0011049708 & .036887617 \\ 18 & 48 & -.069133851 & & & & \end{array}$




\begin{tabular}{|c|c|c|c|c|c|c|c|}
\hline $\begin{array}{c}4.1 \% 13 E R \\
19\end{array}$ & $\begin{array}{l}\text { NAYE OF VAH } \\
\text { ADVANEEL }\end{array}$ & DI & $r i$ & $\begin{array}{l}S T \cdot 0 E \\
00 \pm 0\end{array}$ & $\checkmark A R T A E$ & 10 & ED \\
\hline 1919 & 1.0000000 & .646055720 & .02 & 9631 & .014474053 & .004718306 & .194362660 \\
\hline 1925 & .118600250 & .1060681323 & -.26 & -24100 & .030542289 & .018441340 & .013987839 \\
\hline $13 \quad 31$ & .198112770 & .124162400 & .66 & 225620 & -.249315550 & .035998273 & .022407693 \\
\hline 1437 & .622457121 & .201538112 & .12 & $600: 20$ & .069715875 & $-.23553459 \mathrm{C}$ & .042562744 \\
\hline 1943 & .027071650 & $.63 \cos 3422$ & .28 & 1059500 & .135433040 & .273547762 & -.216243080 \\
\hline
\end{tabular}

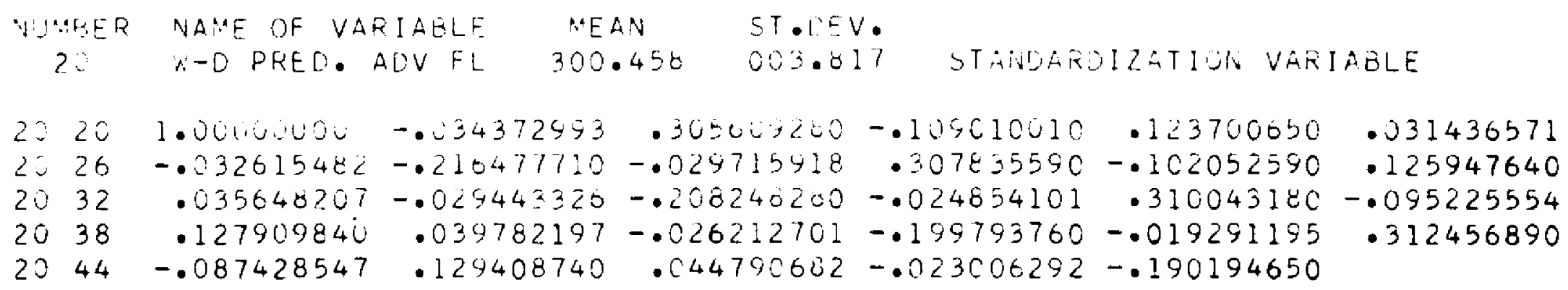




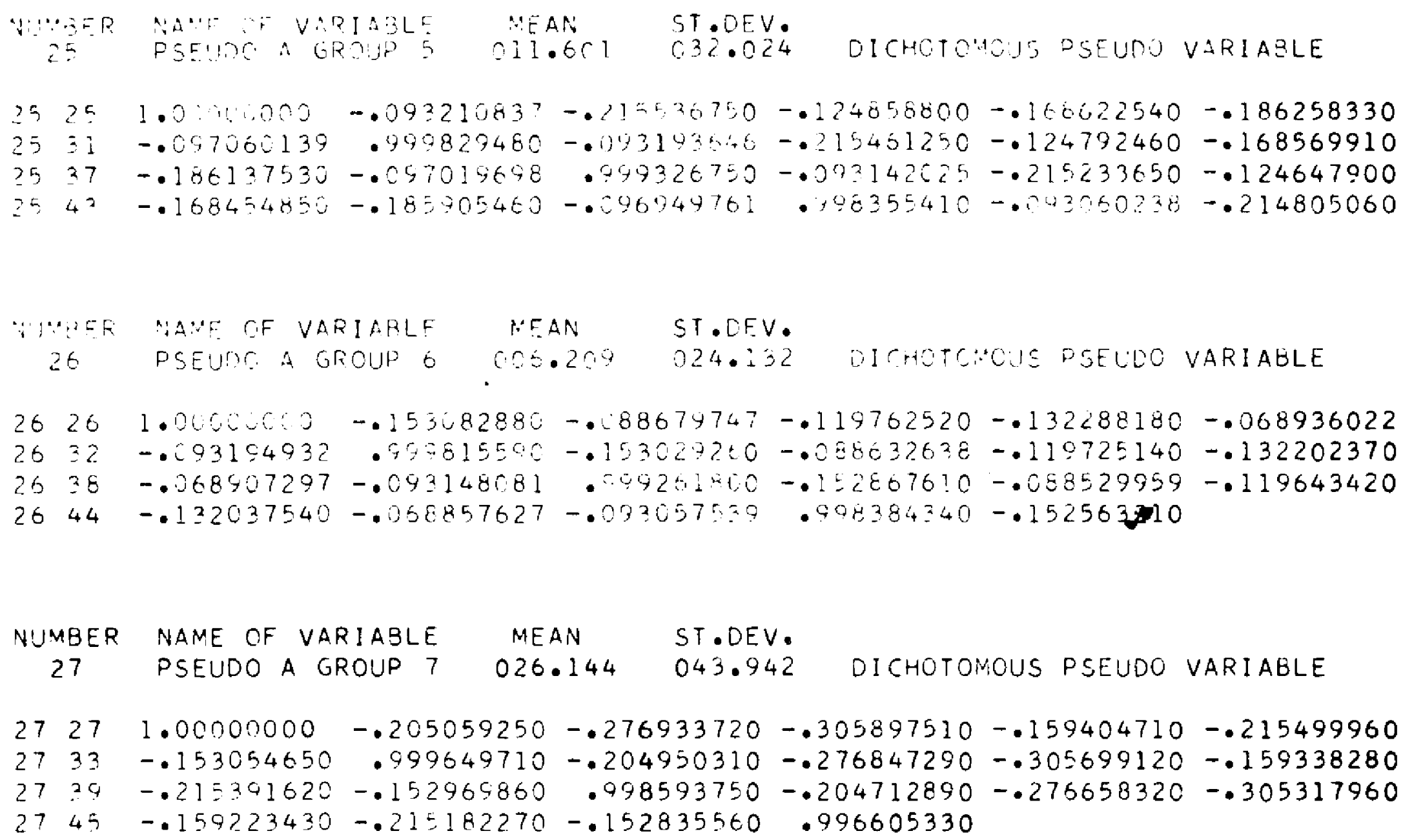




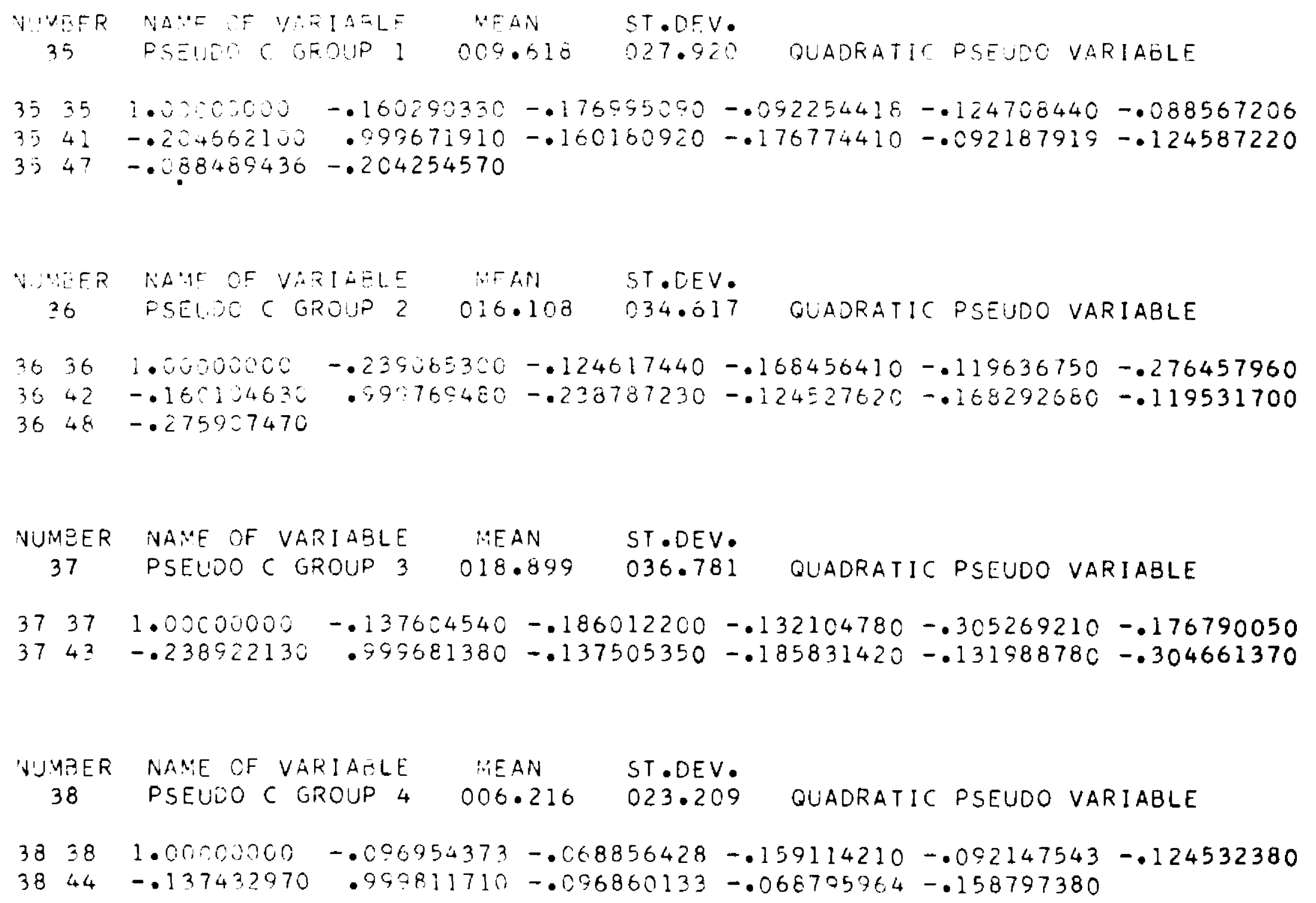




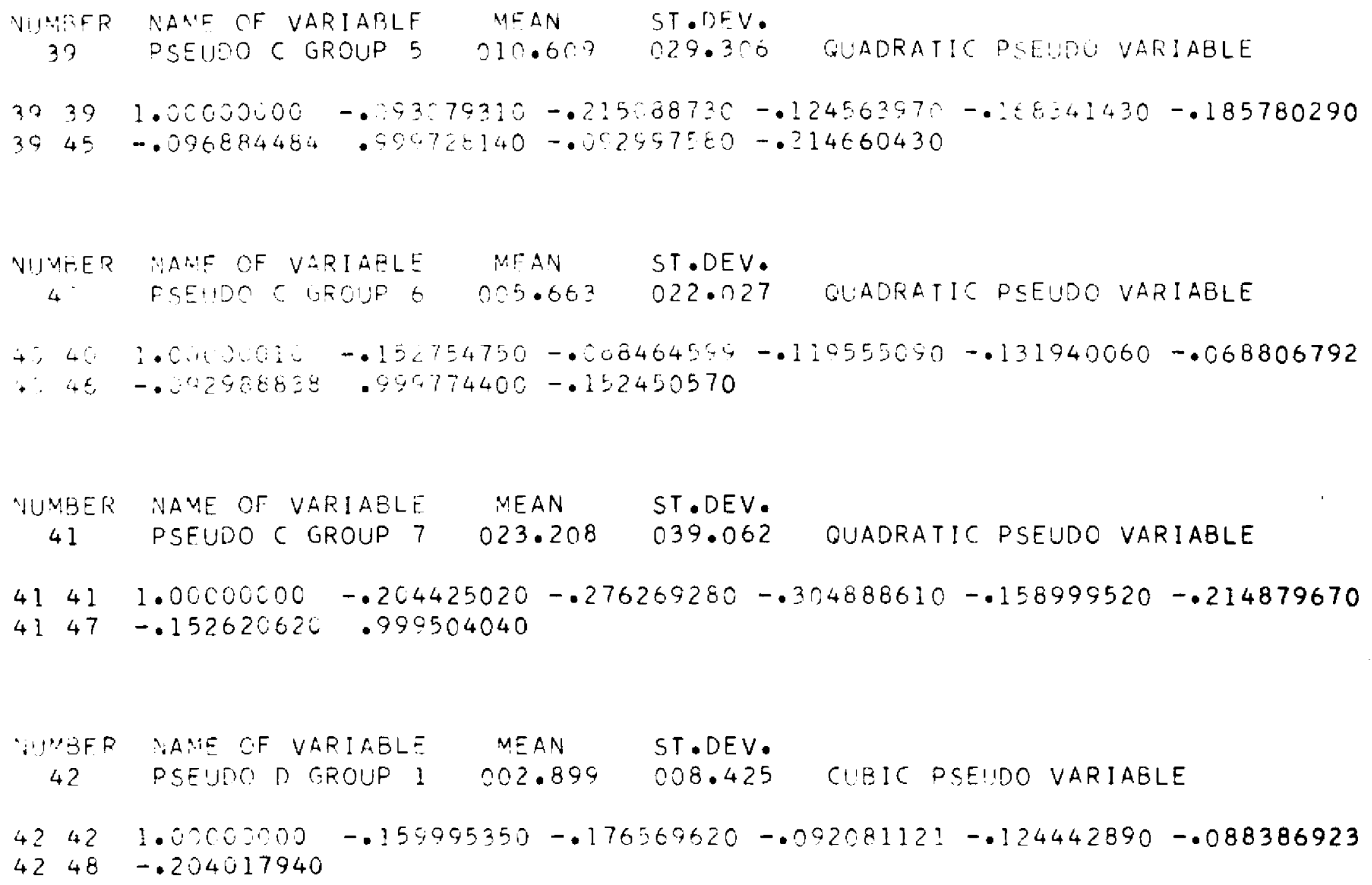




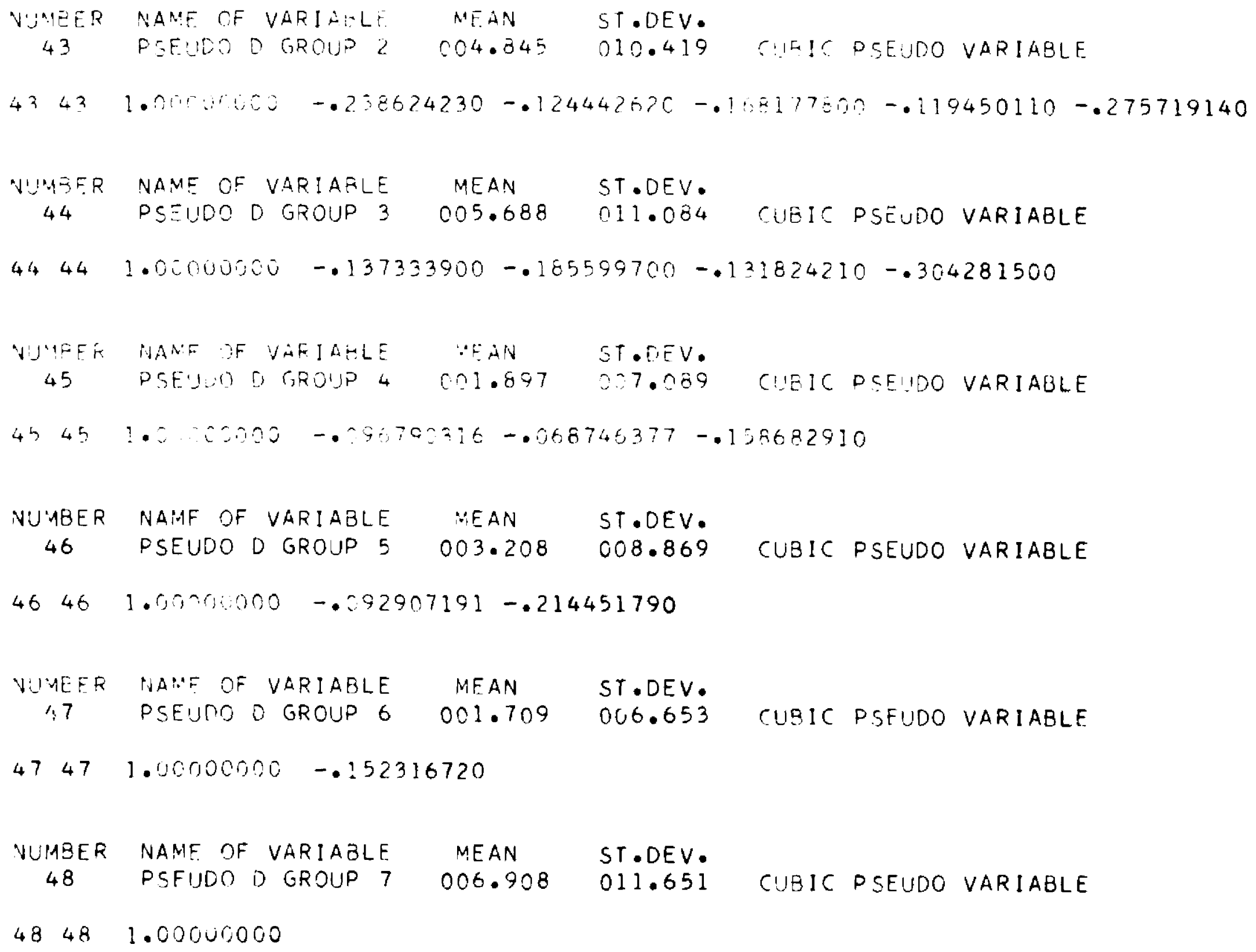




\section{APPENDIX 11}

Intercorrelations, Means, and Standard Deviations of Variables Used In The Validation Study

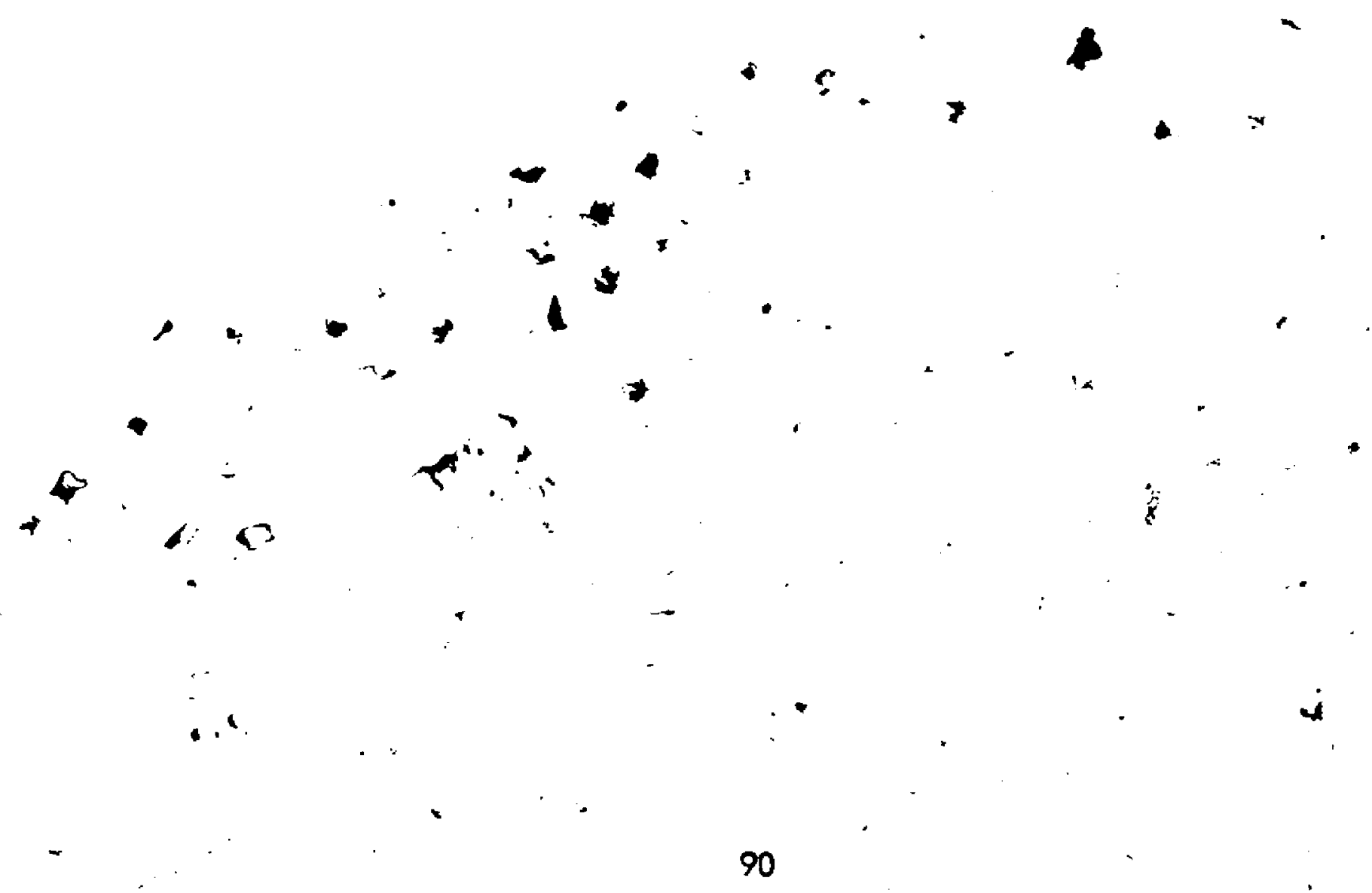




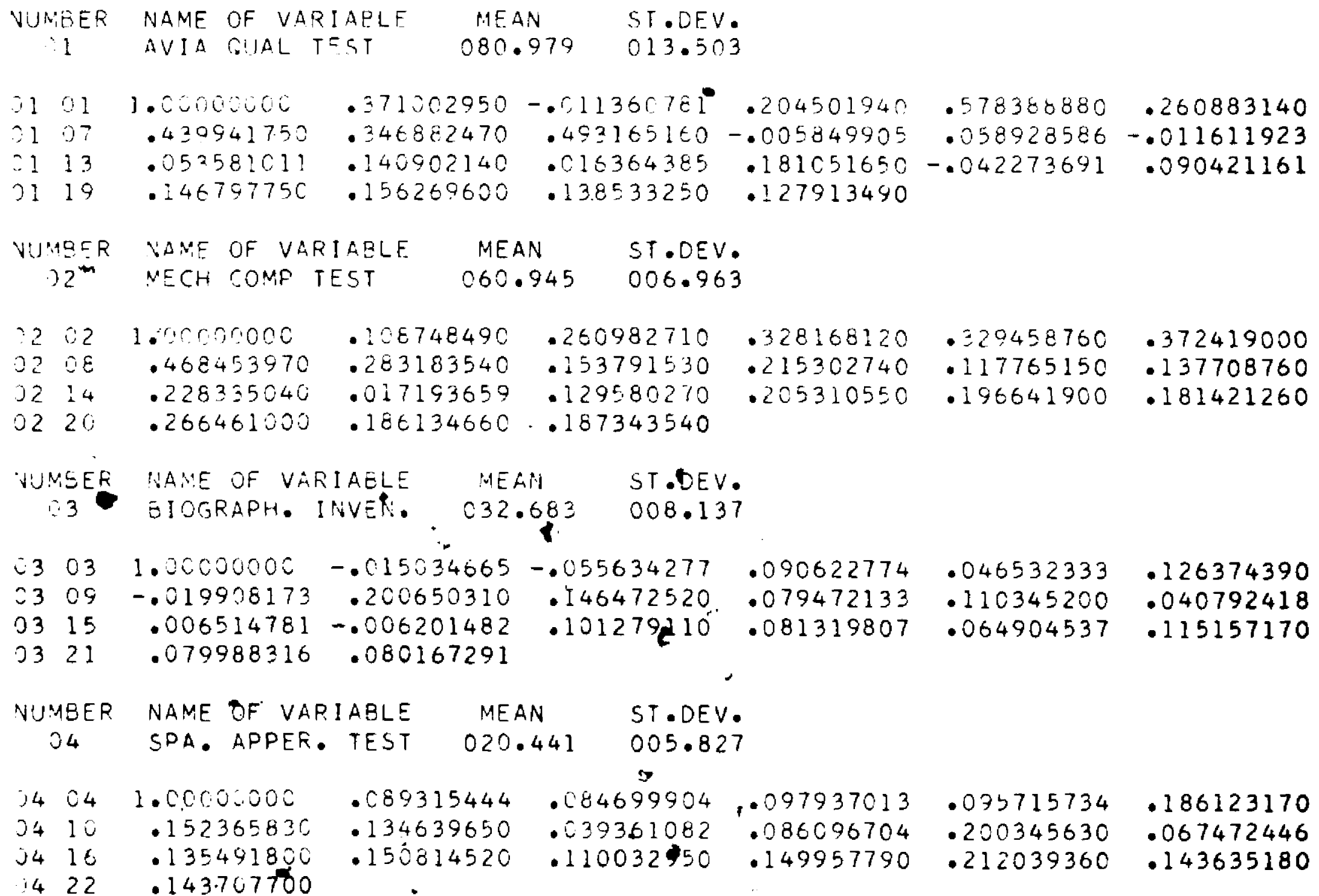

.328168120 .215302740 .205310550

.329458760 - 117765150 .196641900

.372419000 .137708760 .181421260

.126374390 .040792418 .115157170

NUMBER 


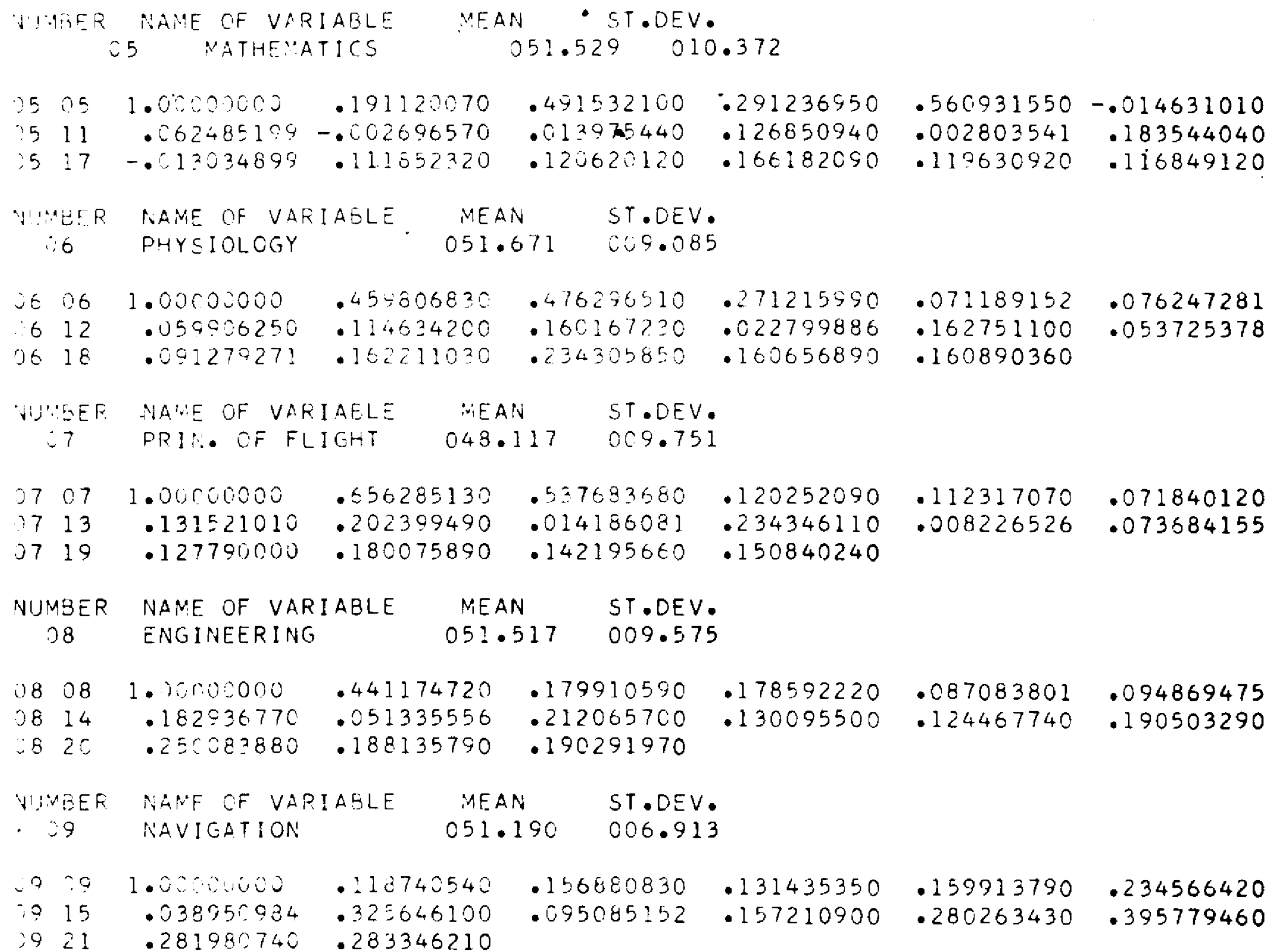




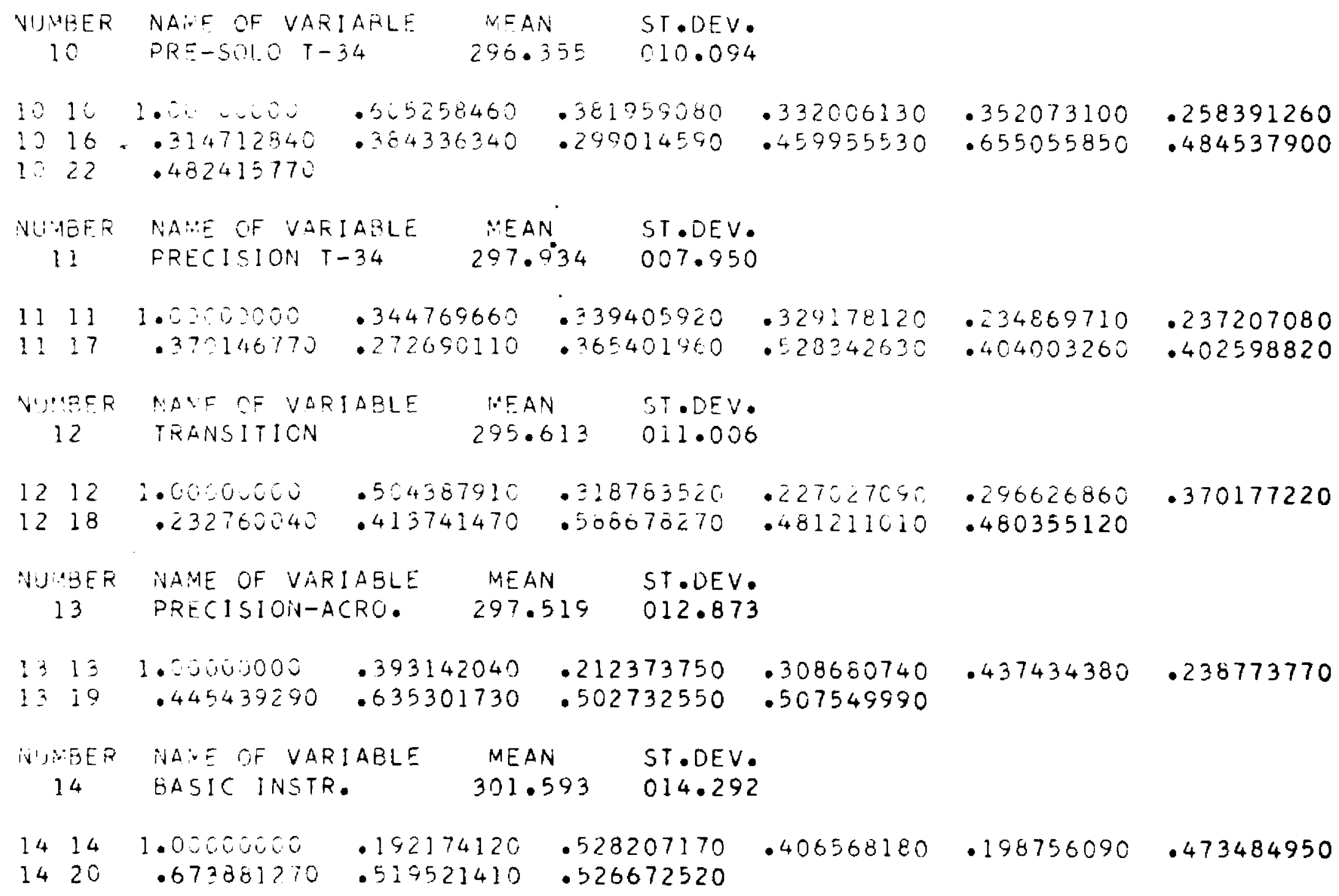




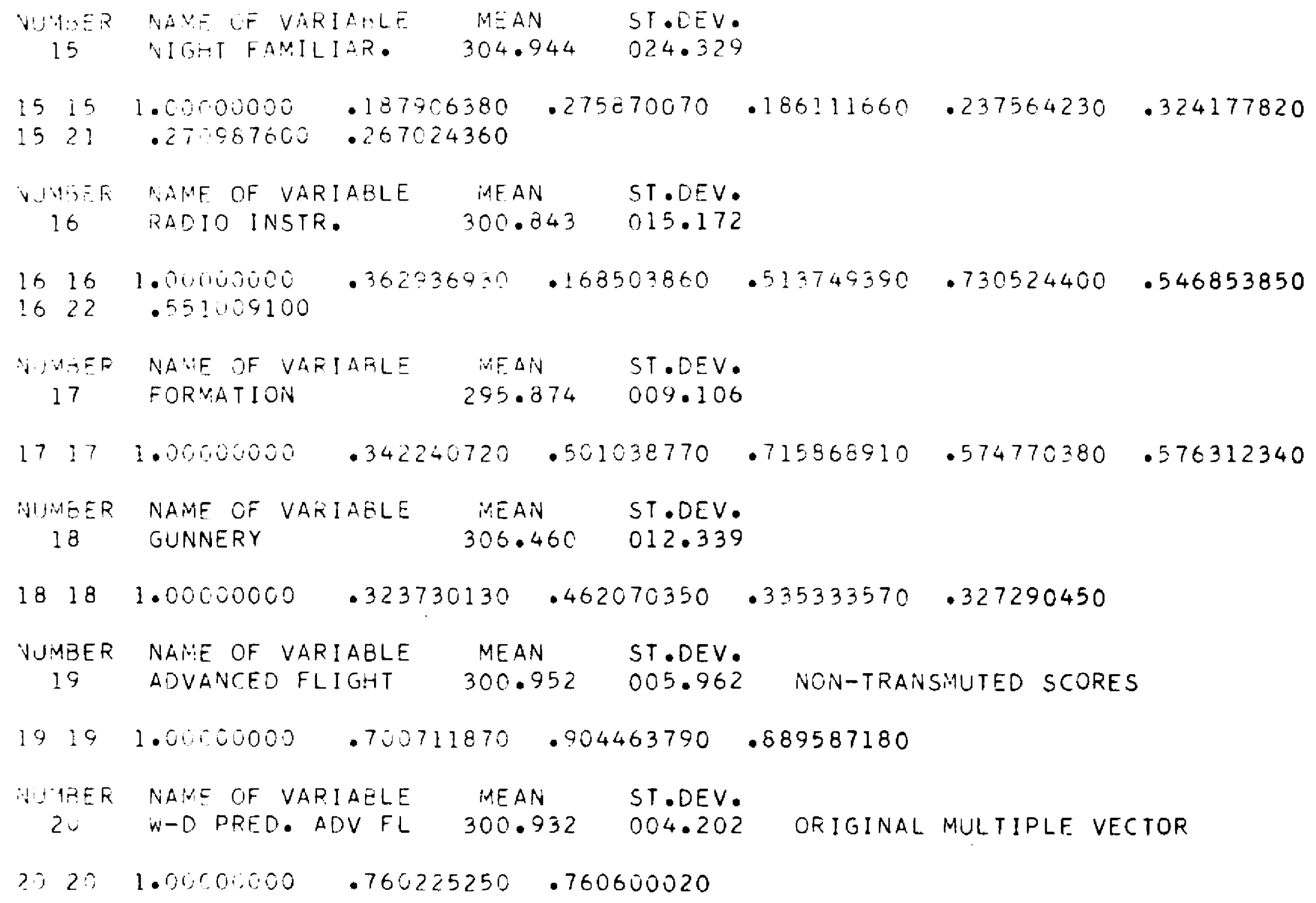




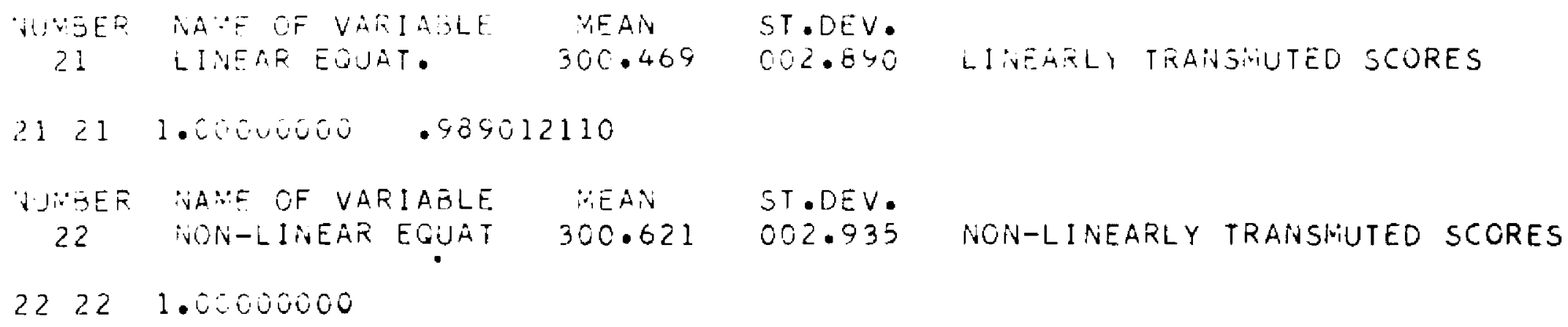




\section{BIBLIOGRAPHY}

1. Ambler, R.K. Preliminary evaluation of two forms of the Spatial Apperception Test. BuMed Project MR005.13-3003 Subtosk 1, Report No. 4. Pensocola, Fla.: Naval School of Aviation Medicine, 1956.

2. Ambler, R.K. Differences between aviation officer cadets and noval aviation cadets on three tests of mental ability. BuMed Project MR005.13-3003 Subtask 1, Report No. 13. Pensacola, Fla.: Naval School of Aviation Medicine, 1956.

3. Angoff, W.H. The equating of non-parallel tests. J. exp. Educ., 25: 241-247, 1957.

4. Berkshire, J.R. Acodemic grades of students in the Naval School of PreFlight. Contract N7onr-383, SDC Report No. 383-1-6 (RBH Project 128), Washington, D.C.: Office of Naval Research, 1948.

5. Bingham, W.V. Halo, invalid and valid. J. appl. Psychol., 25:221-228, 1939.

6. Bottenberg, R.A. and Christal, R.E. An iterative technique for clustering criteria which retains optimum predictive efficiency. WADD-TN-61-30. Lackland Air Force Base, Texas: Personnel Laboratory, 1961.

7. Bottenberg, R.A. and Ward, J.H., Jr. Applied multiple linear regression. Technical Documentary Report PRL-TDR-63-6. Lackland Air Force Base, Texas: Personnel Research Laboratory, Aerospace Medical Division, Air Force Systems Command, 1963.

8. Brogden, H.E. Voriation in test validity with variation in the distribution of item difficulties, number of items, and degree of item correlation. Psychometrika, 11:197-214, 1946.

9. Conrad, H.S. The personal equation in ratings: 1. An experimental determination. Pedagogical Sem., 41:267-293, 1932.

10. Conrad, H.S. The personal equation in ratings: 11. A systematic evaluation. J. educ. Psychol., 24:39-46, 1933. 
11. Coombs, C.H. A rationale for the mecsurement of troits in individuals. Psychometrika, 13:59-68, 1948.

12. Cotton, J.W., Campbell, D.T. and Malono, R.D. Factorial composition of test items and measures of test reliability. Psychometrika, 4:347-357, 1957.

13. Dingman, H.F. and Guilford, J.P. A new mothod for obtoining woighted composites of ratings. J. appl. Psychol., 38:305-307, 1954.

14. Drever, R.S. Training as a means of improving employee performance rating. Personnel, 18:314-370, 1942.

15. Dudycha, G.J. A note on the "halo effect"' in ratings. J. soc. Psychol.., 15:331-333, 1942.

16. Englehart, M.D. Obtaining comporoble scores on two or more tests. Educ. Psychol. Measmt. , 1:55-64, 1959.

17. Fiske, D.W. Validation of noval aviation cadet selection tests. J. appl. Psychol., 31:601-614, 1947.

18. Flanggan, J.C. General considerations in the selection of test items and a short method of estimating the product-moment coefficient from dato ot the tails of the distribution. J. educ. Psychol., 30:674-680, 1939.

19. Flanagan, J.C. Units, scores, and norms. In Lindquist, E.F., (Ed.), Educational Measurement. Washington, D.C.: American Council on Education, 1950.

20. Goron, W.W. Introduction to Linear Programming. New York: McGraw-Hill Co., 1960 .

21. Guilford, J.P. Psychometric Methods. New York: John Wiley \& Sons, Inc., 1950.

22. Guilford, J.P. and Jorgenson, A.P. Some constant errors in ratings. J. exp. Psychol., 22:43-57, 1938.

23. Gulliksen, H. The relationship of item difficulty and inter-item correlation to test variance and reliability. Psychometrika, 10:79-91, 1945.

24. Gulliksen, H. Theory of Mental Tests. New York: John Wiley \& Sons, Inc, 1950. 
25. Heim, A.W. Individual assessment: some problems and suggestions. Occup. Psychol., 20:24-33, 1946.

26. Hotelling, H. The most predictable criterion. J. oduc. Psychol., 16:139-142, 1935.

27. Jones, M.8. Composite ratings and the case of unit rank. J. appl. Psychol., 41: $198,1957$.

28. Lord, F.M. Equating test scores - a maximum likelihood solution. Psychometrika, 19:193-200, 1955.

29. McNemar, Q. Attenuation and interaction. Psychometrika, 23:259-265, 1958.

30. Rogers, O.E. and O'Connor, W.F. Stabilization of multiple regression weights through factor analysis: an empirical evaluation. BuMed Project NM 140211 Subtask 1, Report No. 30. Pensacola, Fla.: Naval School of Aviation Medicine, 1958.

31. Shoenberger, R.W., Wherry, R.J., Jr. and Berkshire, J.R. Predicting success in oviation training. BuMed Project MR005.13-3003 Subtask 10, Report No. 7. Pensacola, Fla.: Naval School of Aviation Medicine, 1963.

32. Thorndike, E.L. Fundamental theorems in judging men. J. oppl. Psychol., 2:67-76, 1918 .

33. Thorndike, E.L. A constant error in psychological ratings. 1. appl. Psychol., $4: 25-27,1920$.

34. Thorndike, R.L.Personnel Selection. New York: John Wiley \& Sons, Inc., 1949.

35. Thurstone, L.L. A method for scaling psychological and educational tests. 1. educ. Psychol., 16:433-451, 1925.

36. Thurstone, L.L. Multiple Factor Analysis. New York: University of Chicago Press, 1947.

37. Toops, H.A. The tronsmutation of marks. Ohio College Association Bulletin №. 88 (Mimeo.):1093-2000, 1933.

38. Tucker, L.R. Selecting appropriate score scales for tests - scoles minimizing the importance of reference groups. In Proc. 1952 Invitational Conference on Testing Problems. Princeton, N.J.: 22-28, Educational Testing Ser. 1953 
39. Viteles, M.S. Motivation and Morale in Industry. New York: W.W. Norton \& Co., Inc., 1953.

40. Ward, J.H., Jr. An application of linear and curvilinear joint functional regression in psychological prediction. Research Bulletin AFPTRC-TR-54-86, Lackland Air Force Base, Texas: Air Force Personnel and Training R'esearch Center, 1954.

41. Wherry, R.J., Sr. Test Selection. In Stead, W.H., Shartle, C.L., et al. Occupational Counseling Techniques.-New York: American Book, 245-255, 1940.

42. Wherry, R.J., Sr. Maximal weighting of qualitative data. Psychometrika, 9:263-265, 1944.

43. Wherry, R.J., Sr. Item Analysis. In Henry, E.R. and Fryer, D. (Ed.), Applied Psychology. New York: John Wiley \& Sons, Inc., 177-182, 1950.

44. Wherry, R.J., Sr. Control of bias in ratings: A theory of ratings. PRB Report No. 922. Washington, D.C.: Personnel Research Branch, AGO, Dept. Army, 1952.

45. Wherry, R.J., tr. The hypersphere concept: a new model for correlation theory. In Tri-Service Conference on Selection Research. Washington,D.C: Office of Noval Research, 1960.

46. Wiley, L., Haber, H.B., and Georgia, M.J. Evidence for a generalized rating tendency. Eng. indust. Psychol., 1:55-61, 1959.

47. Willingham, W.W. and Jones, M.B. On the identification of halo through onalysis of variance. Educ. Psychol. Meosmt. , 18:403-407, 1958. 